\title{
Transition Metal Free One-Pot Tandem Synthesis of 3- Ketoisoquinolines from Aldehydes and Phenacyl azides
}

Budaganaboyina Prasad, ${ }^{\dagger}$ Mandalaparthi Phanindrudu, ${ }^{\dagger}$ Dharmendra Kumar Tiwari, ${ }^{*} \S$ and Ahmed Kamal*,:

†Division of Organic Synthesis and Process Chemistry, CSIR-Indian Institute of Chemical Technology, Hyderabad 500007, India.

$\S$ Molecular Synthesis and Drug Discovery Laboratory, Center of Biomedical Research, Sanjay Gandhi Post-Graduate Institute of Medical Sciences Campus, Raebareli Road, Lucknow 226014, India. Email:

Email: $\underline{\text { dkt80.org@gmail.com \& dktiwari@,cbmr.res.in }}$

$\$$ School of Pharmaceutical Education and Research (SPER), Jamia Hamdard, 110062 , New Delhi, India.

Email: ahmedkamal@iict.res.in

\section{Table of contents}

\section{Contents}

Page No.

1. ${ }^{1} \mathrm{H}$ and ${ }^{13} \mathrm{C}$ spectral data of compounds

S2-S49 


\section{${ }^{1} \mathrm{H}$ and ${ }^{13} \mathrm{C}$ spectra of Compounds (1a-1i)}

${ }^{1}$ H NMR spectrum of compound 1a

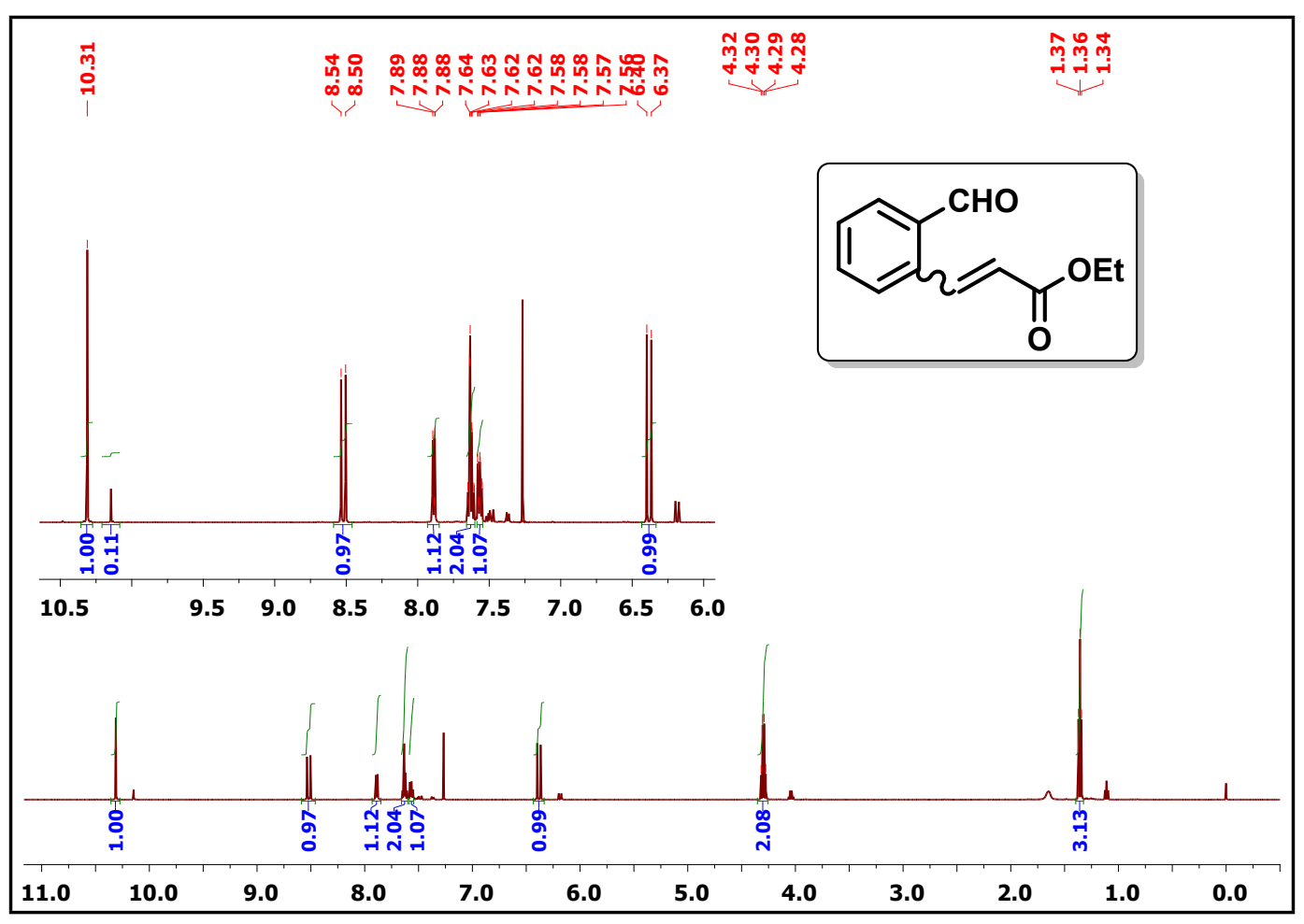

${ }^{1} \mathrm{H}$ NMR spectrum of compound $1 \mathrm{~b}$

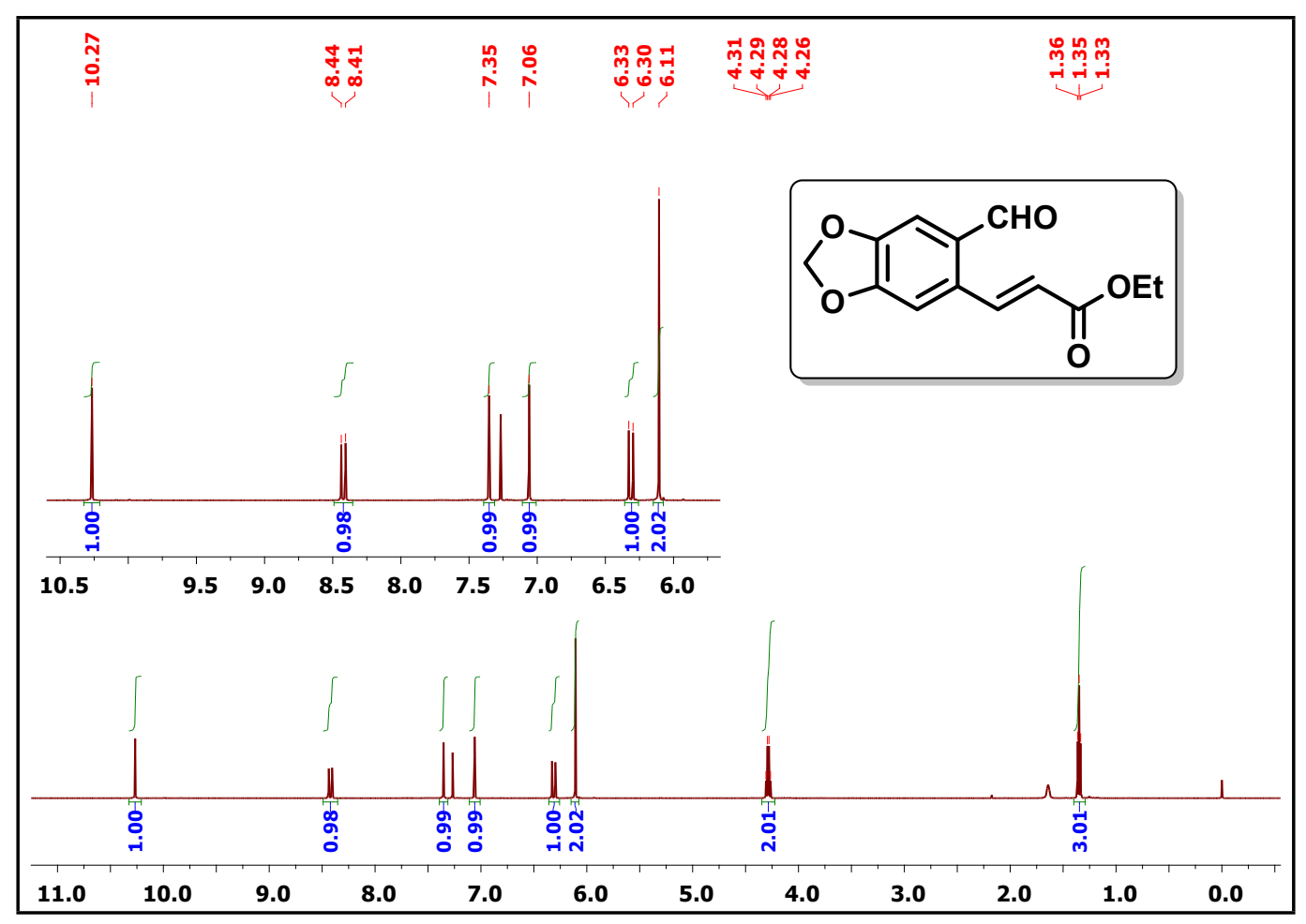


${ }^{1} \mathrm{H}$ NMR spectrum of compound $1 \mathrm{c}$

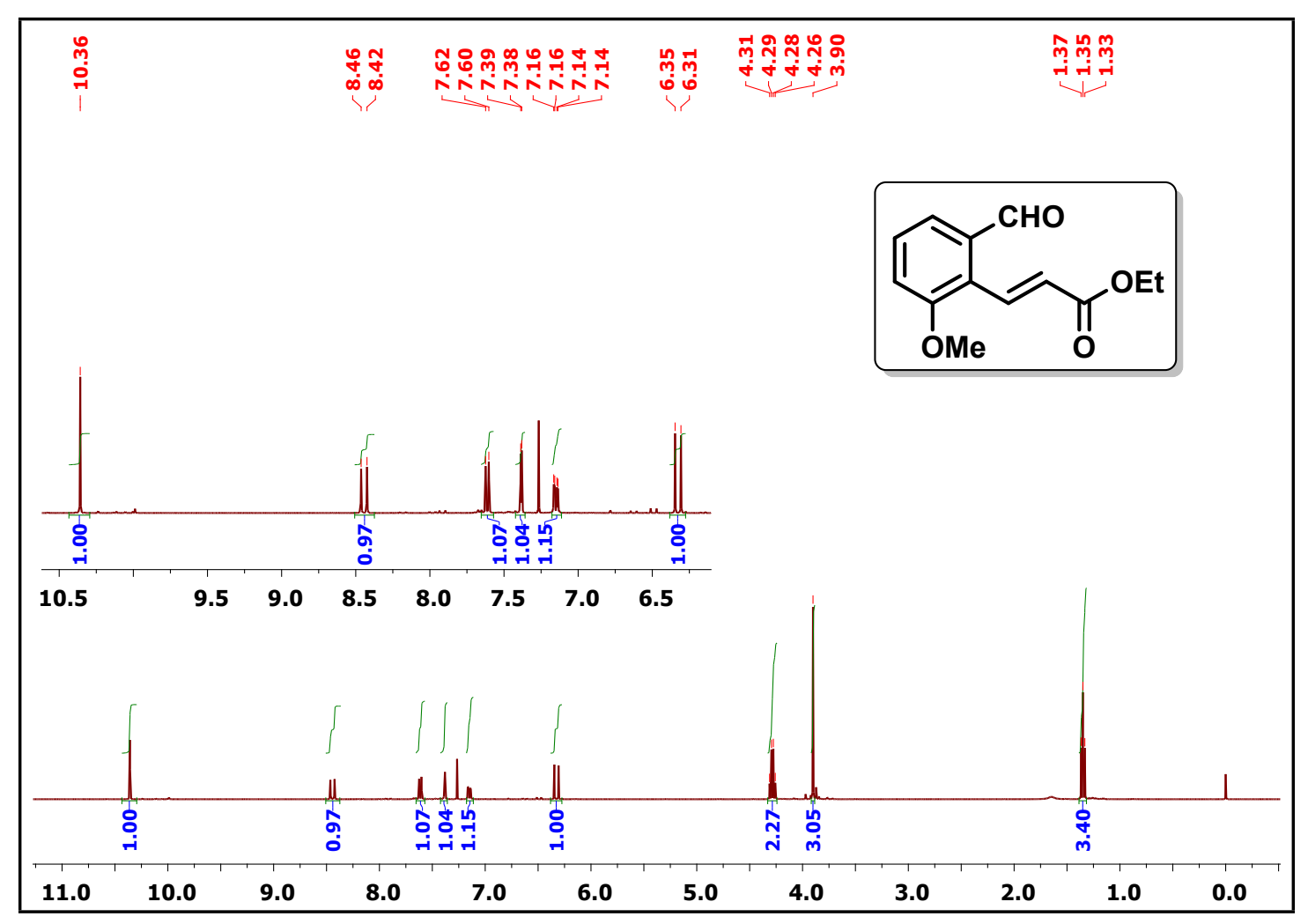

${ }^{13} \mathrm{C}$ NMR spectrum of compound $1 \mathrm{c}$

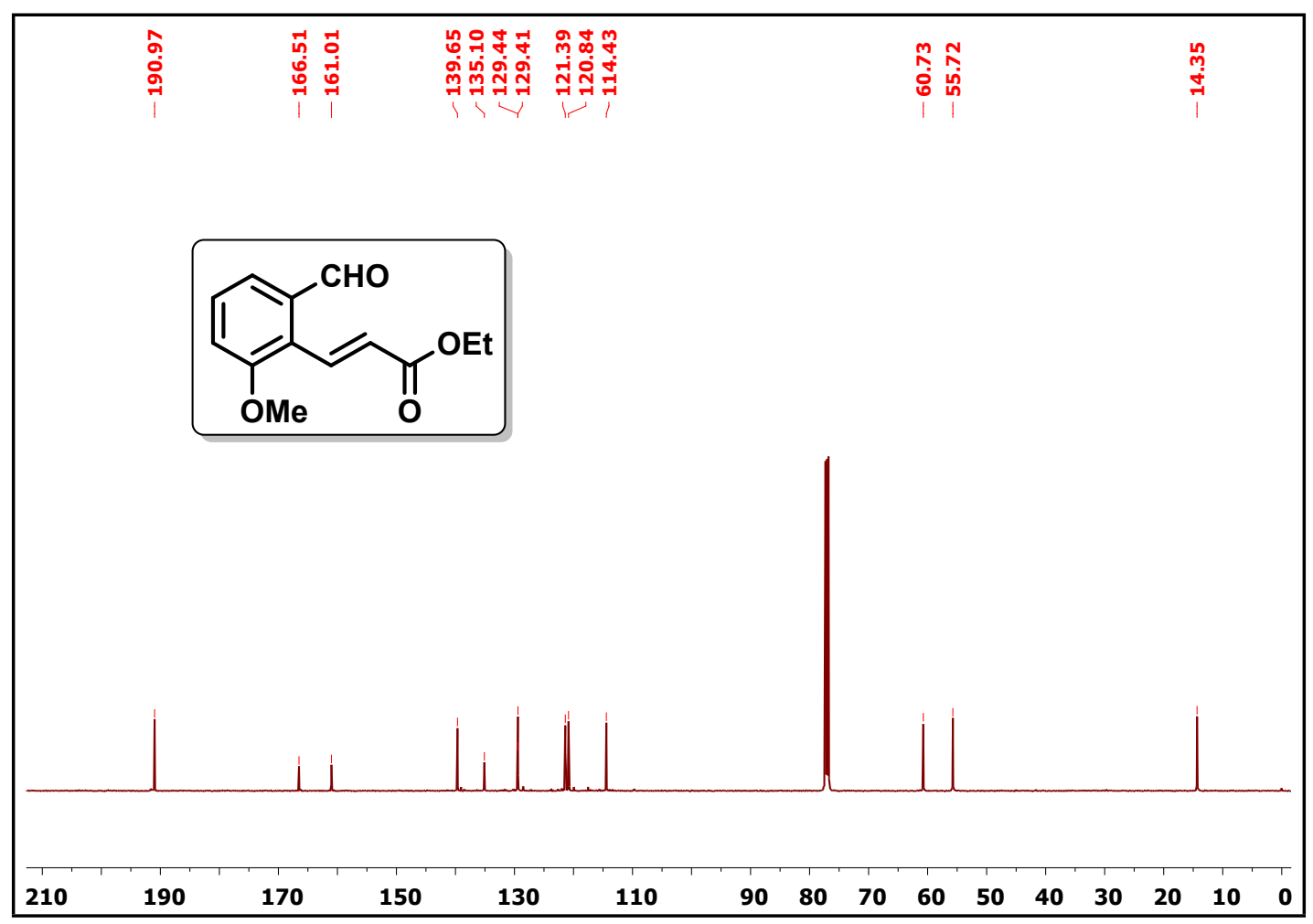


${ }^{1} \mathrm{H}$ NMR spectrum of compound 1d

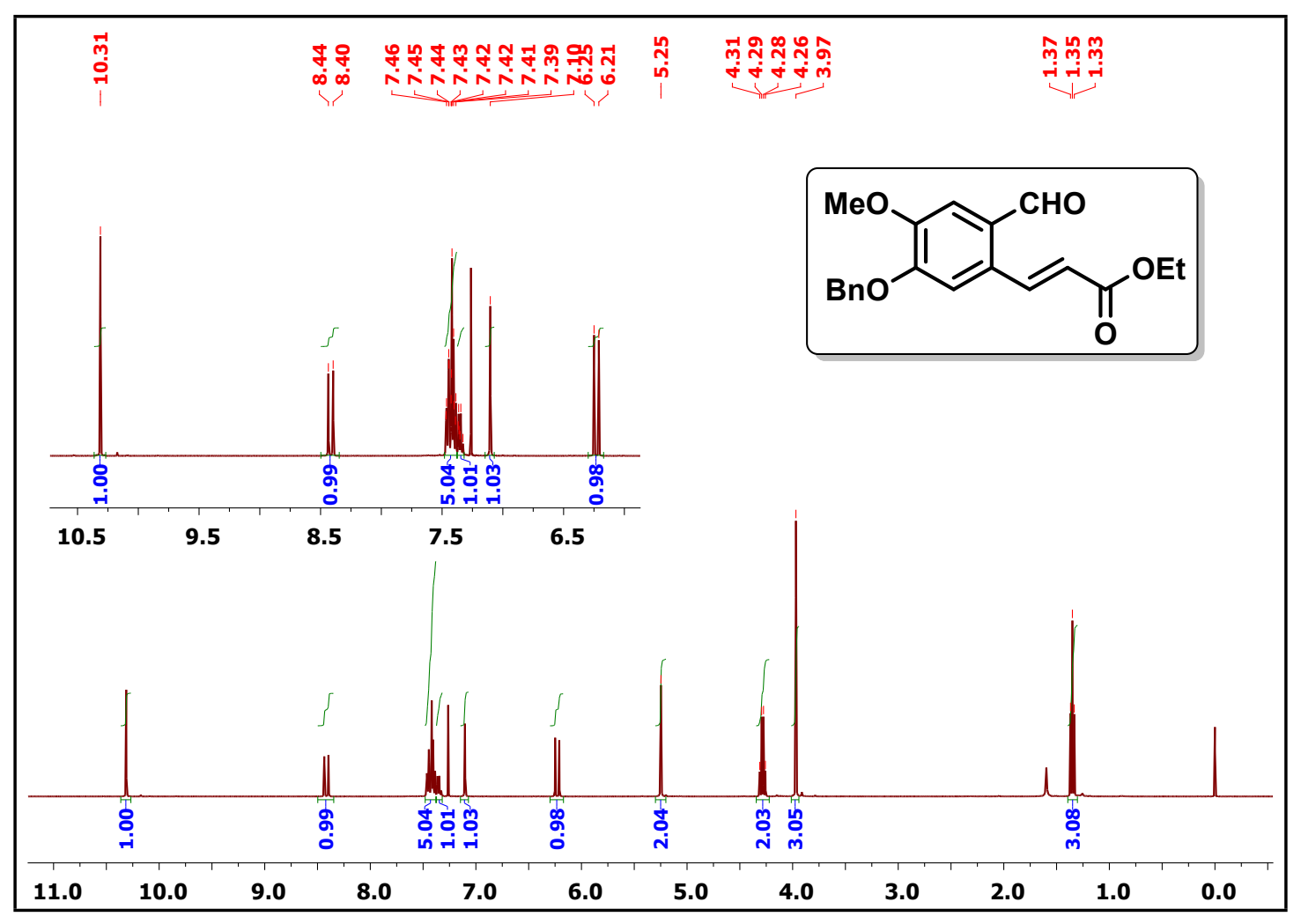

${ }^{13} \mathrm{C}$ NMR spectrum of compound 1d

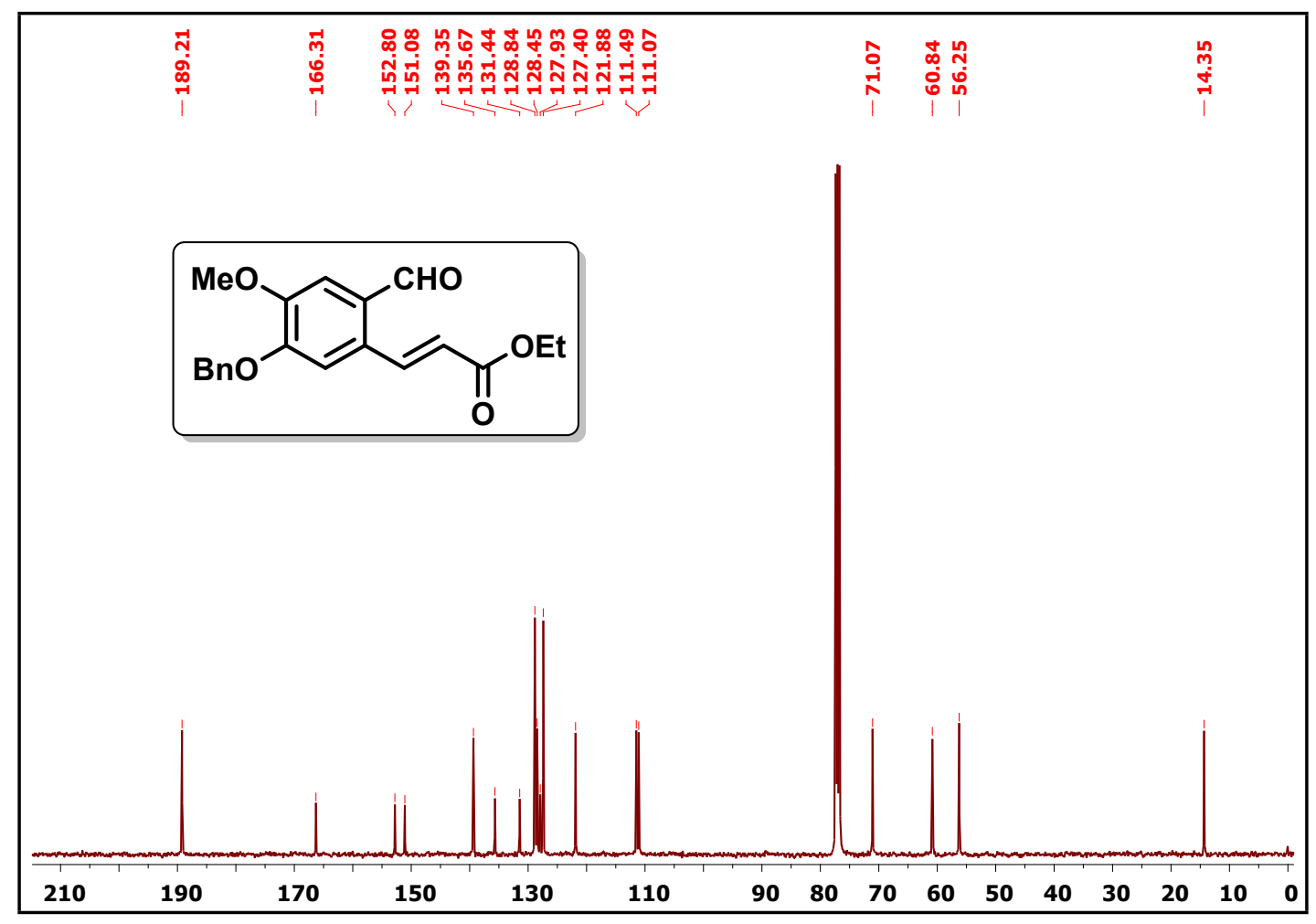


${ }^{1} \mathrm{H}$ NMR spectrum of compound $1 \mathrm{e}$

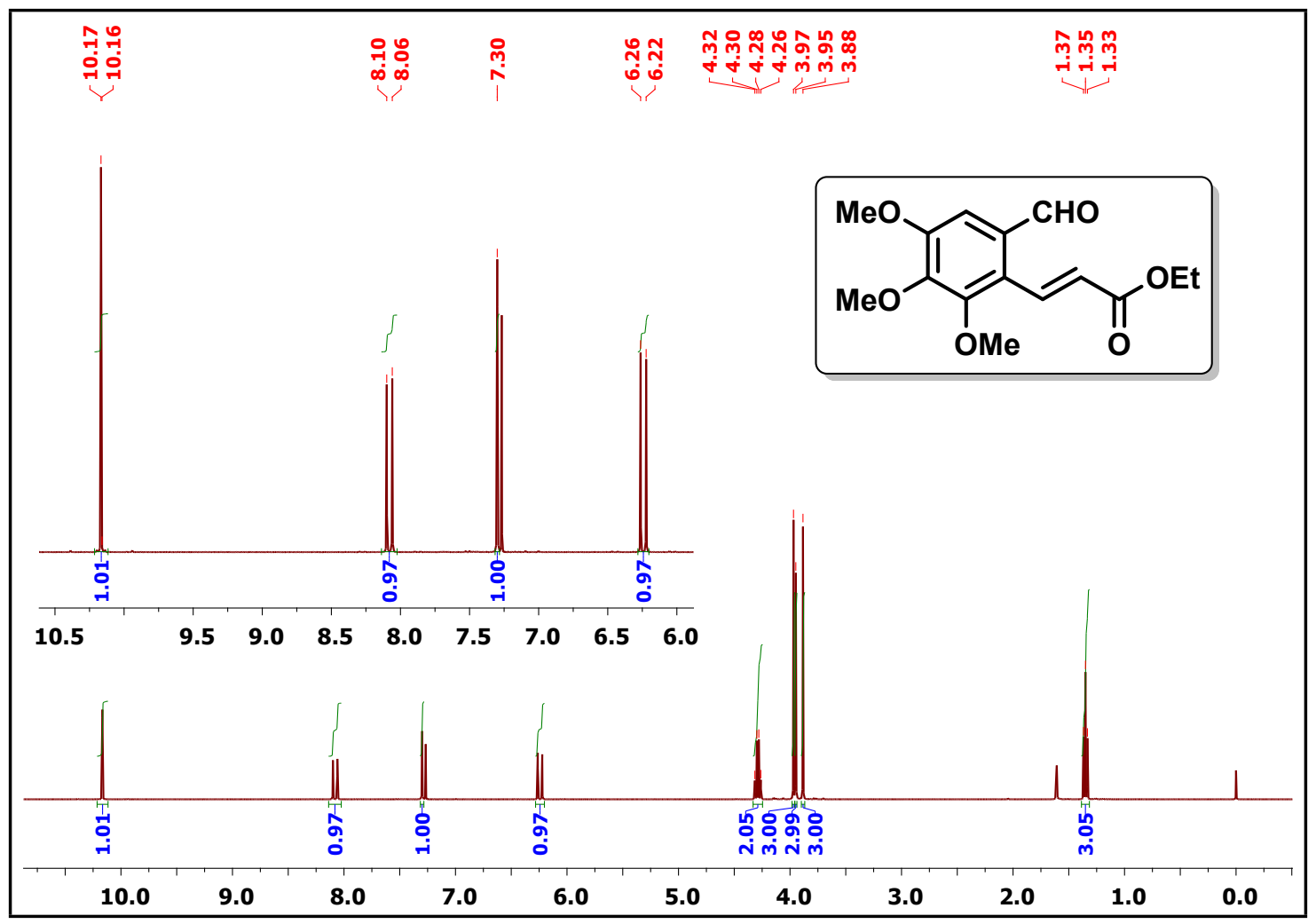

${ }^{13}$ C NMR spectrum of compound $1 \mathrm{e}$

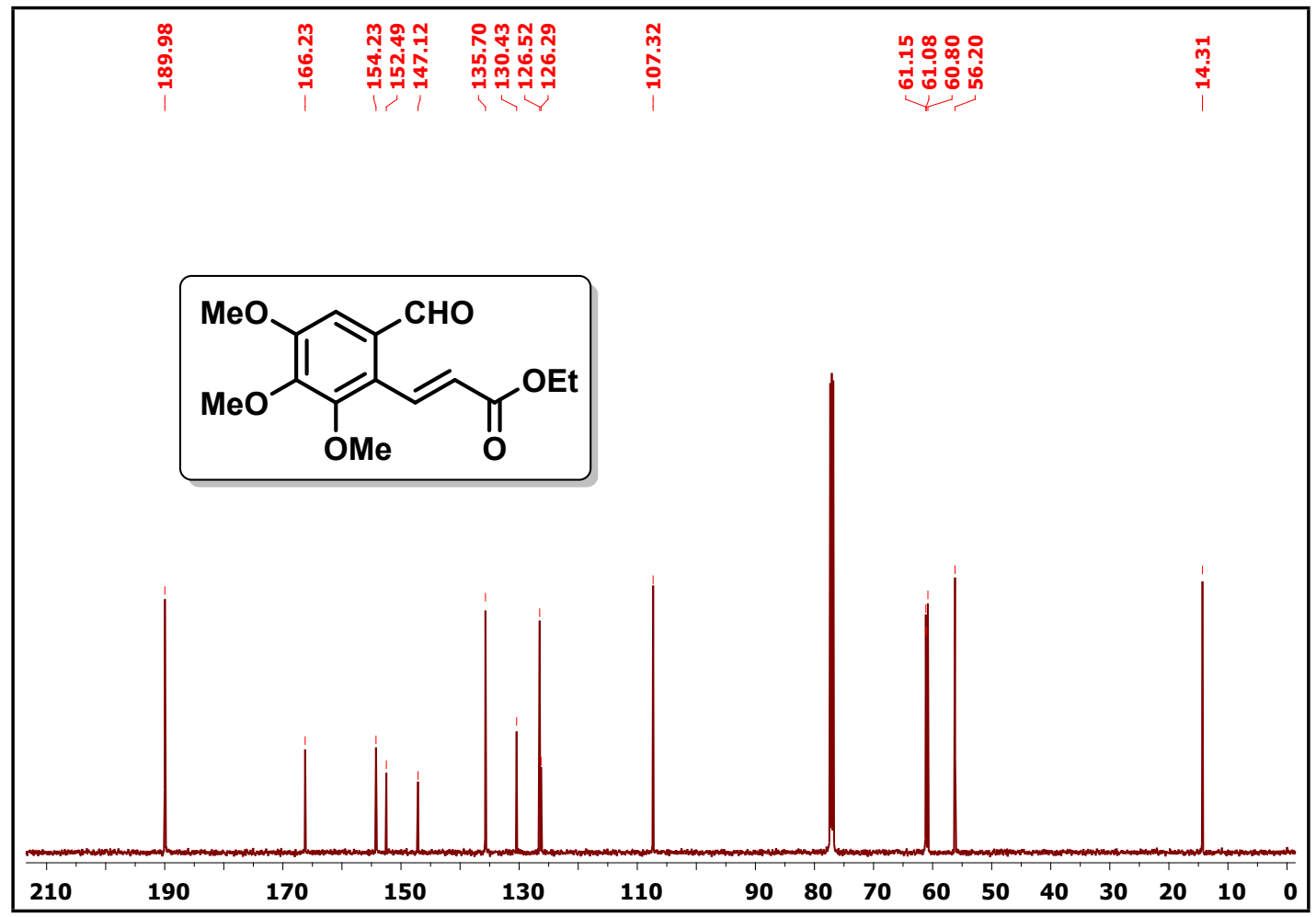




\section{${ }^{1} \mathrm{H}$ NMR spectrum of compound 1f}

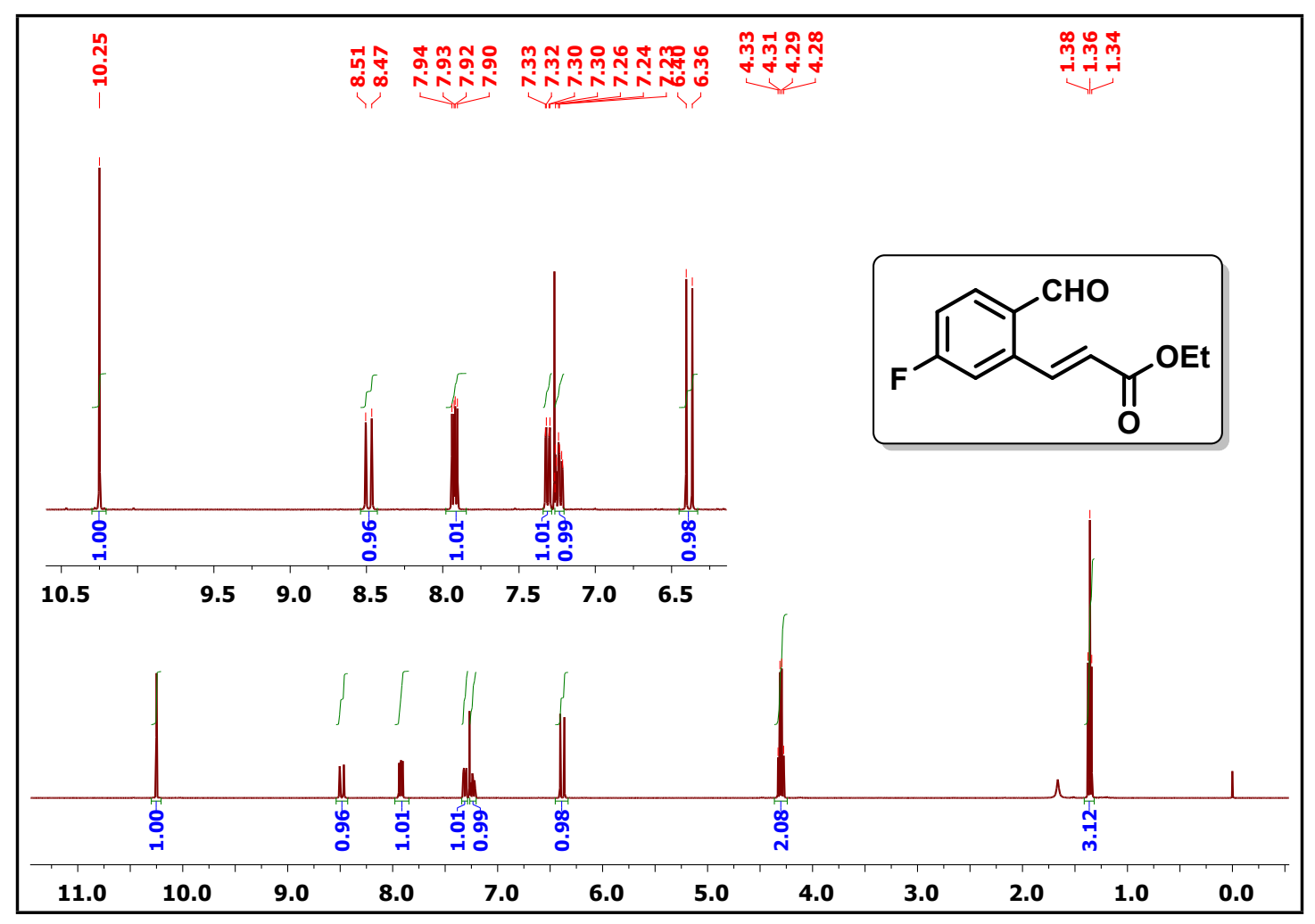

${ }^{1} \mathrm{H}$ NMR spectrum of compound $1 \mathrm{~g}$

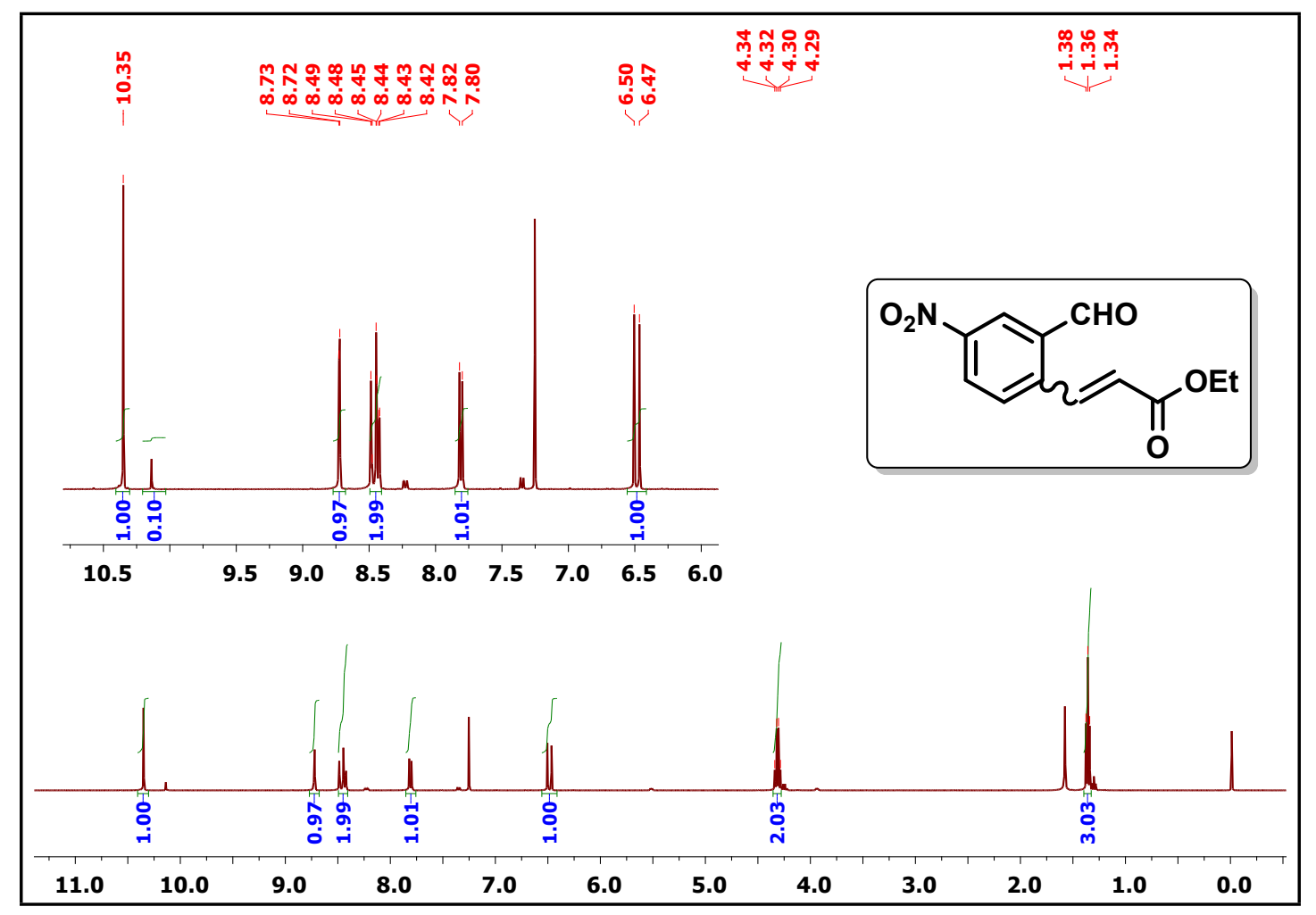




\section{${ }^{1} \mathrm{H}$ NMR spectrum of compound $1 \mathrm{~h}$}

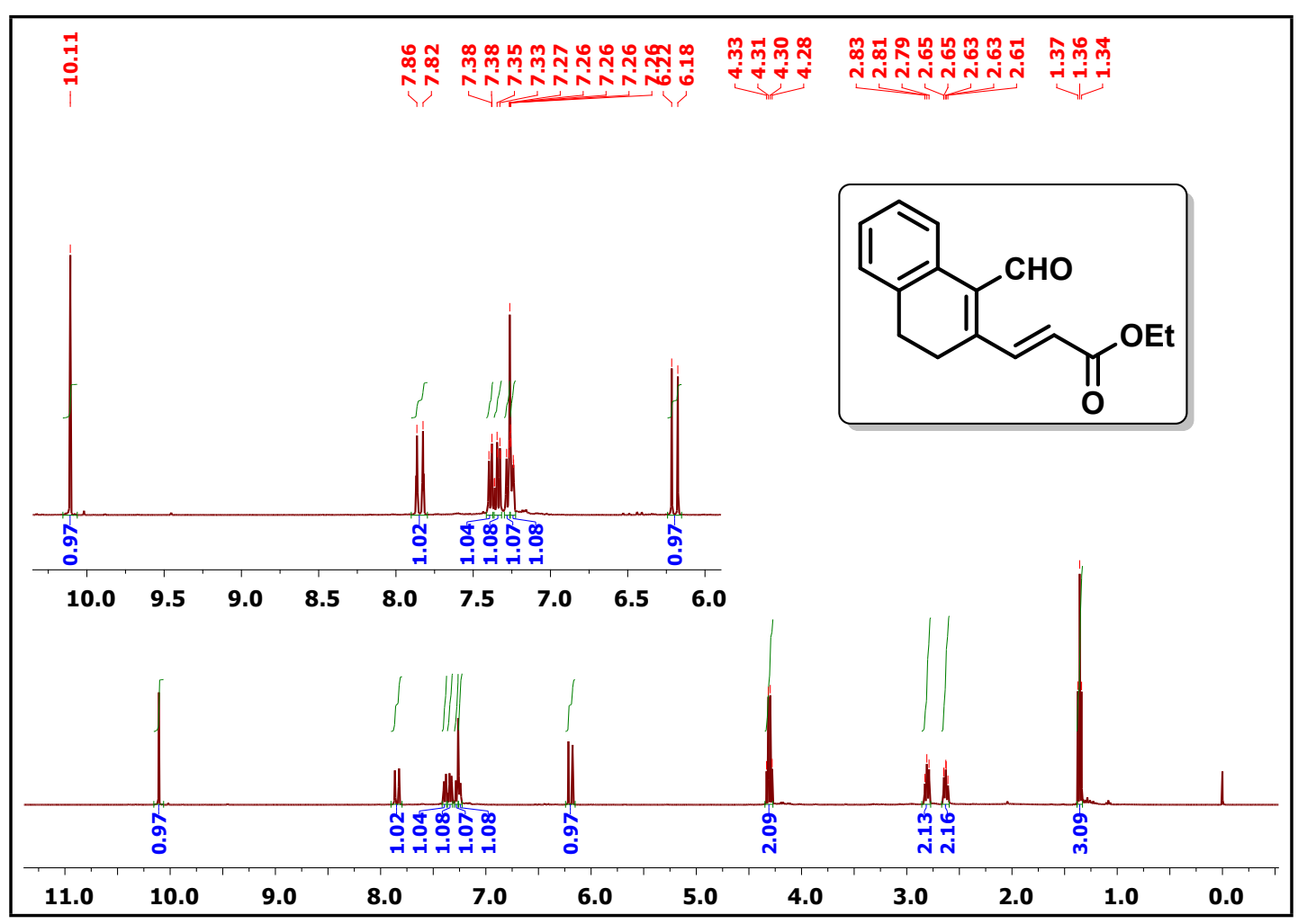

${ }^{13} \mathrm{C}$ NMR spectrum of compound $1 \mathrm{~h}$

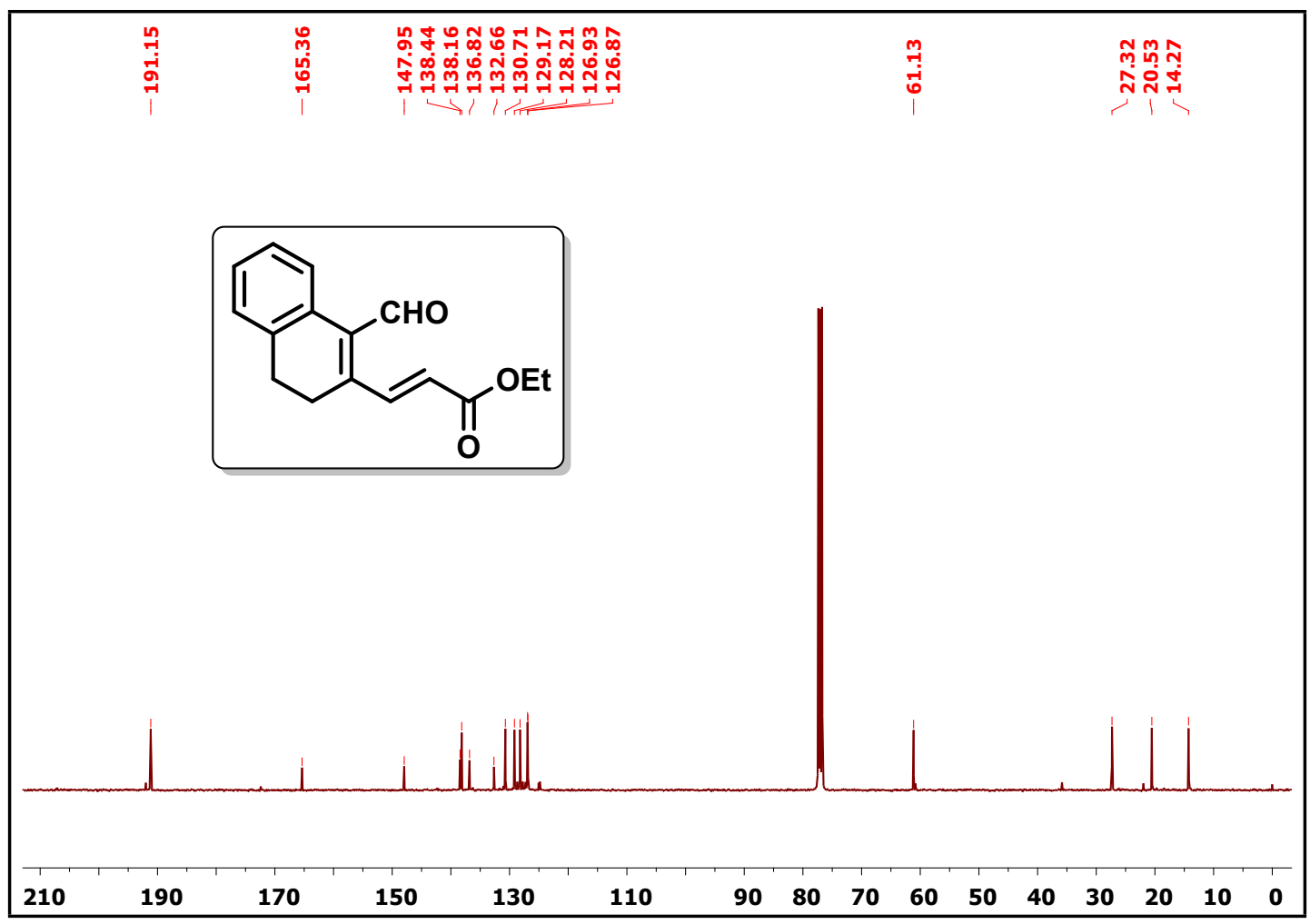


${ }^{1} \mathrm{H}$ NMR spectrum of compound $1 i$

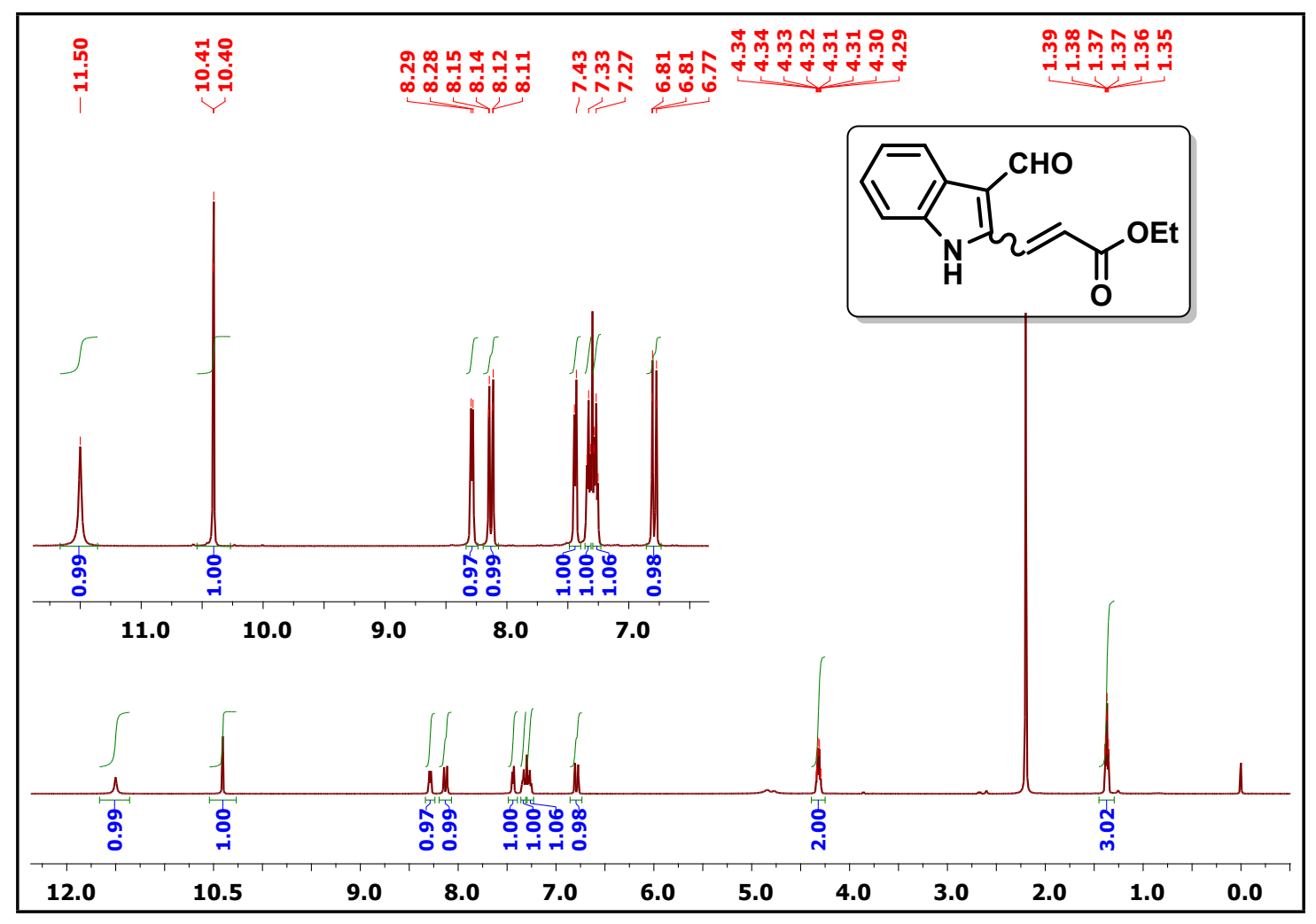

${ }^{13} \mathrm{C}$ NMR spectrum of compound 1i

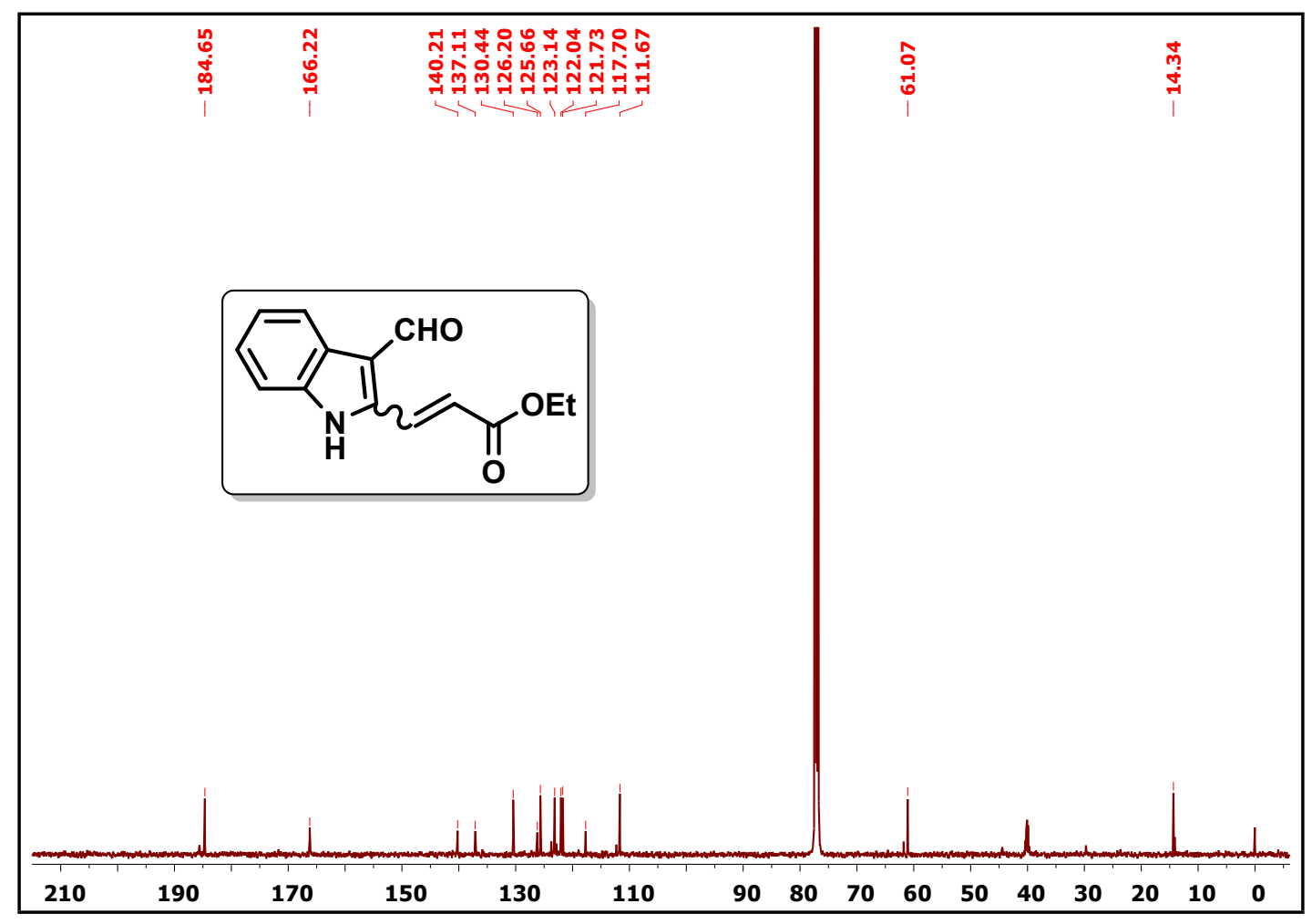




\section{${ }^{1} \mathrm{H}$ and ${ }^{13} \mathrm{C}$ spectra of Phenacyl Azides (2a-2o)}

${ }^{1}$ H NMR spectrum of compound 2 a

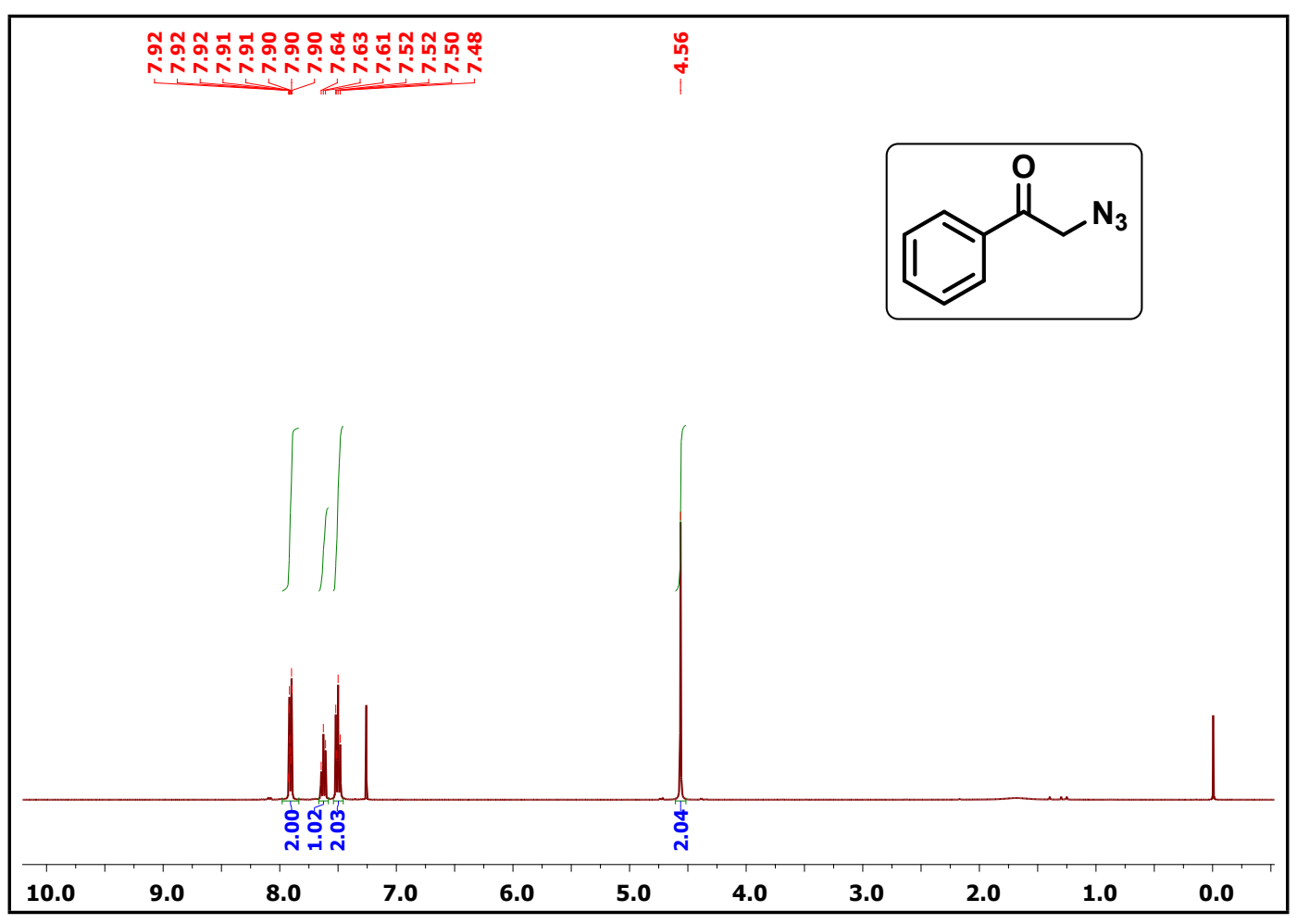

${ }^{1} \mathrm{H}$ NMR spectrum of compound $2 \mathrm{~b}$

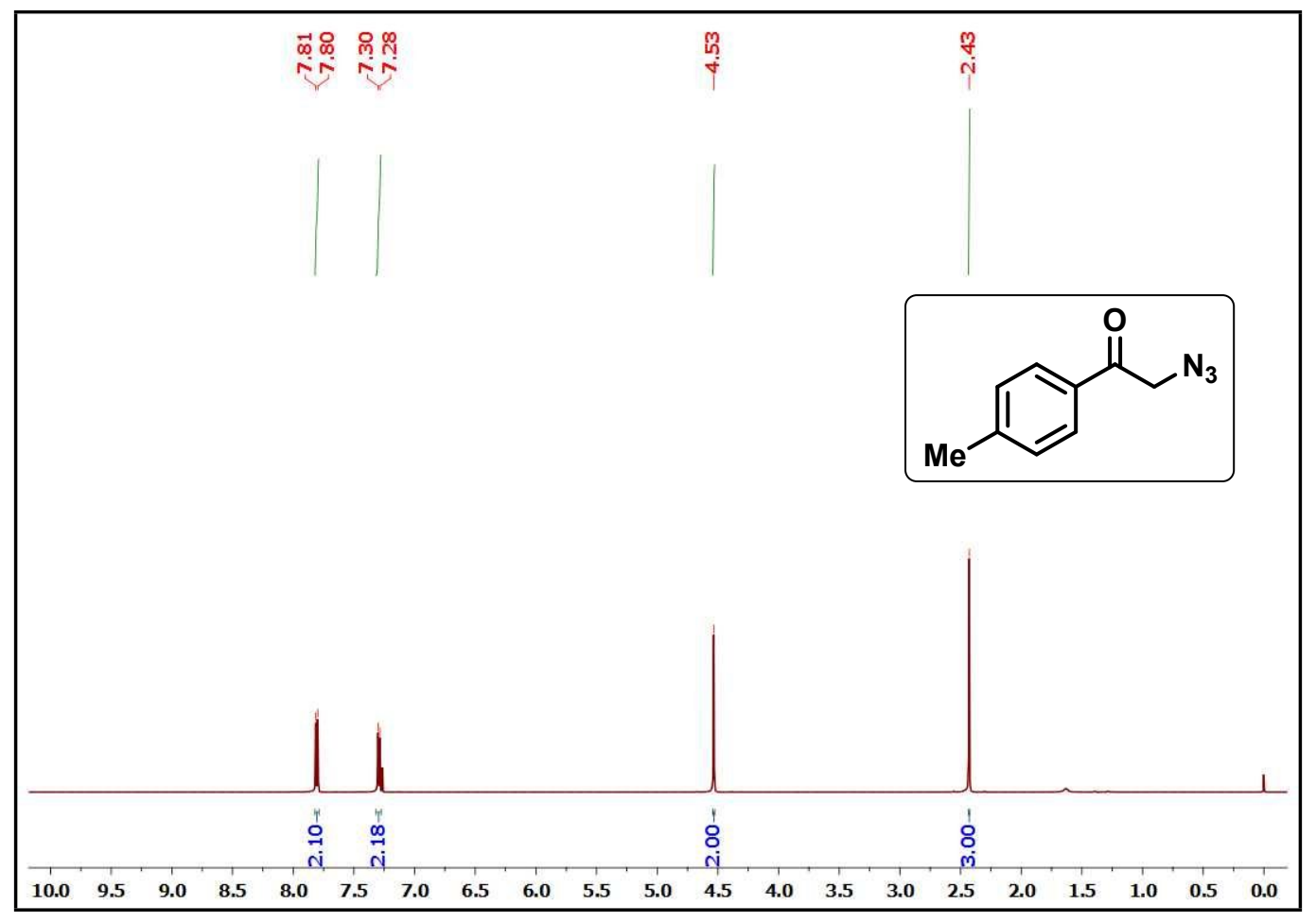


${ }^{1} \mathrm{H}$ NMR spectrum of compound $2 \mathrm{c}$

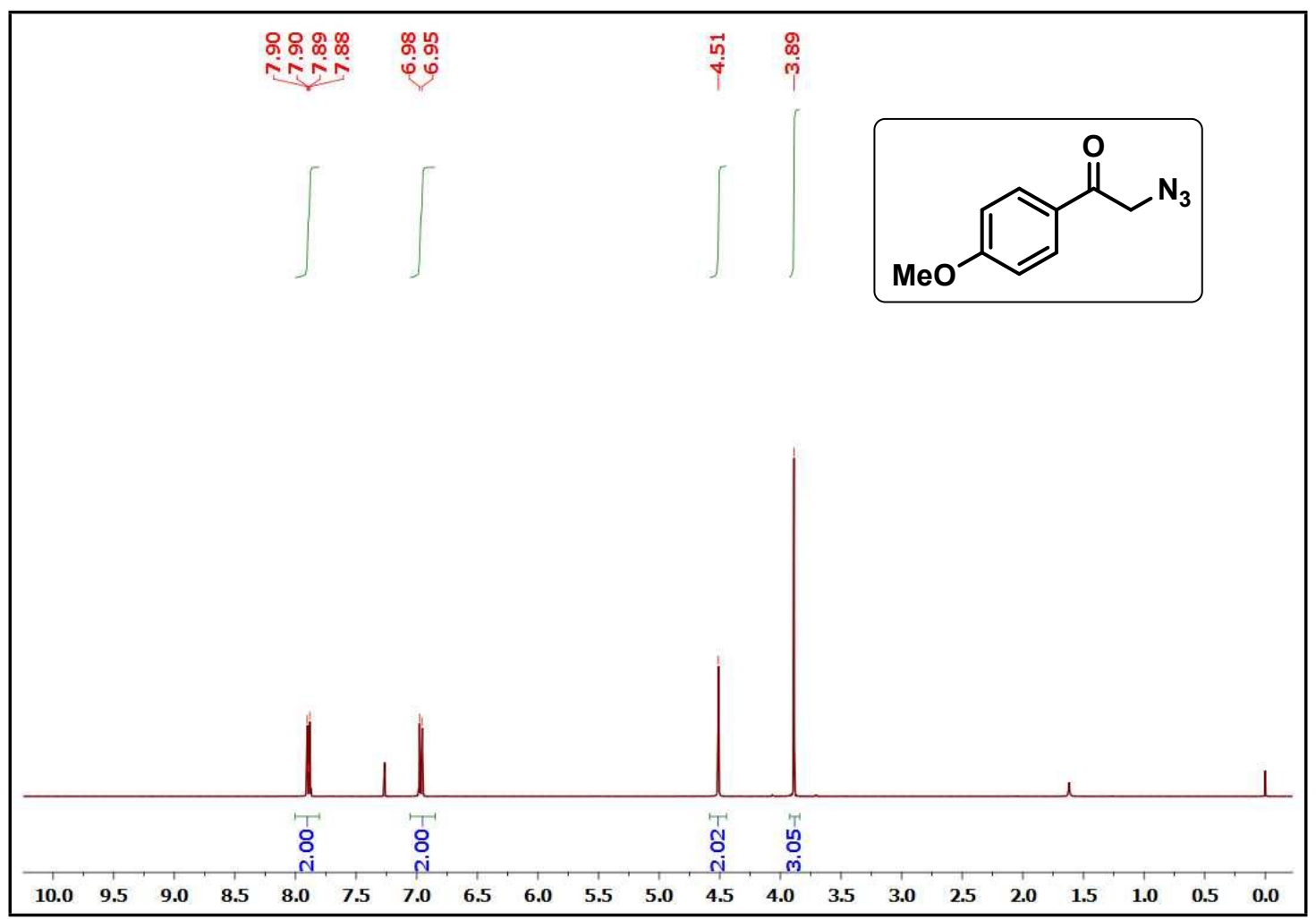

\section{${ }^{1} \mathrm{H}$ NMR spectrum of compound 2d}

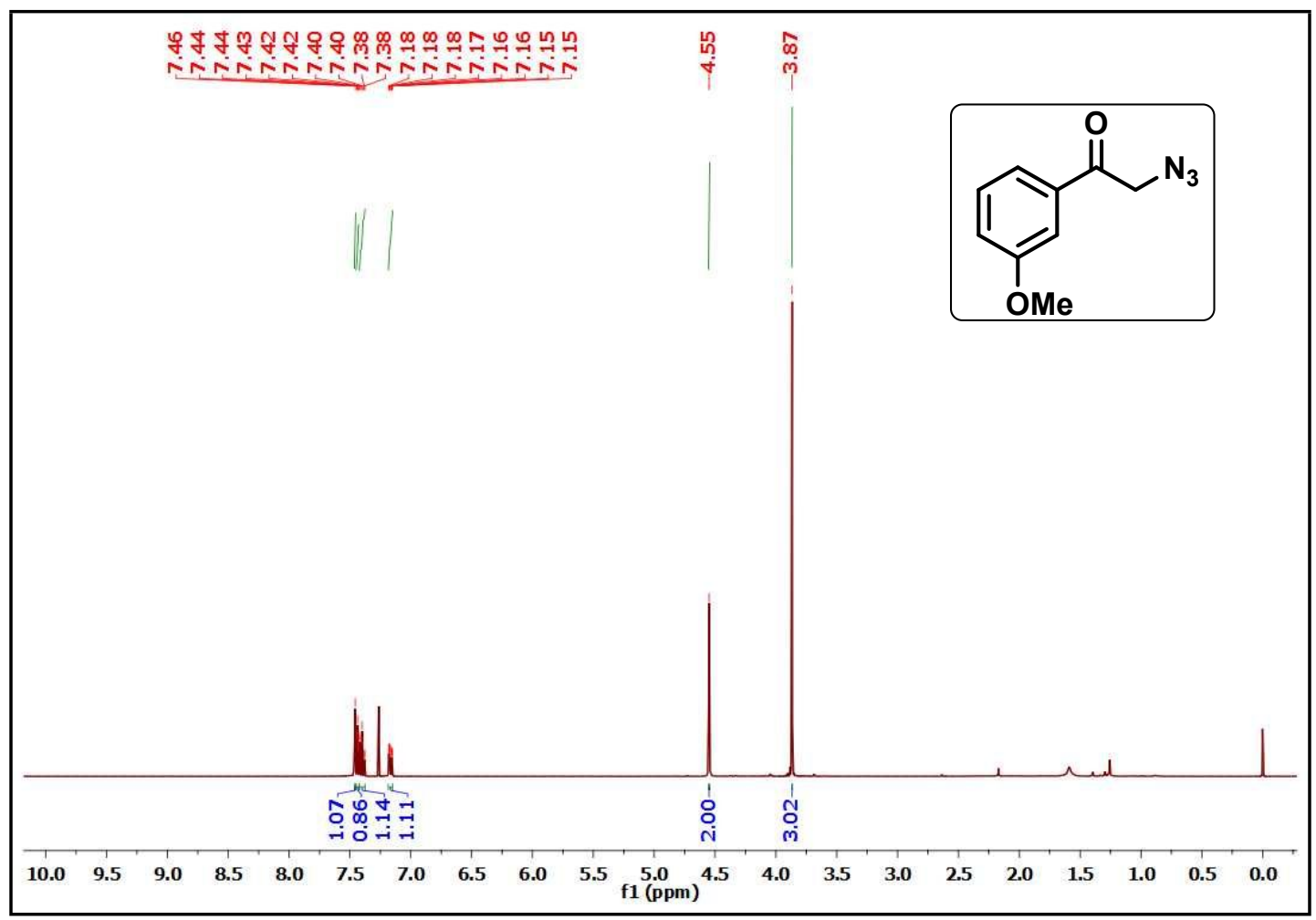




\section{${ }^{1} \mathrm{H}$ NMR spectrum of compound $2 \mathrm{e}$}

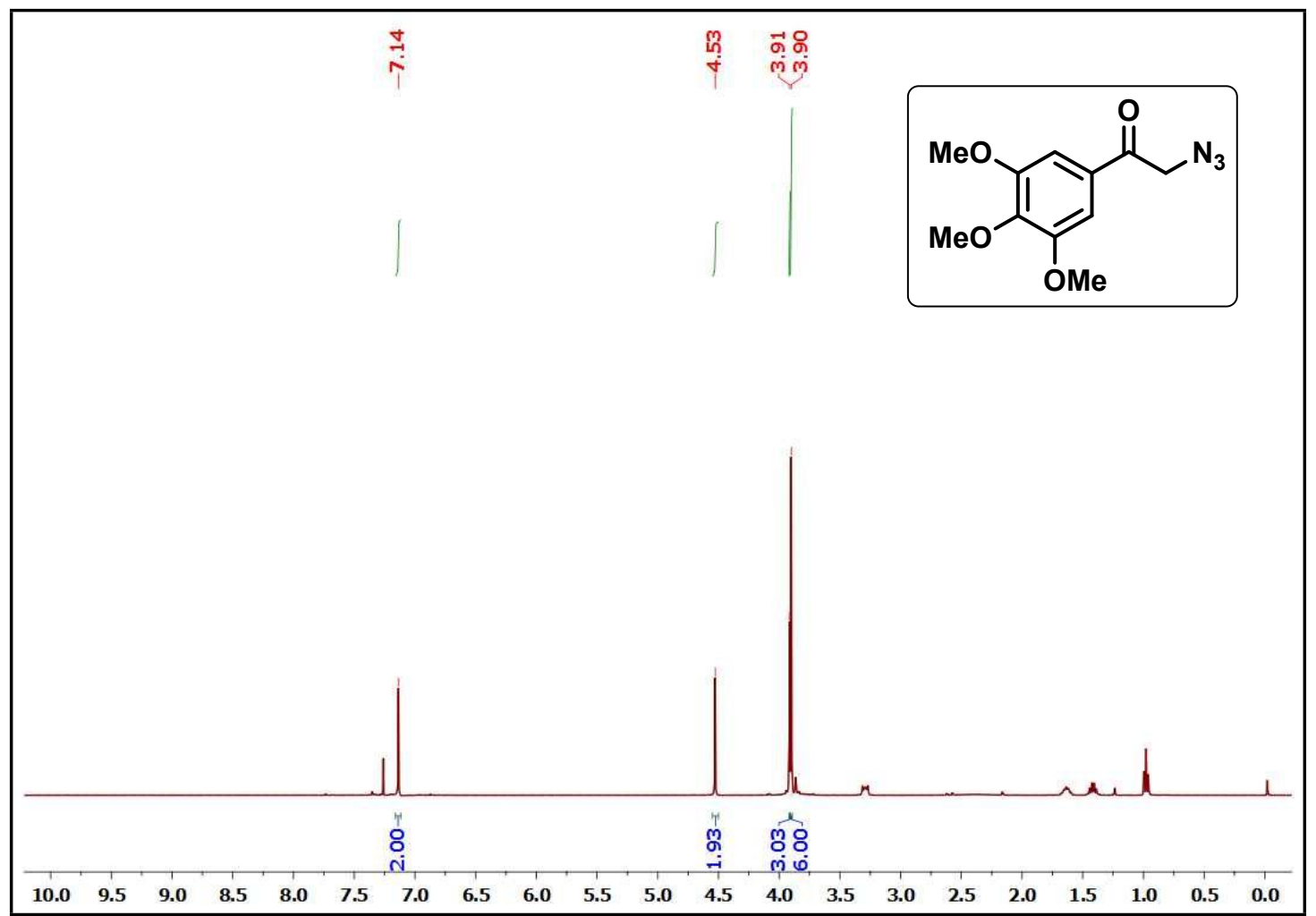

${ }^{1} \mathrm{H}$ NMR spectrum of compound $2 \mathrm{f}$

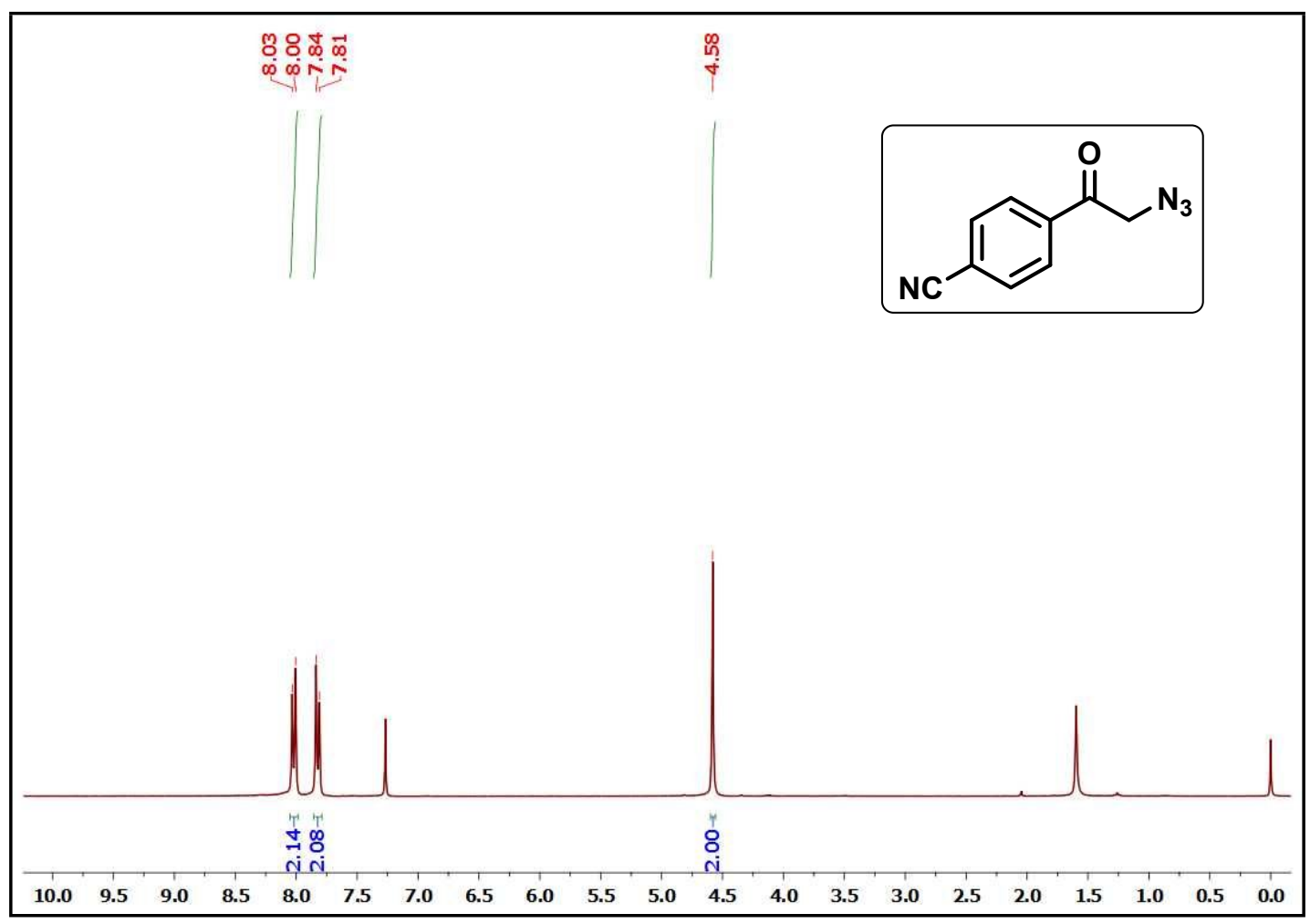


${ }^{1} \mathrm{H}$ NMR spectrum of compound $2 \mathrm{~g}$

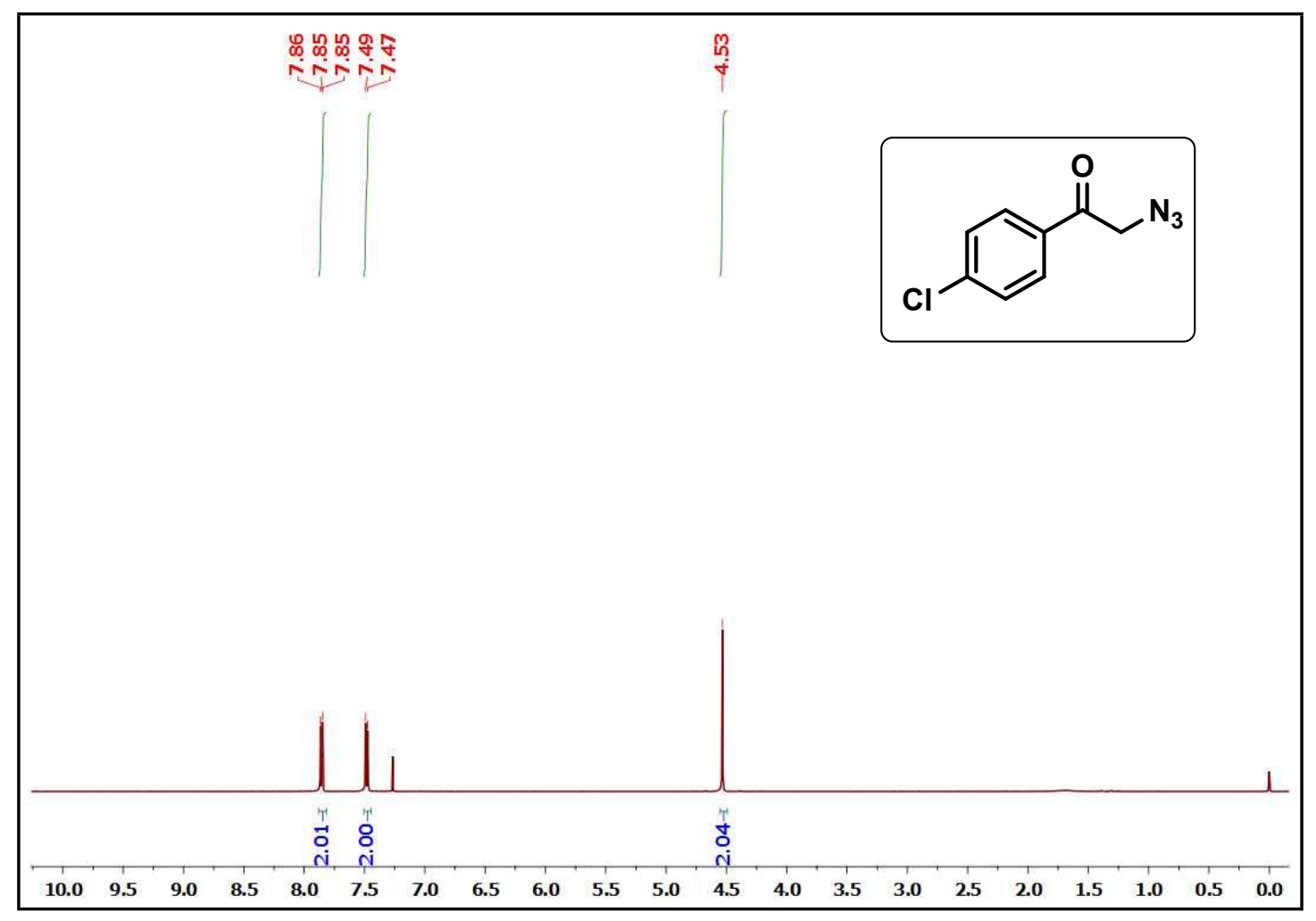

${ }^{1} \mathrm{H}$ NMR spectrum of compound $2 \mathrm{~h}$

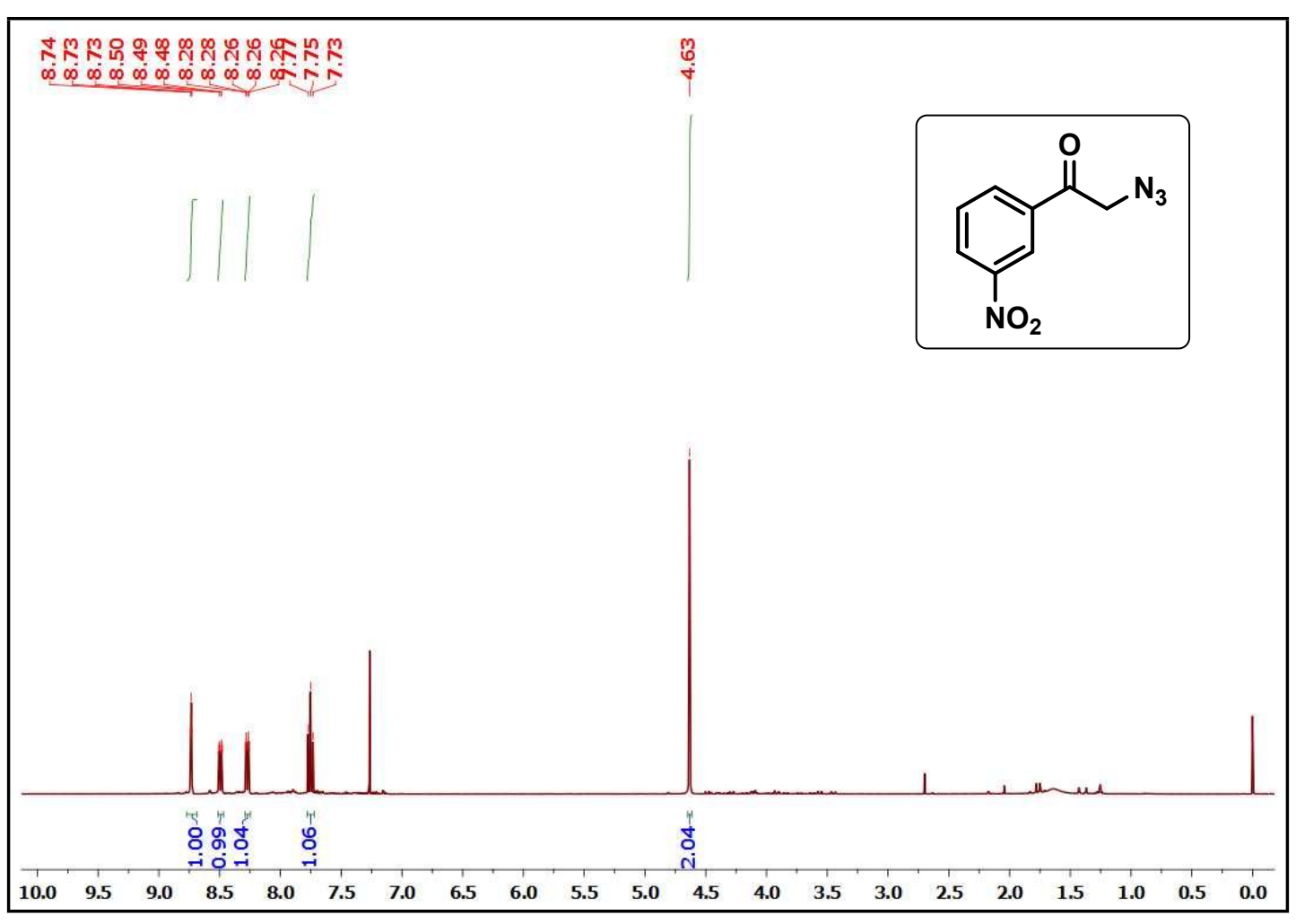


${ }^{1} \mathrm{H}$ NMR spectrum of compound $2 i$

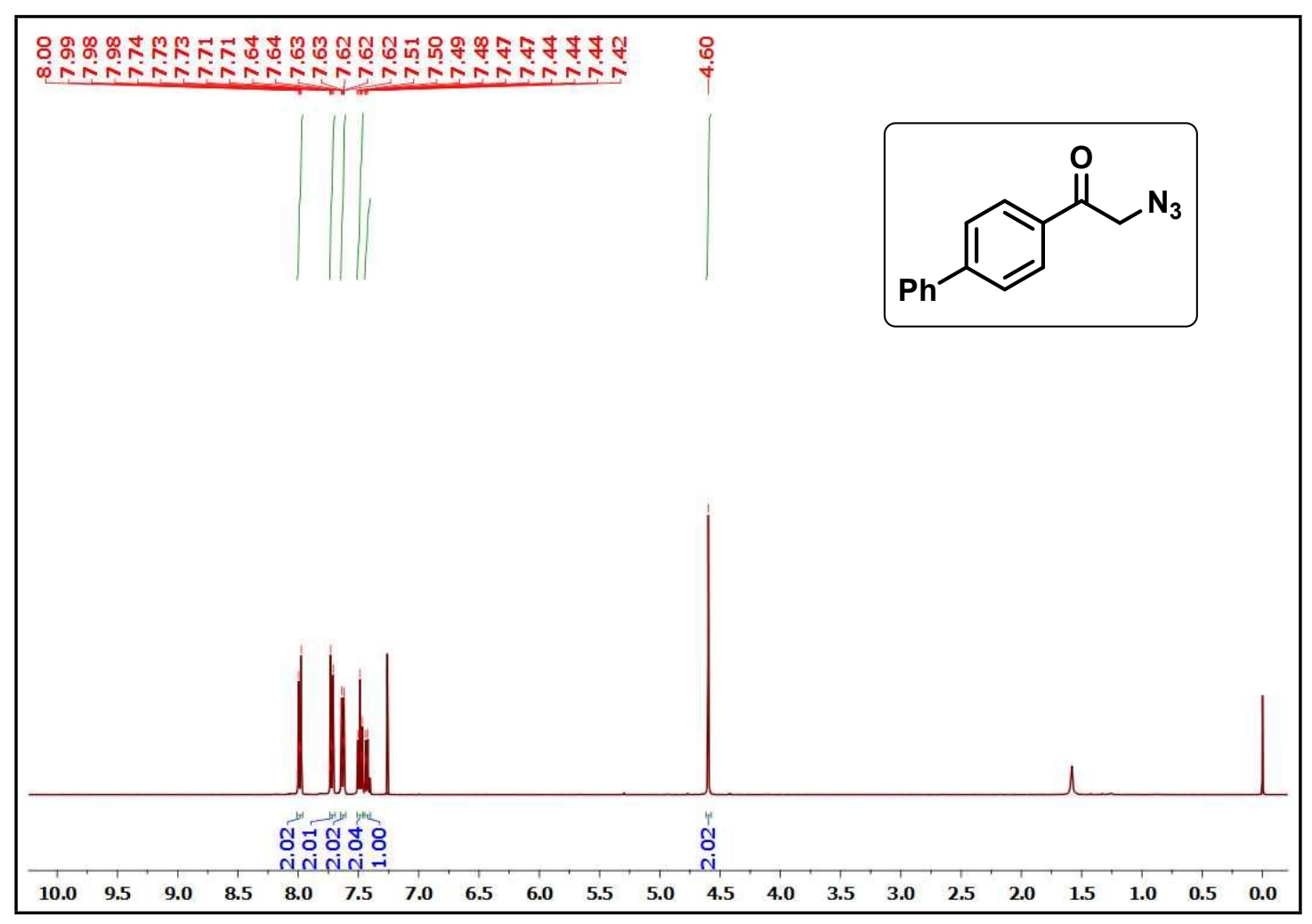

${ }^{1} \mathrm{H}$ NMR spectrum of compound $2 \mathrm{j}$

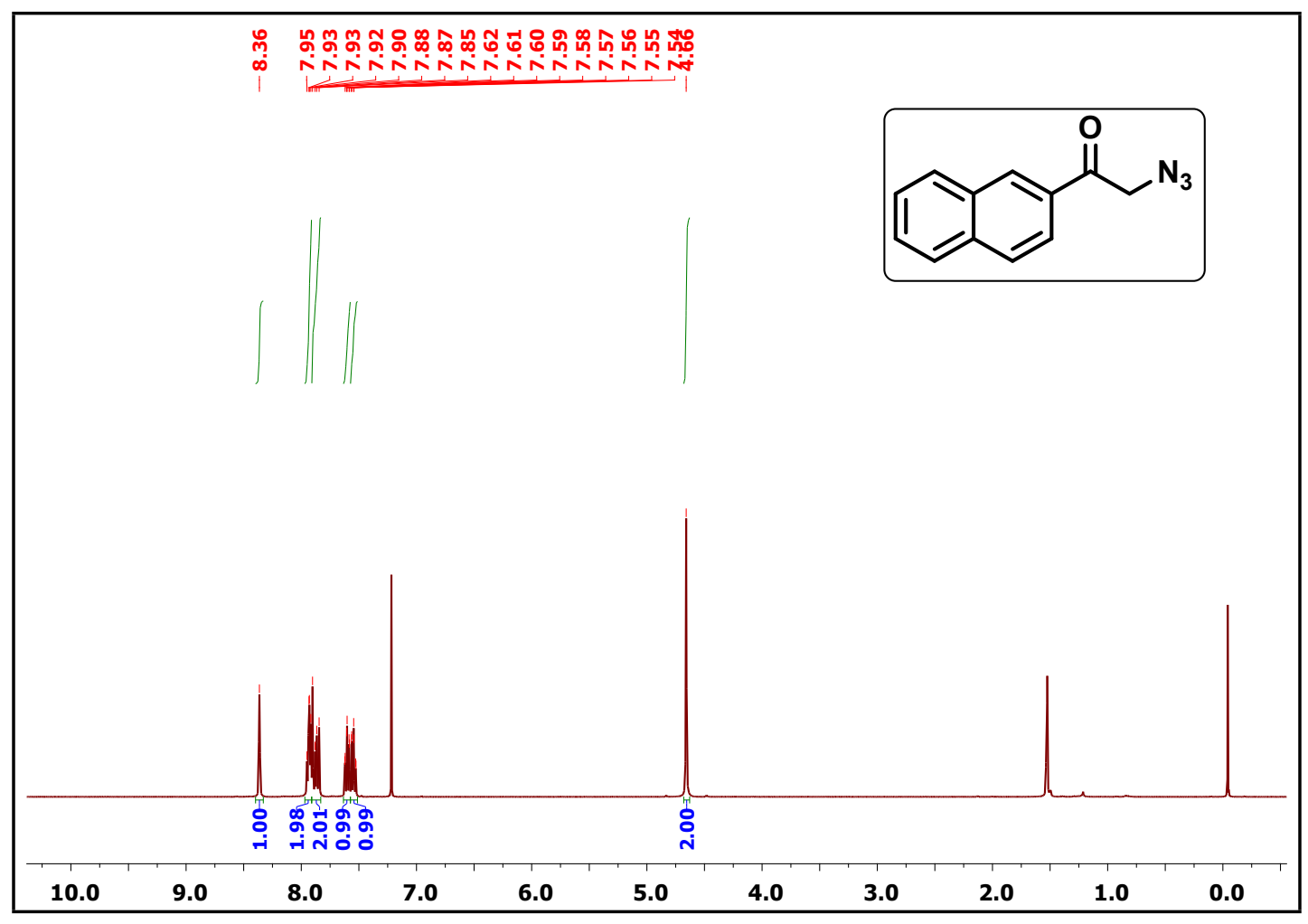


${ }^{1} \mathrm{H}$ NMR spectrum of compound $2 \mathrm{k}$

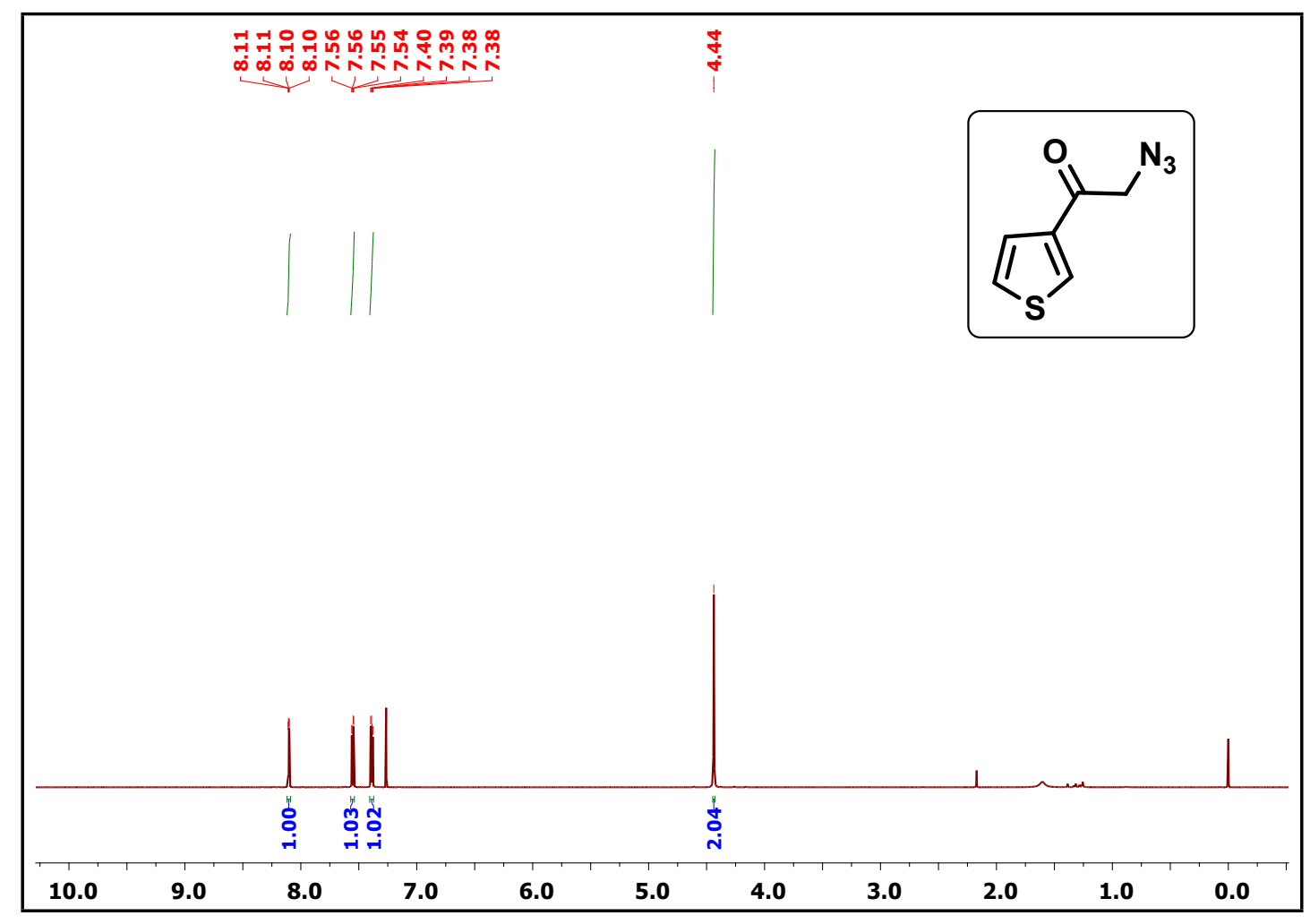

${ }^{13} \mathrm{C}$ NMR spectrum of compound $2 \mathrm{k}$

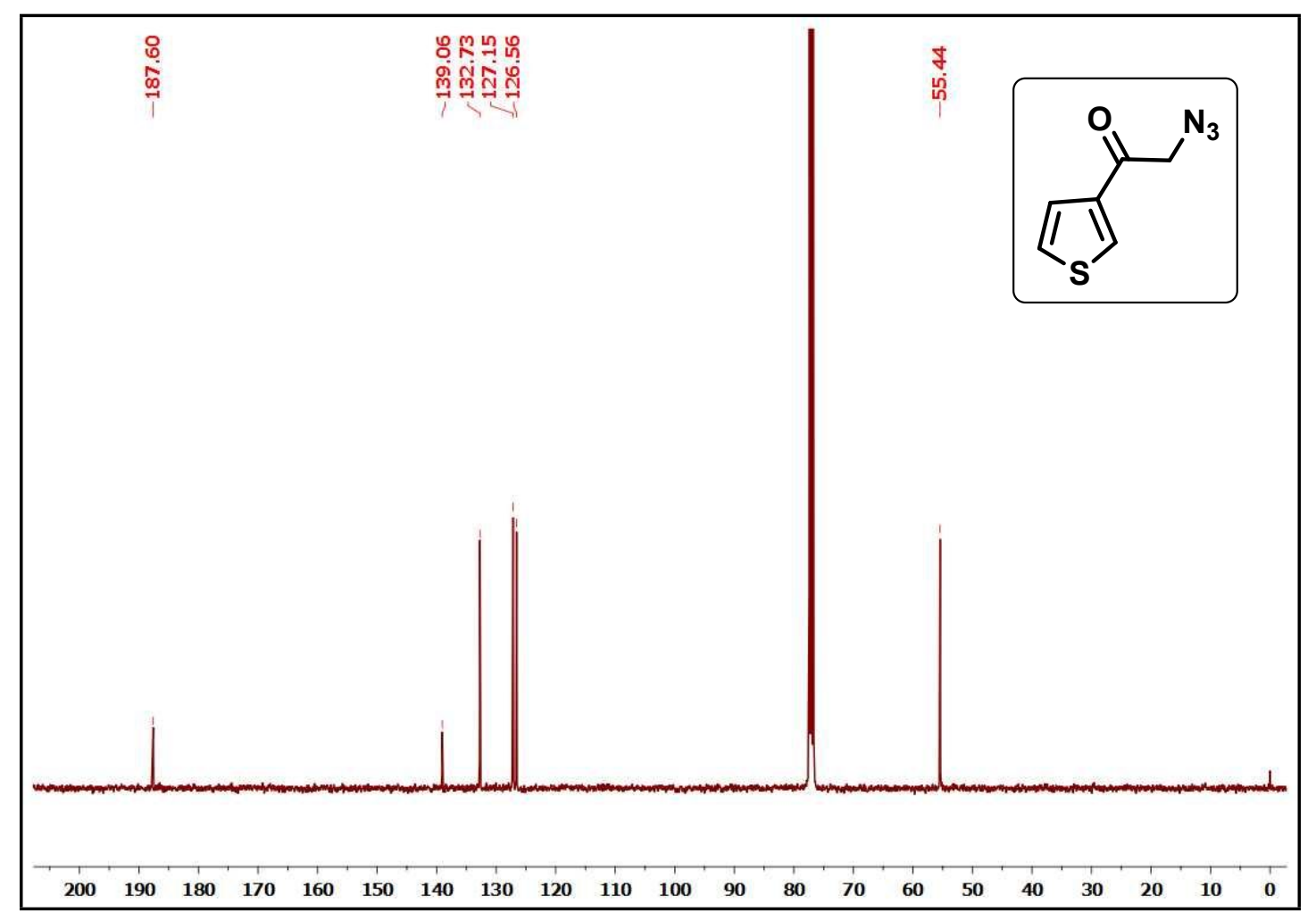




\section{${ }^{1} \mathrm{H}$ NMR spectrum of compound $2 \mathrm{I}$}

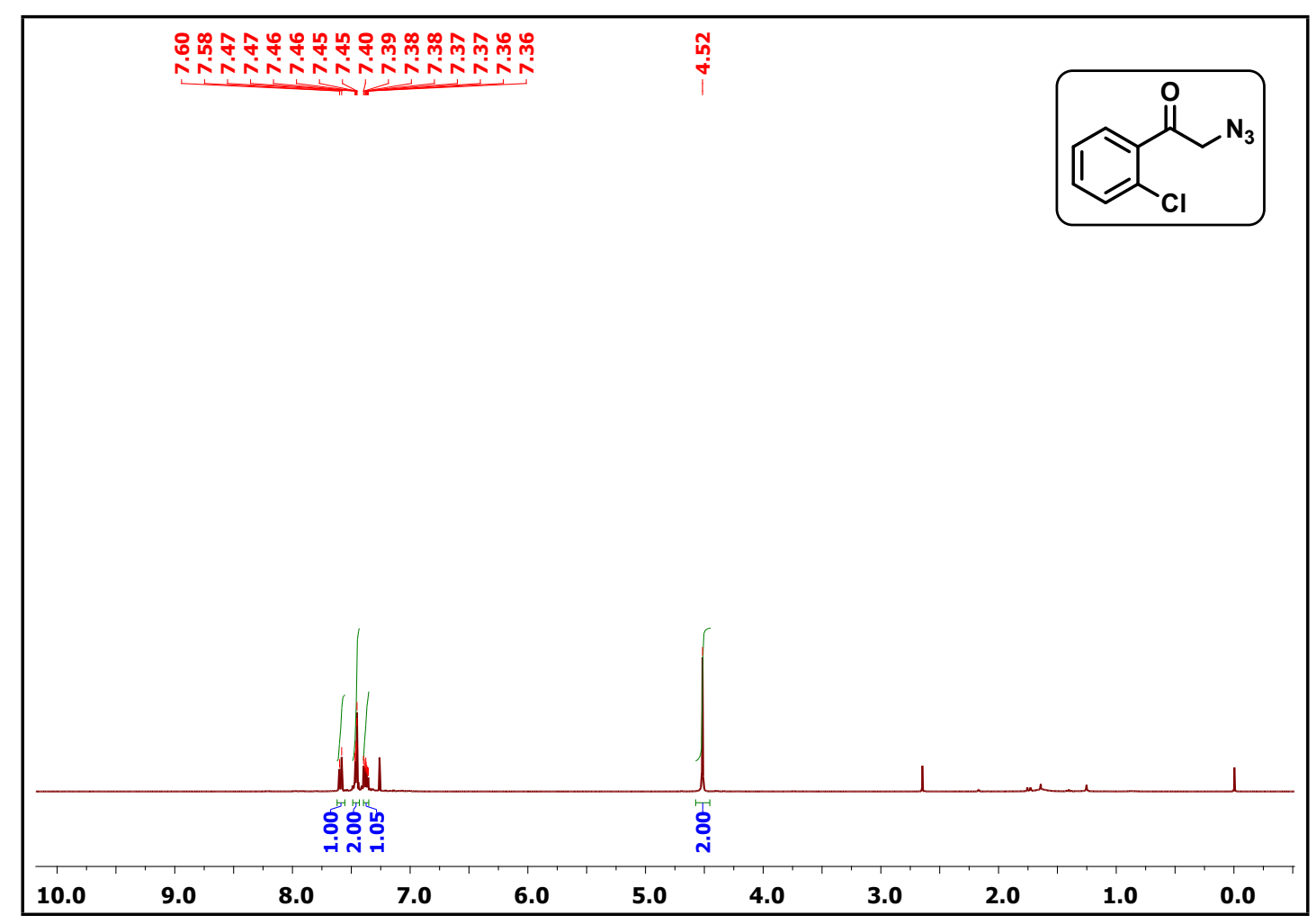

${ }^{1} \mathrm{H}$ NMR spectrum of compound $2 \mathrm{~m}$

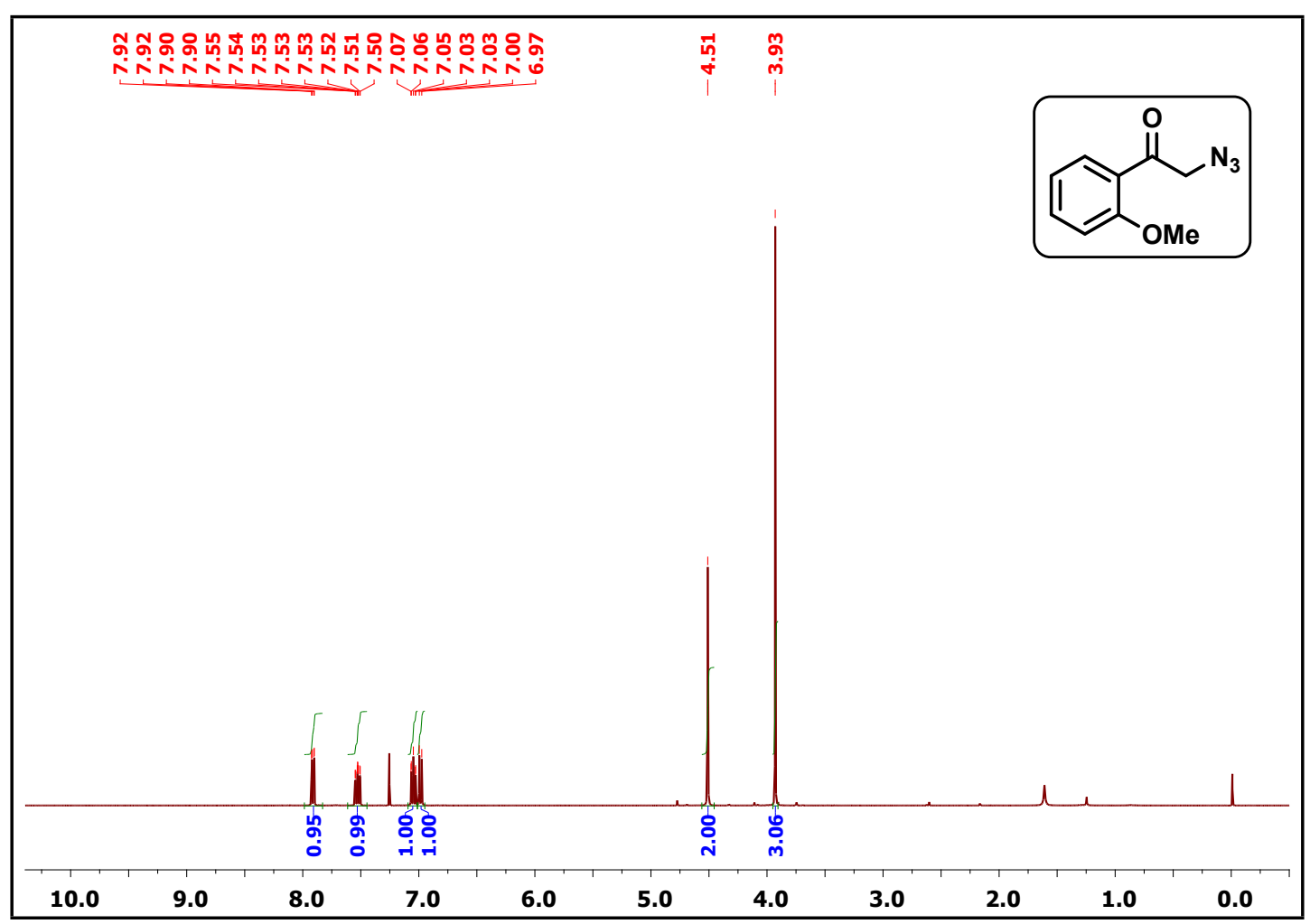


${ }^{1} H$ NMR spectrum of compound $2 n$

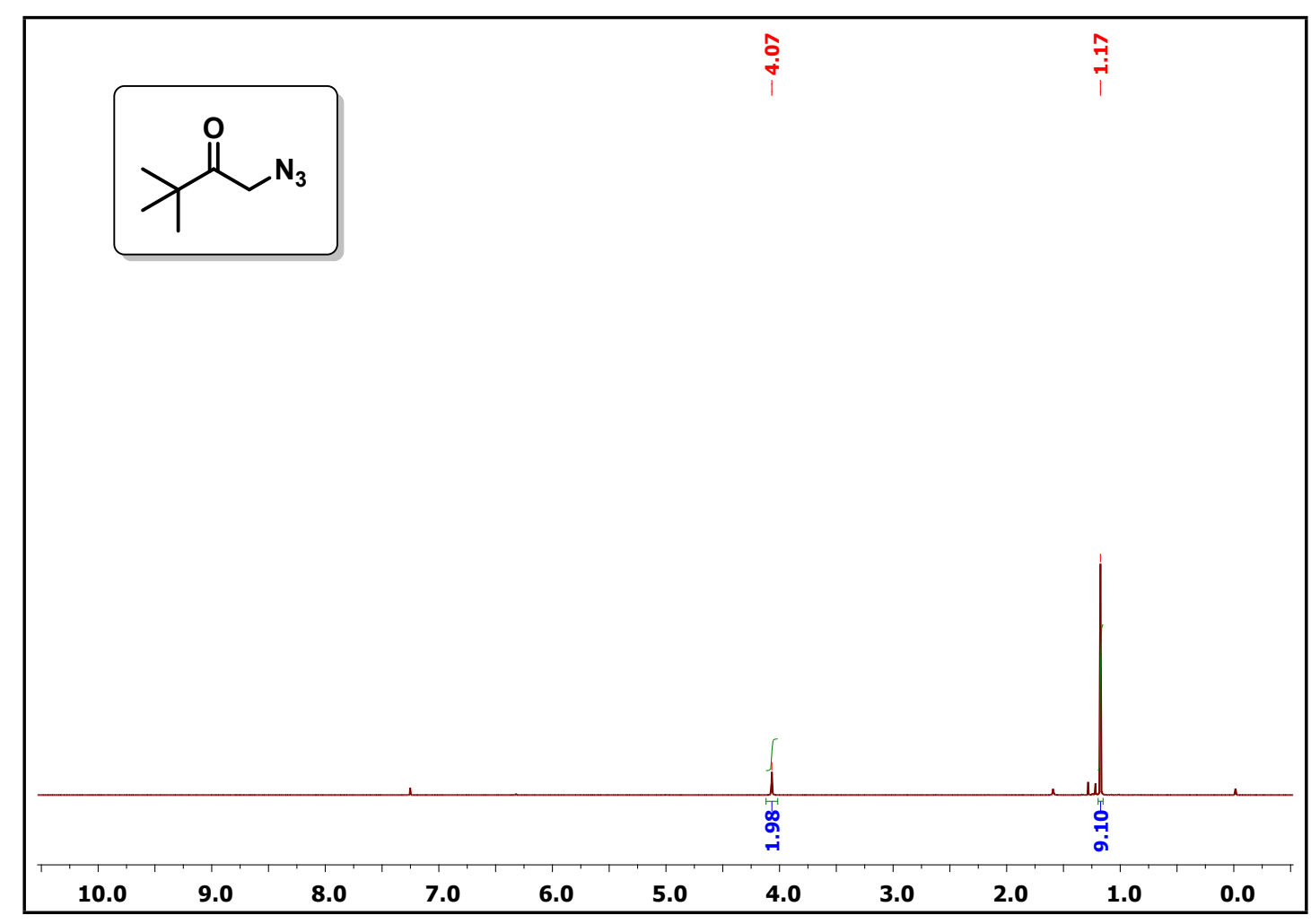


${ }^{1} \mathrm{H}$ NMR spectrum of compound 20

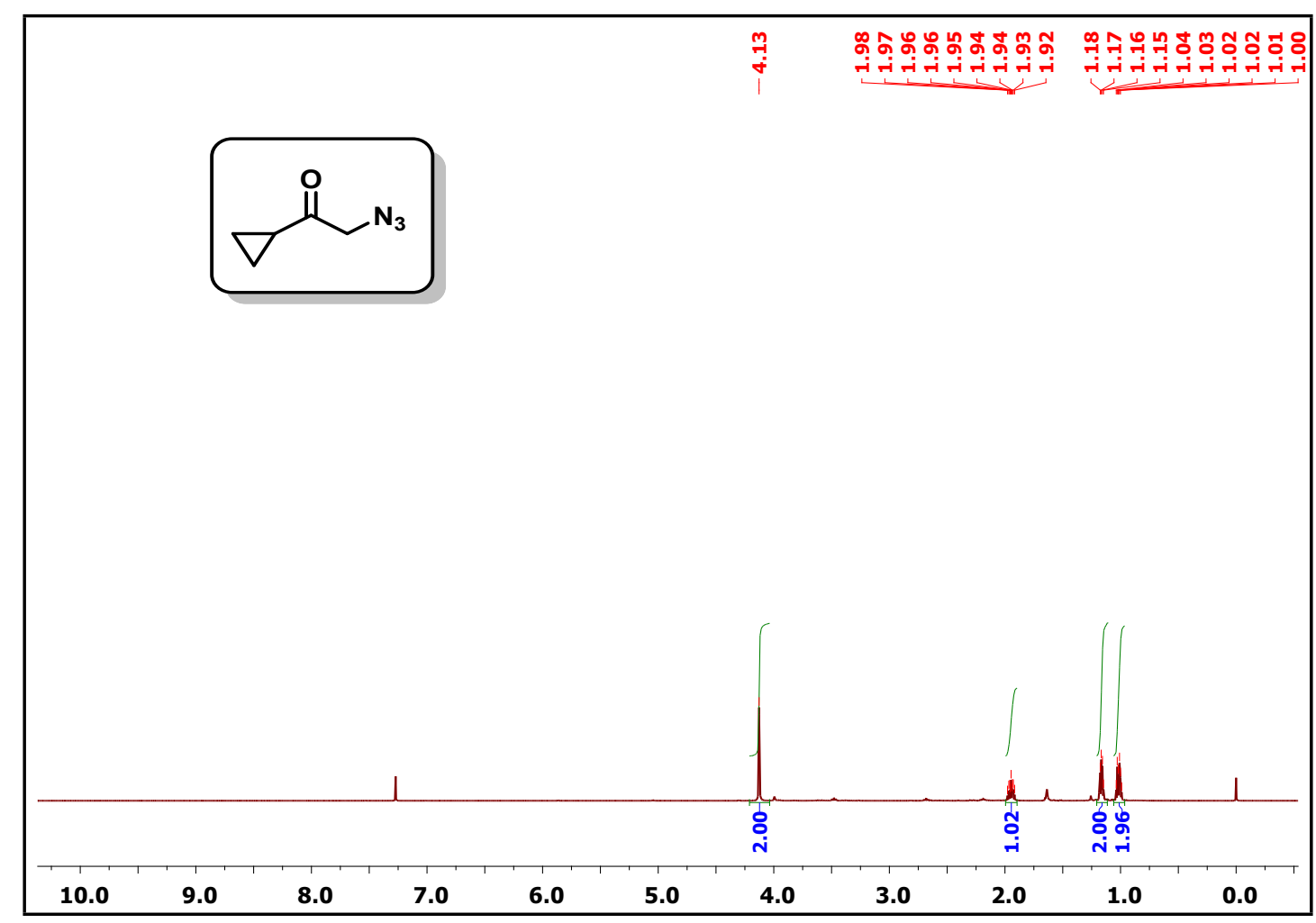

${ }^{13} \mathrm{C}$ NMR spectrum of compound 20

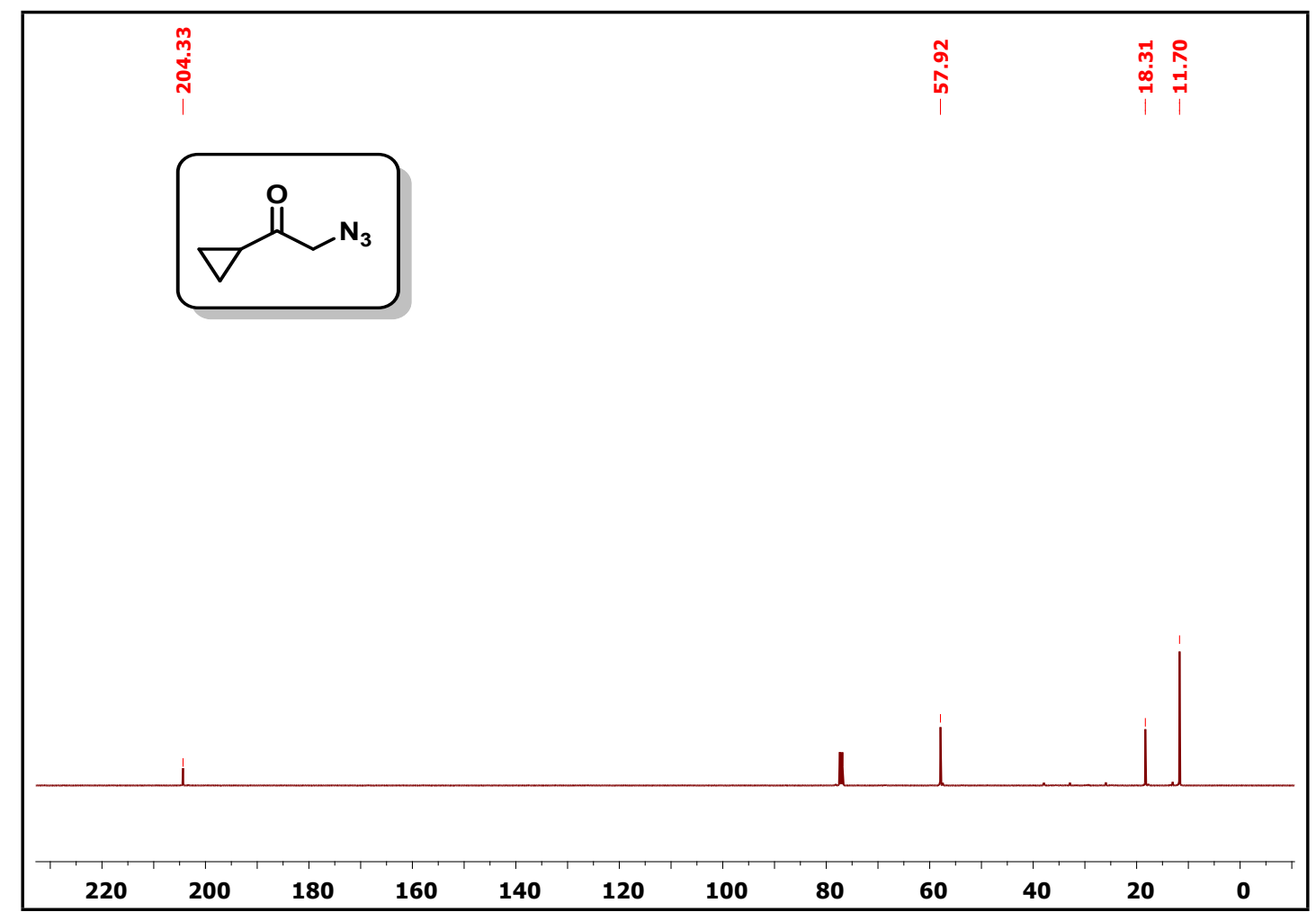




\section{${ }^{1} \mathrm{H}$ NMR spectrum of compound $3 \mathrm{ba}$}

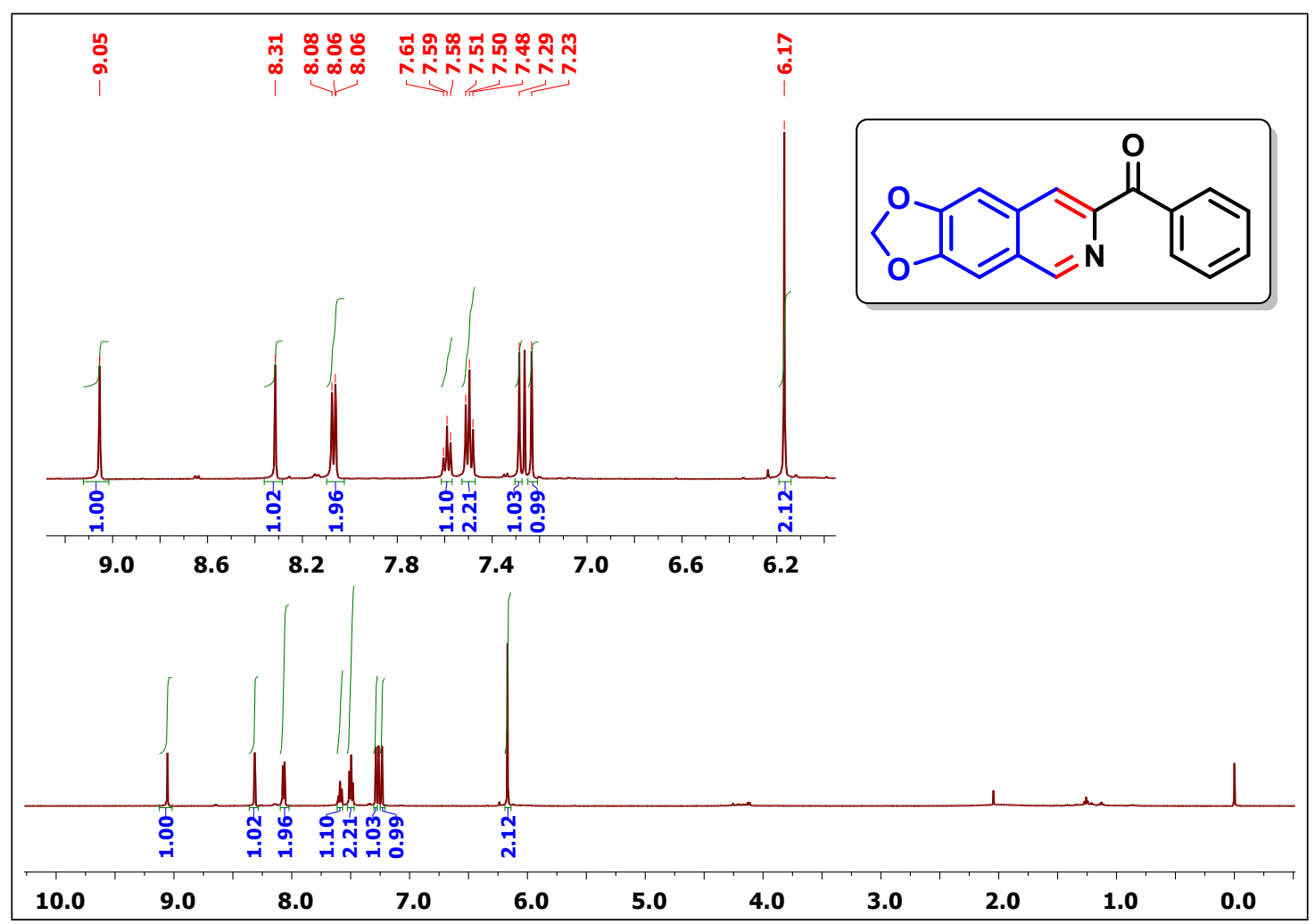

${ }^{13} \mathrm{C}$ NMR spectrum of compound $3 \mathrm{ba}$

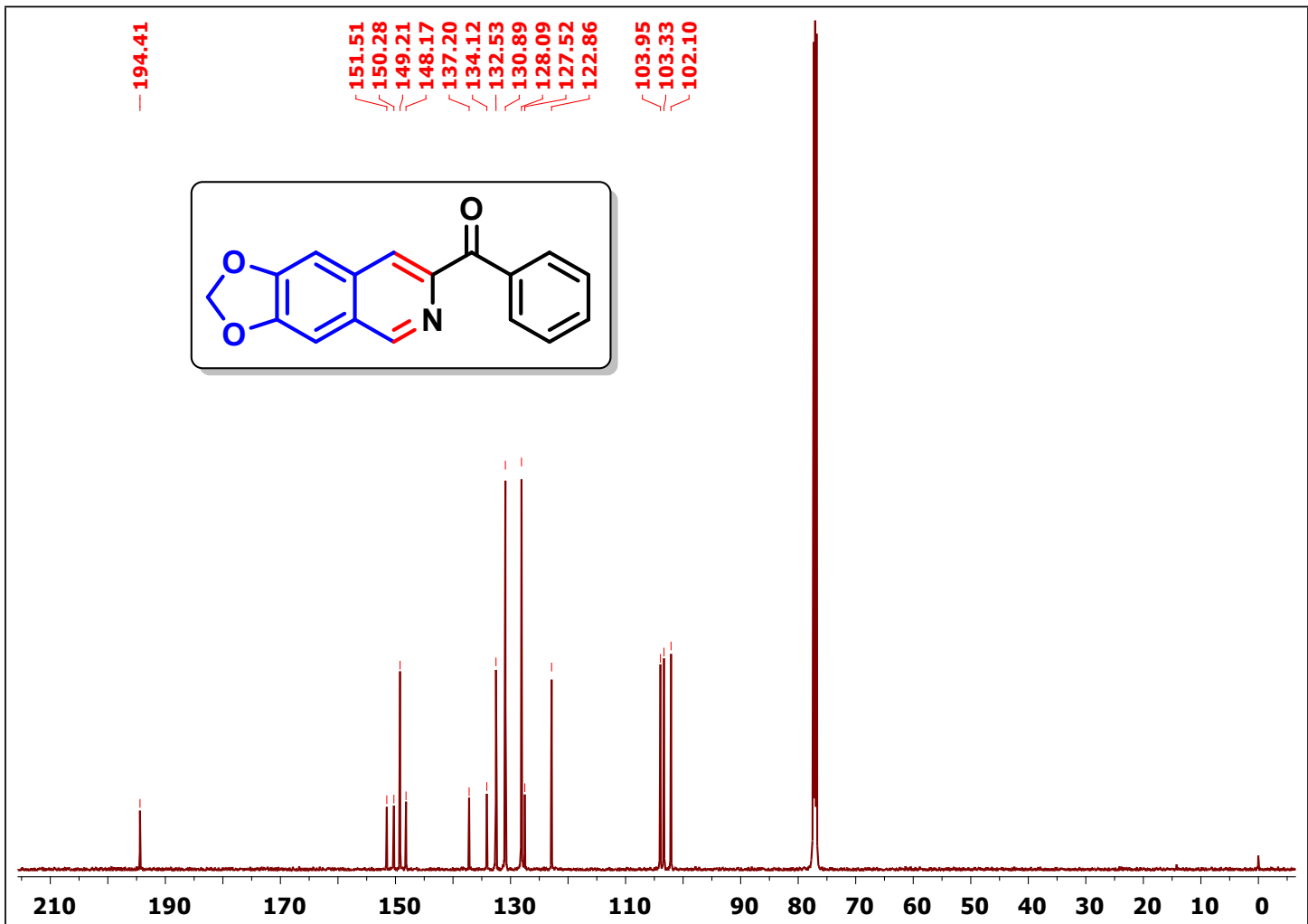


${ }^{1} \mathrm{H}$ NMR spectrum of compound 3ca

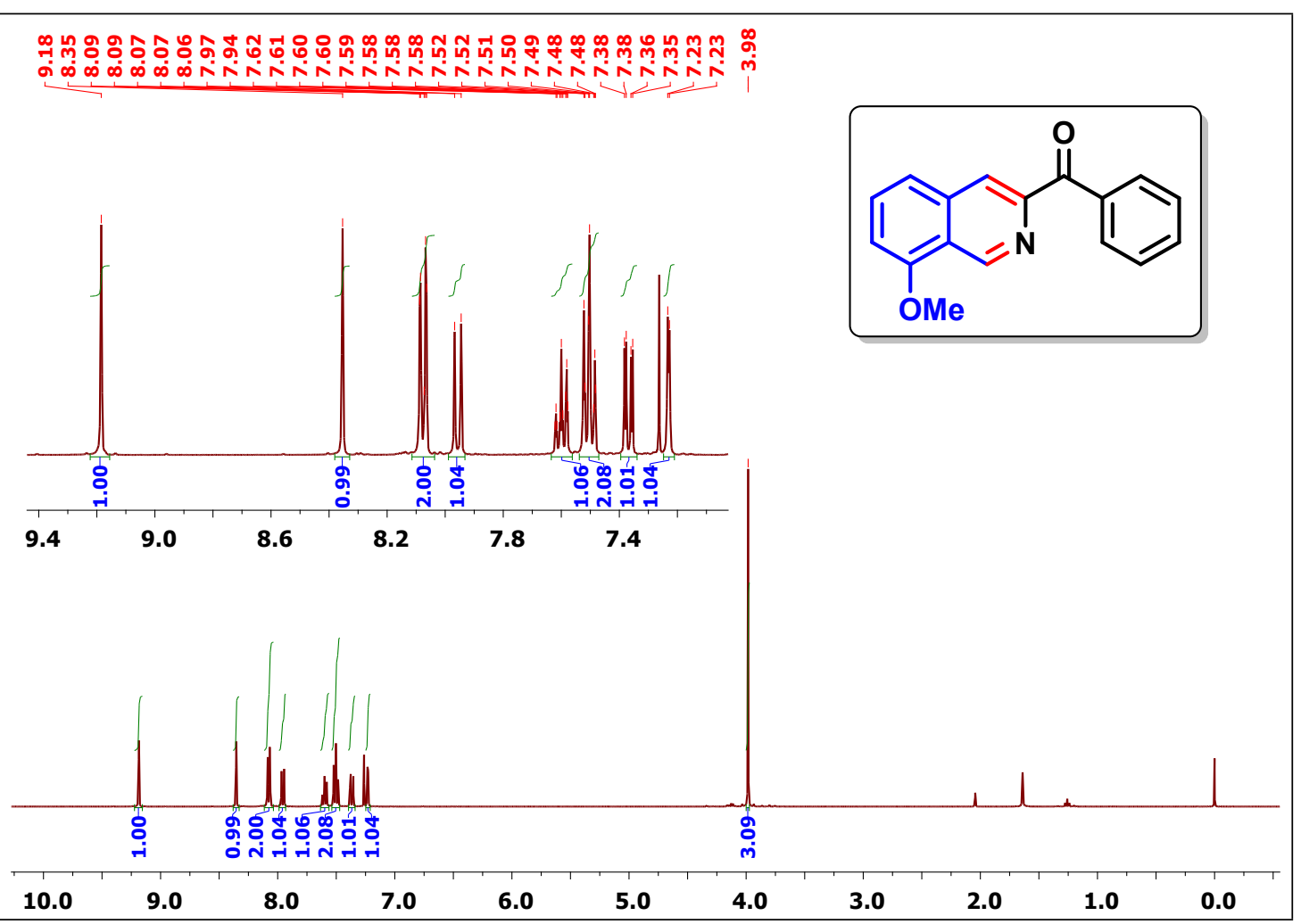

${ }^{13} \mathrm{C}$ NMR spectrum of compound $3 \mathrm{ca}$

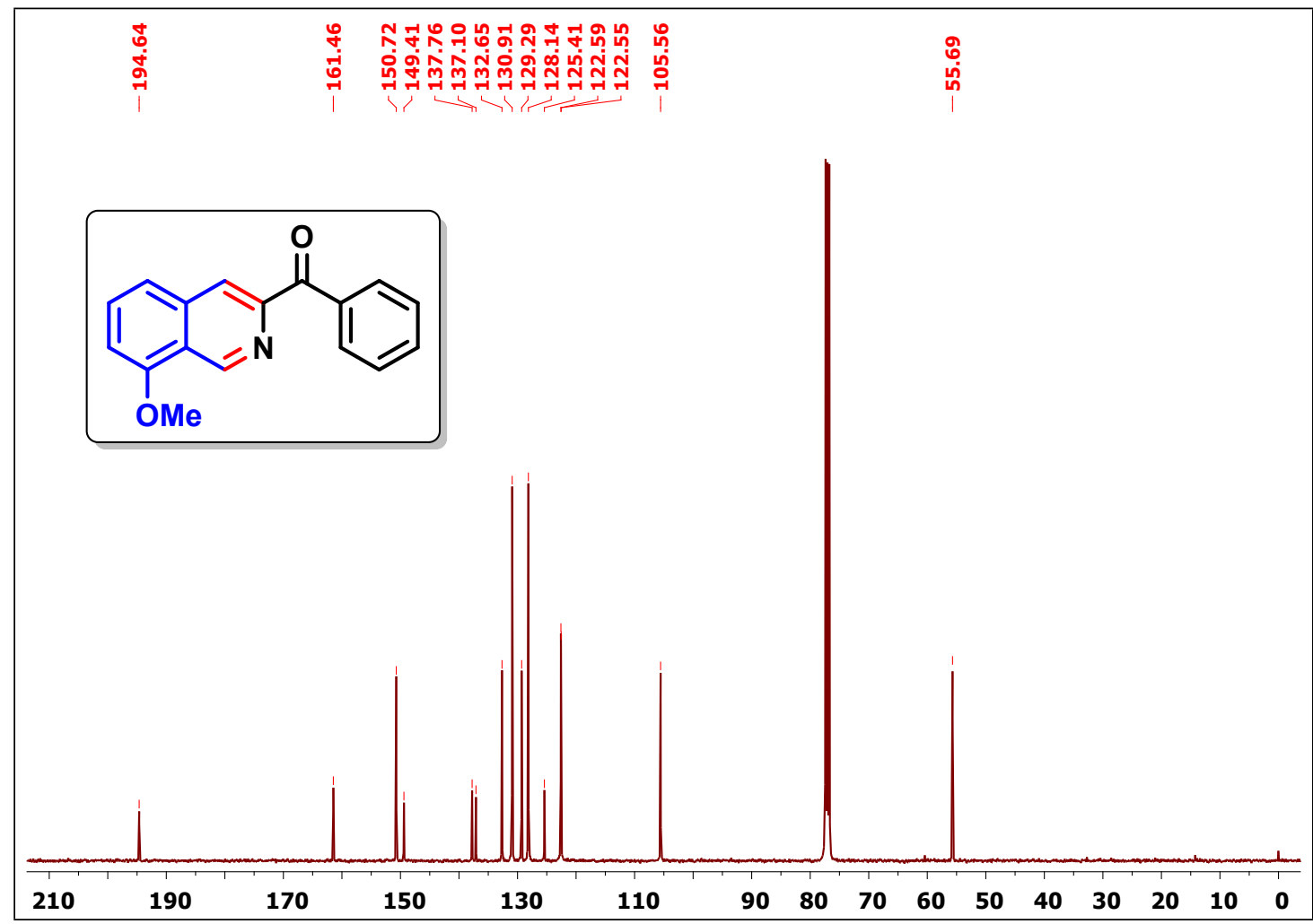

S19 


\section{${ }^{1} \mathrm{H}$ NMR spectrum of compound 3da}

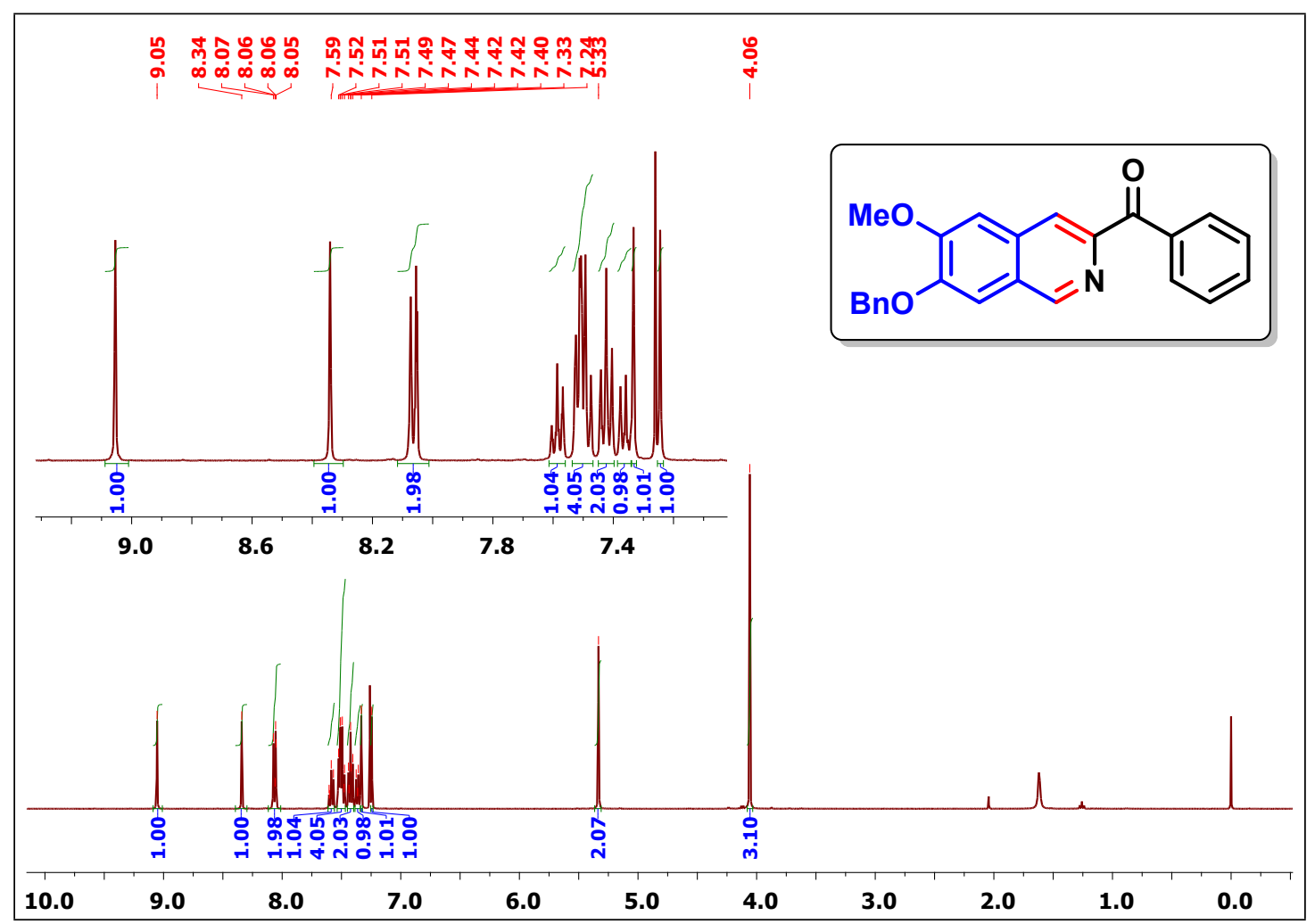

${ }^{13} \mathrm{C}$ NMR spectrum of compound $3 \mathrm{da}$

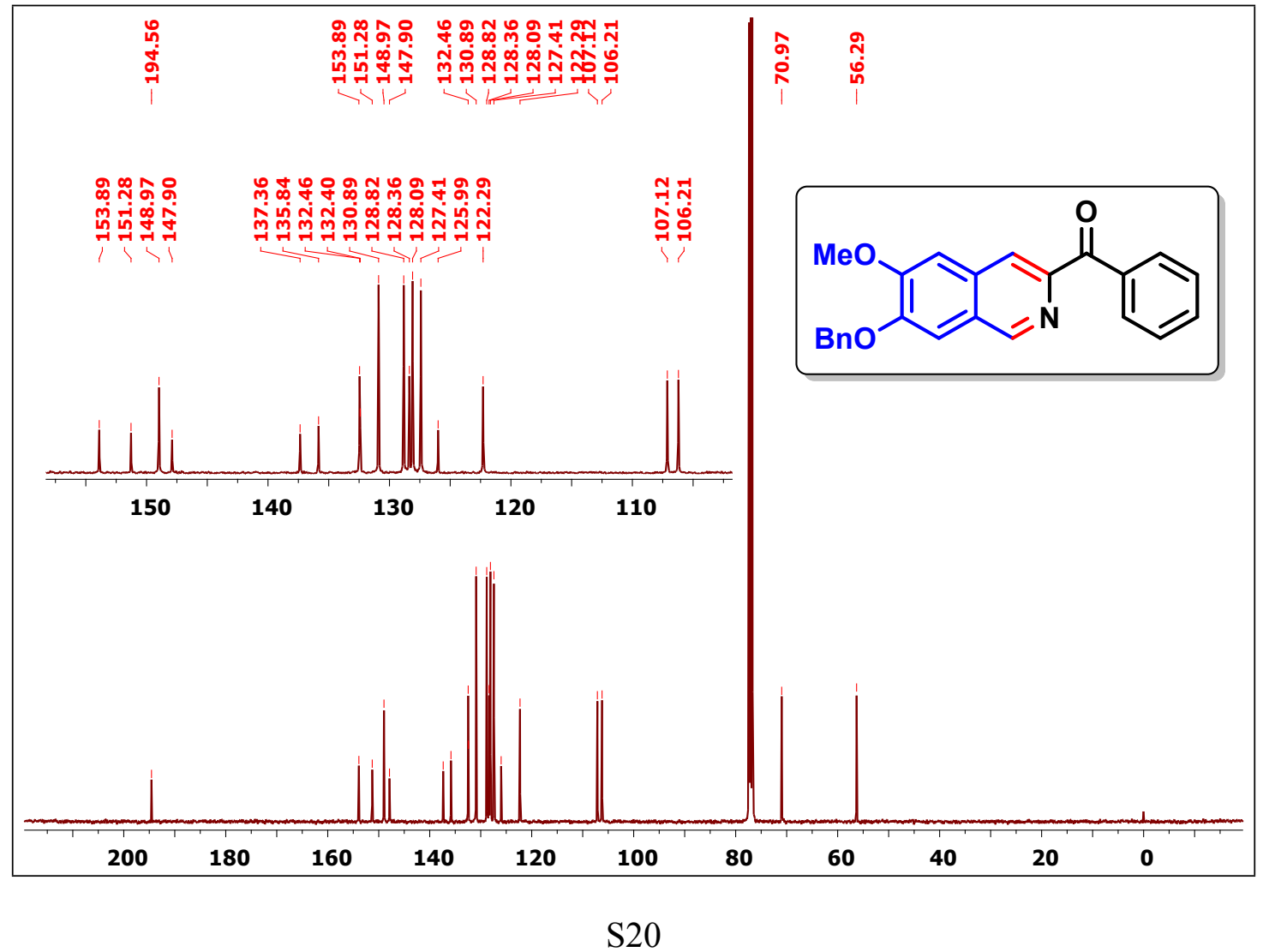




\section{${ }^{1} \mathrm{H}$ NMR spectrum of compound 3ea}

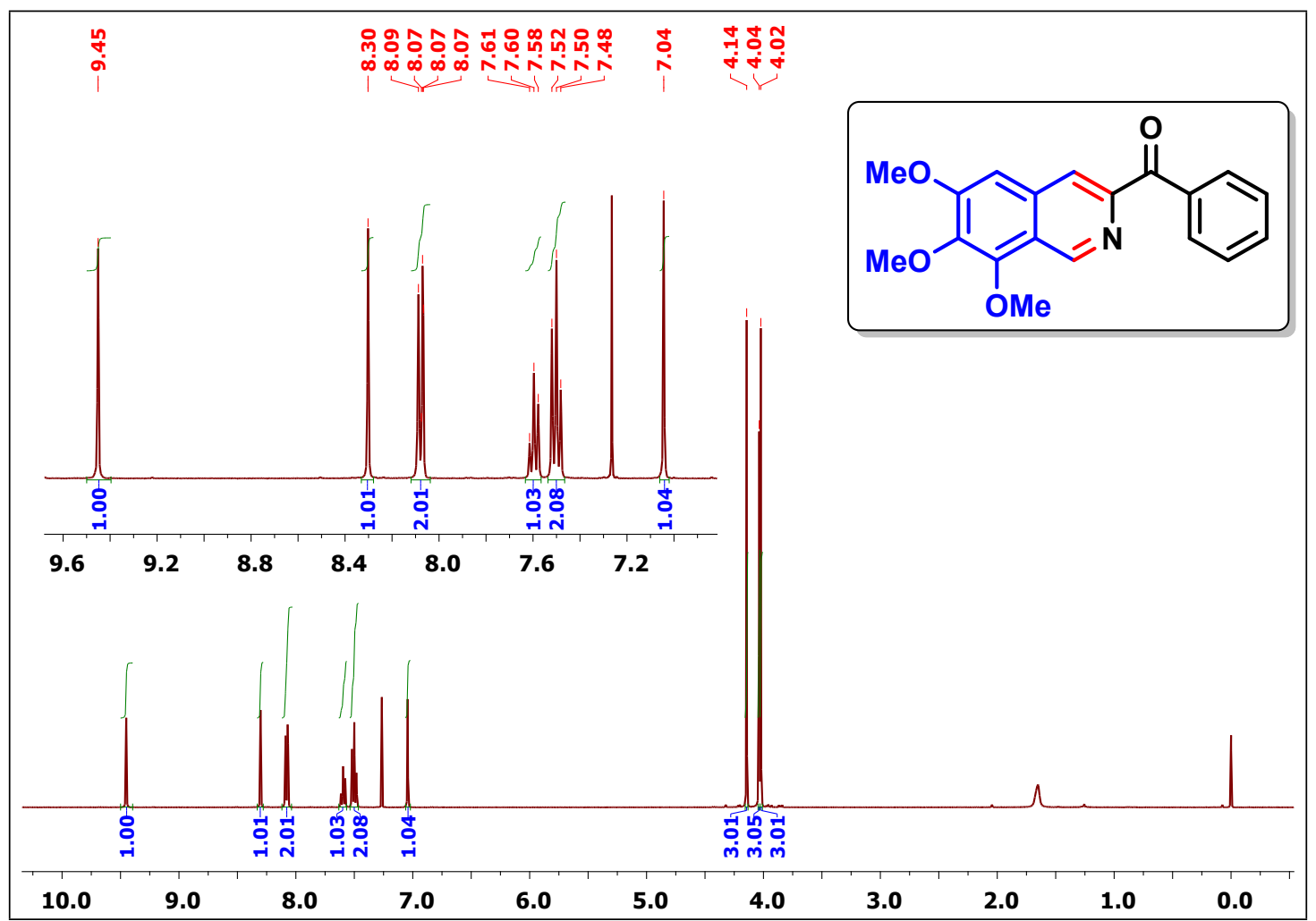

${ }^{13} \mathrm{C}$ NMR spectrum of compound 3ea

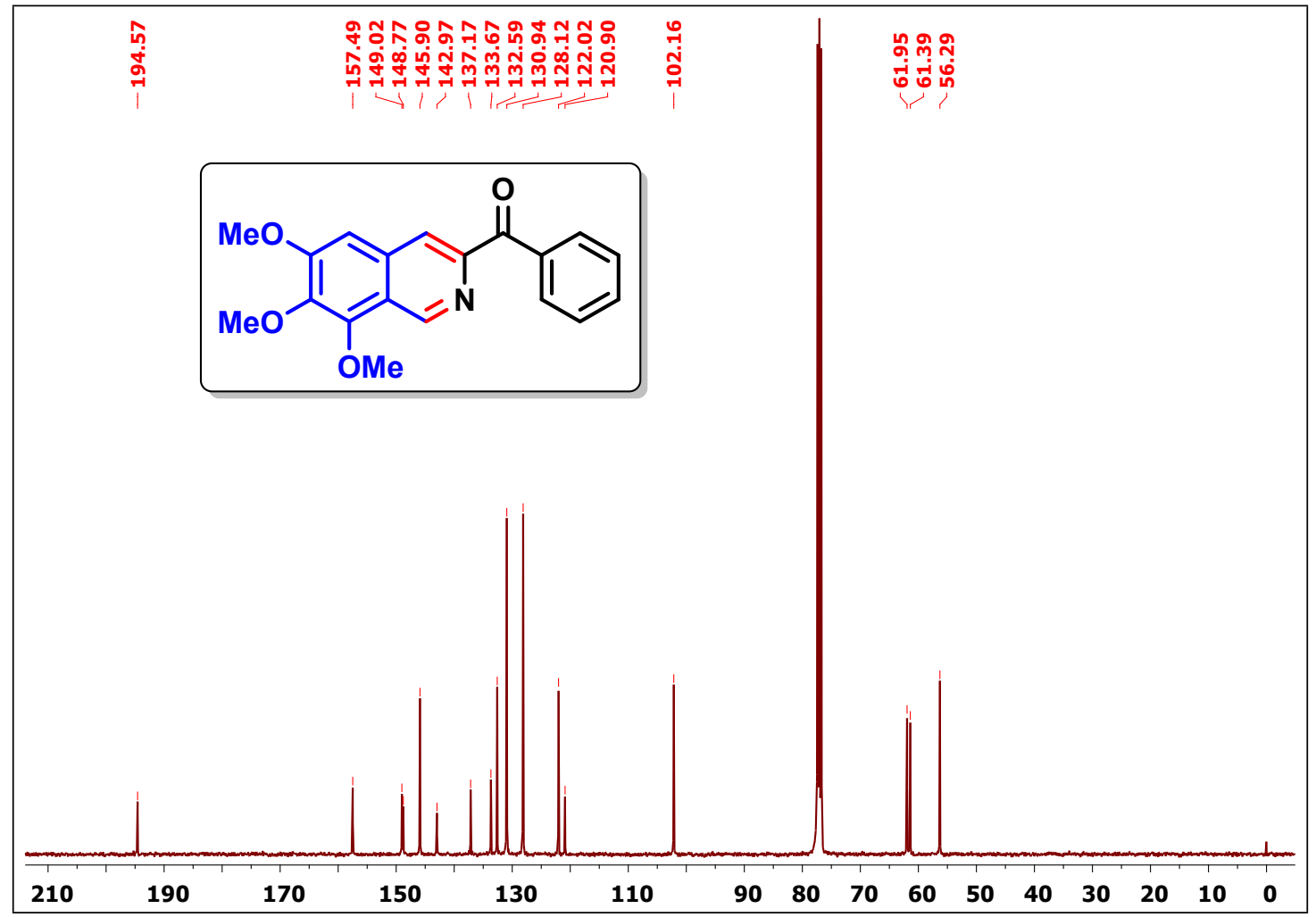




\section{${ }^{1} \mathrm{H}$ NMR spectrum of compound $3 \mathrm{fa}$}

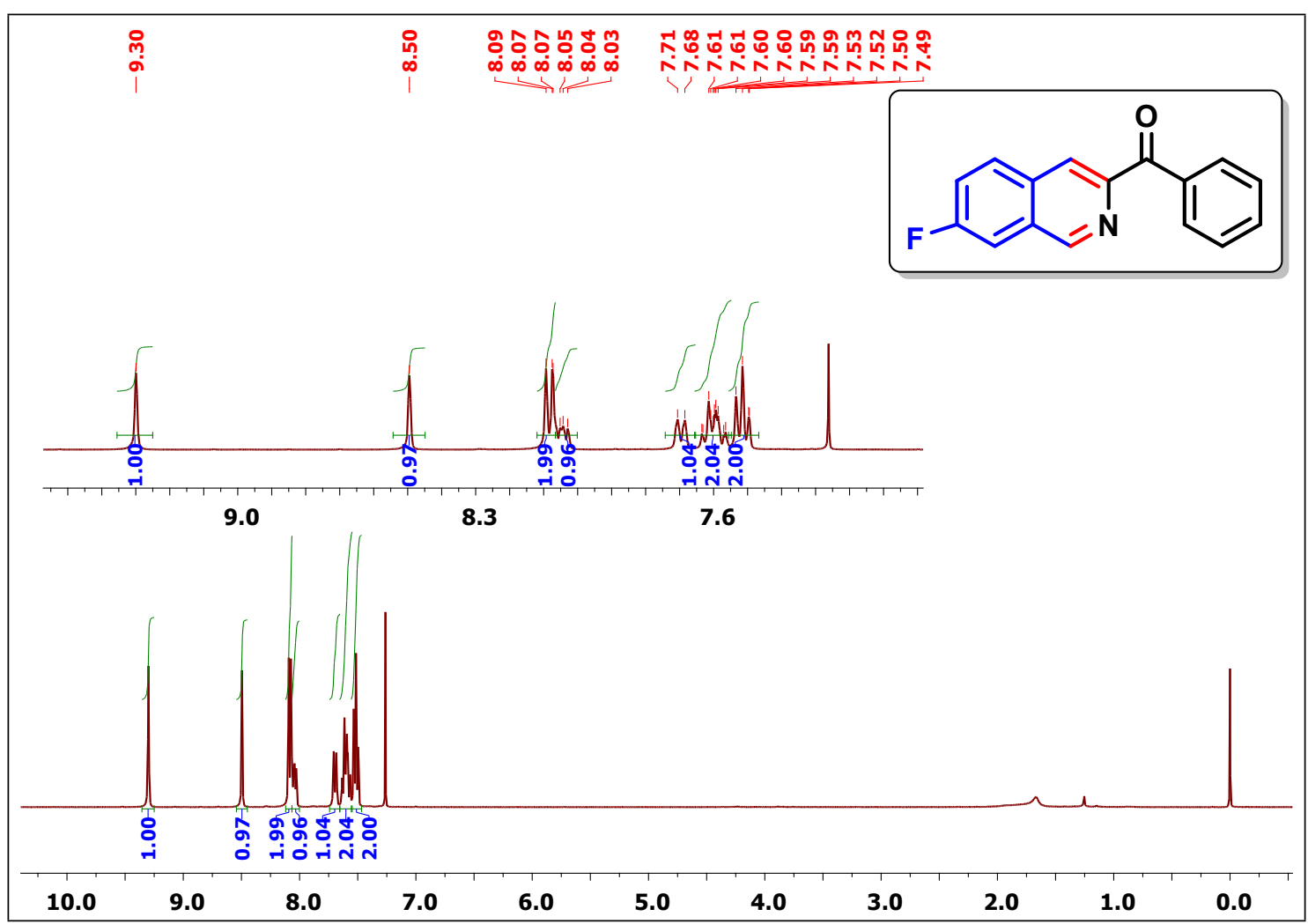

${ }^{13} \mathrm{C}$ NMR spectrum of compound $3 \mathrm{fa}$

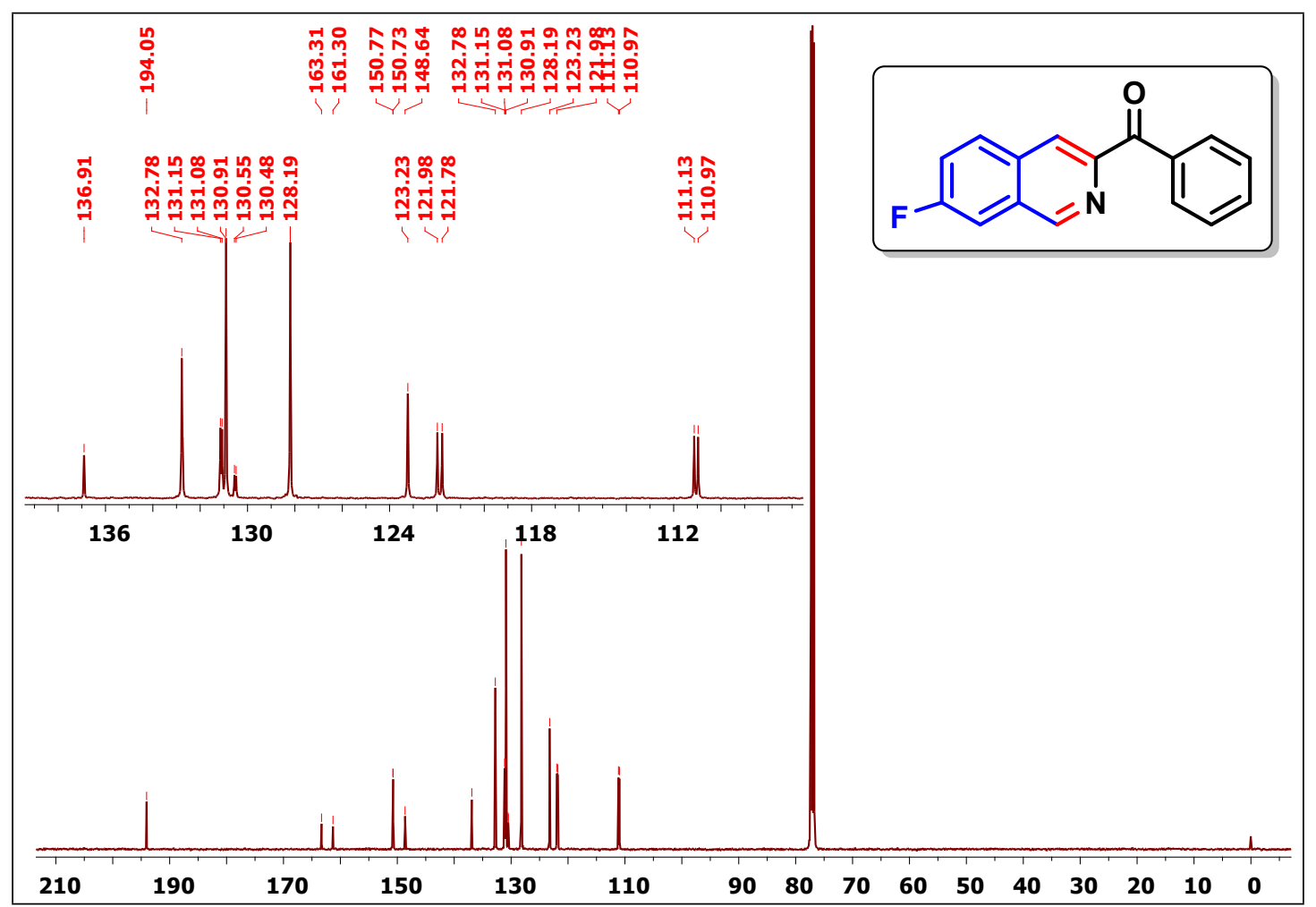




\section{${ }^{19} \mathrm{~F}$ NMR spectrum of compound 3 fa}

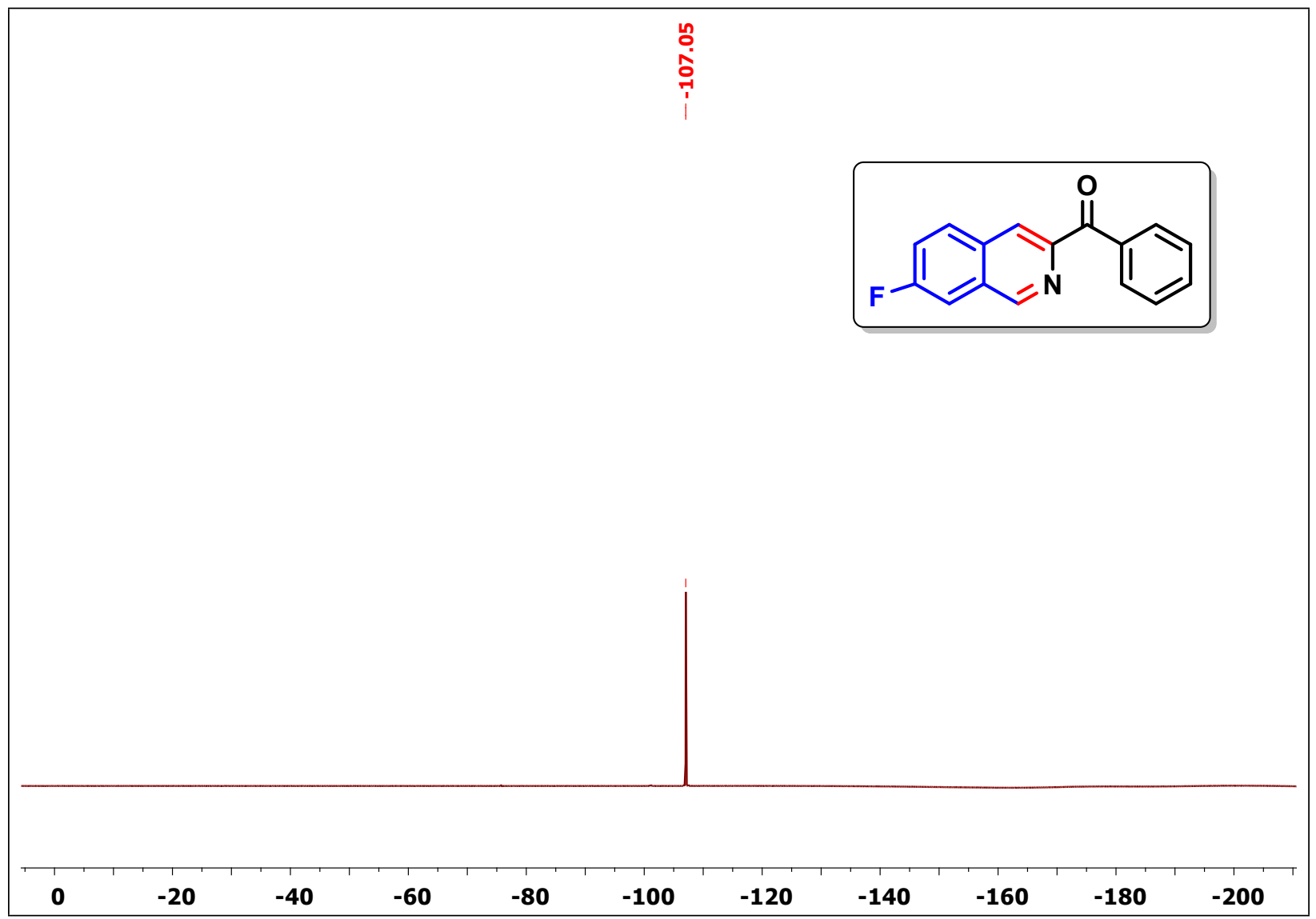




\section{${ }^{1} \mathrm{H}$ NMR spectrum of compound 3ga}

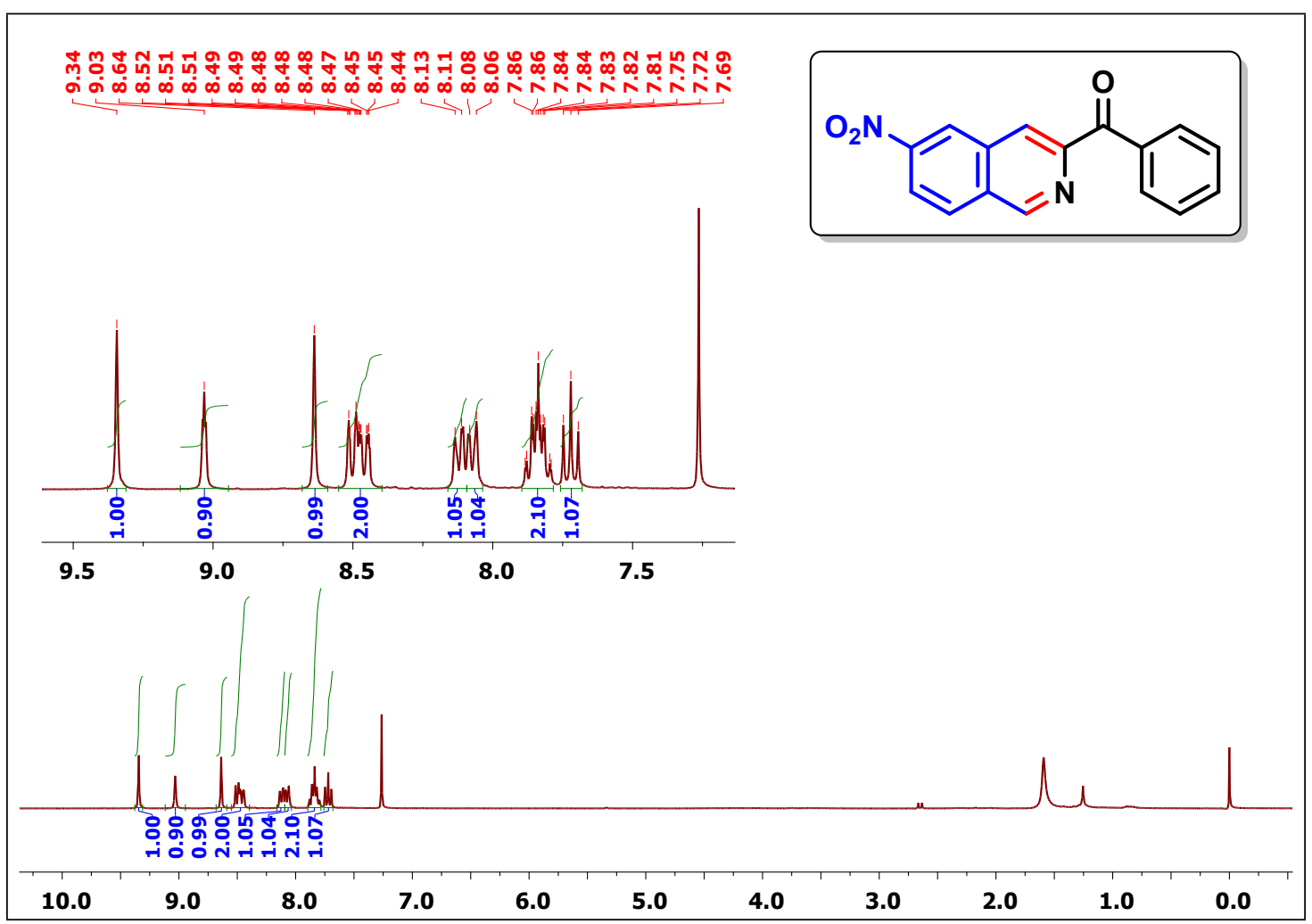

${ }^{13} \mathrm{C}$ NMR spectrum of compound 3ga

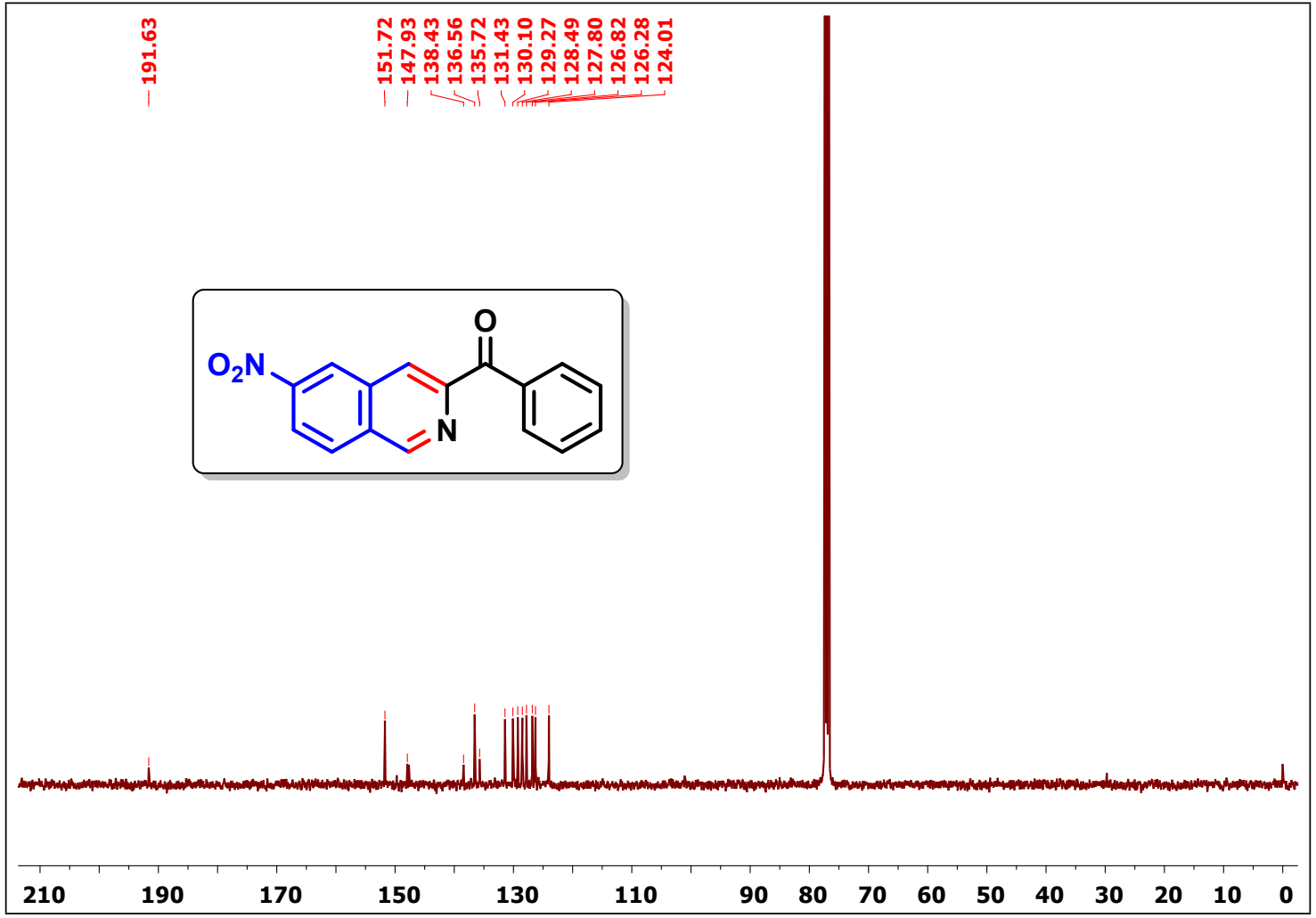




\section{${ }^{1} \mathrm{H}$ NMR spectrum of compound $3 \mathrm{ha}$}

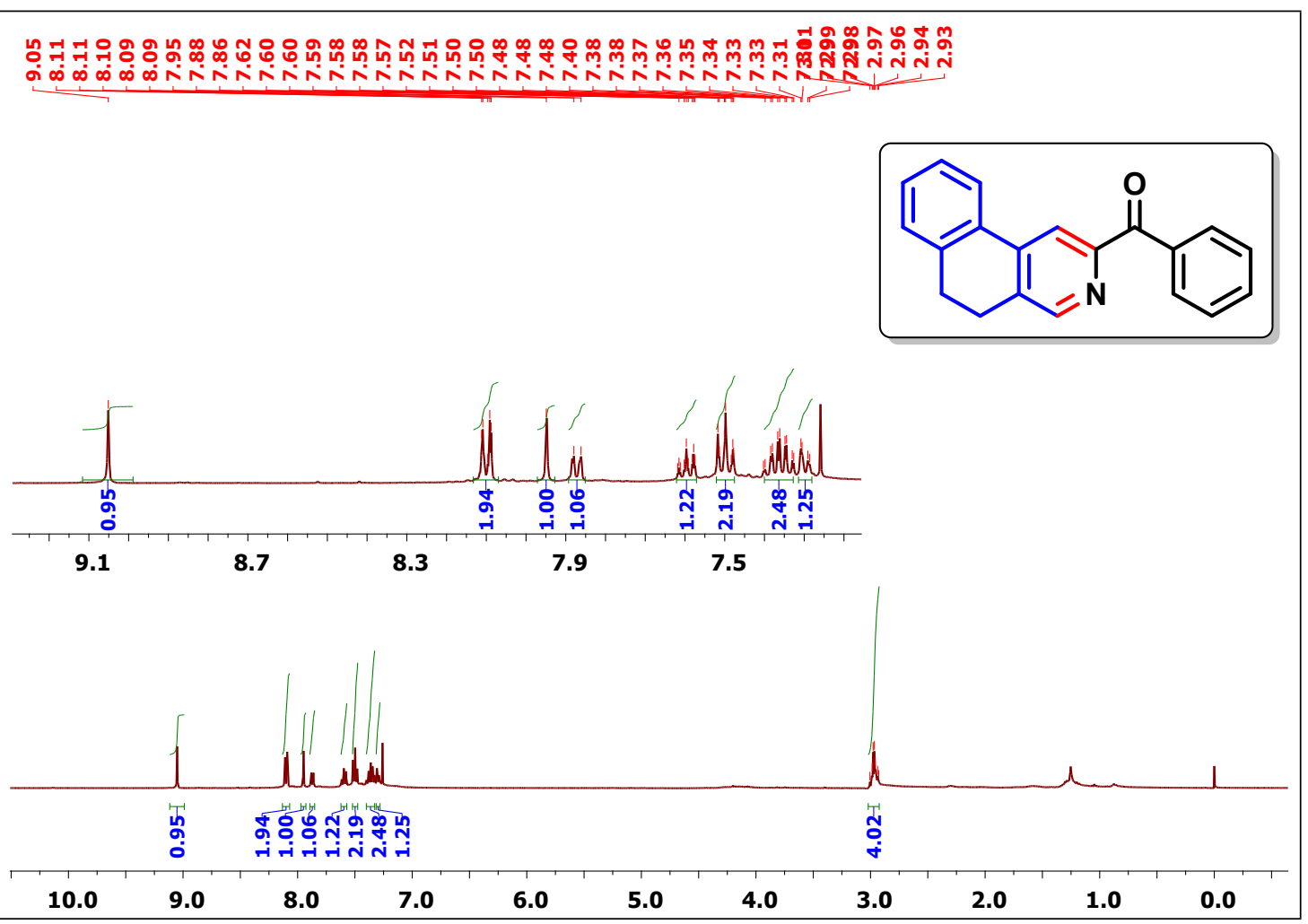

${ }^{13} \mathrm{C}$ NMR spectrum of compound $3 \mathrm{ha}$

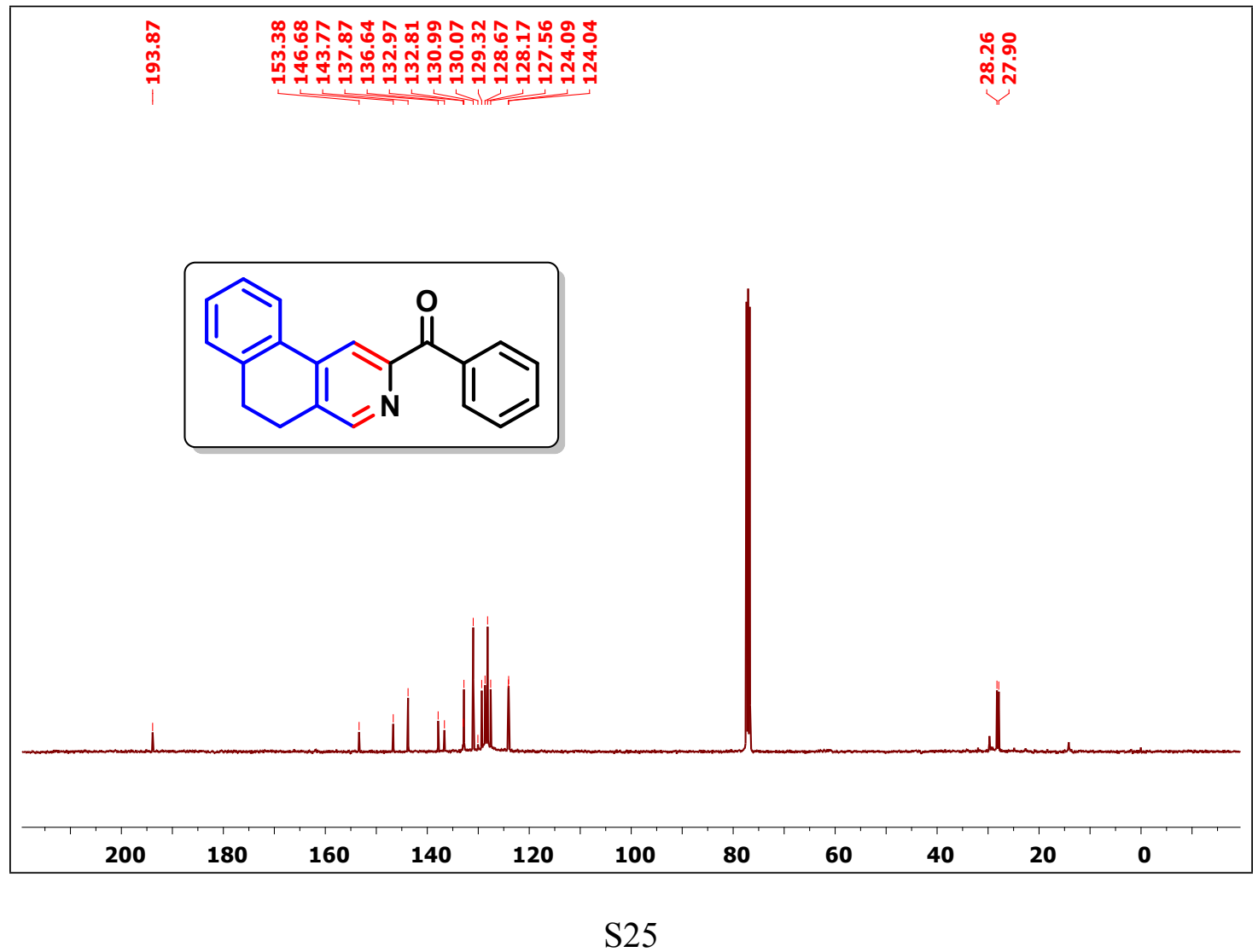




\section{${ }^{1} \mathrm{H}$ NMR spectrum of compound 3il}

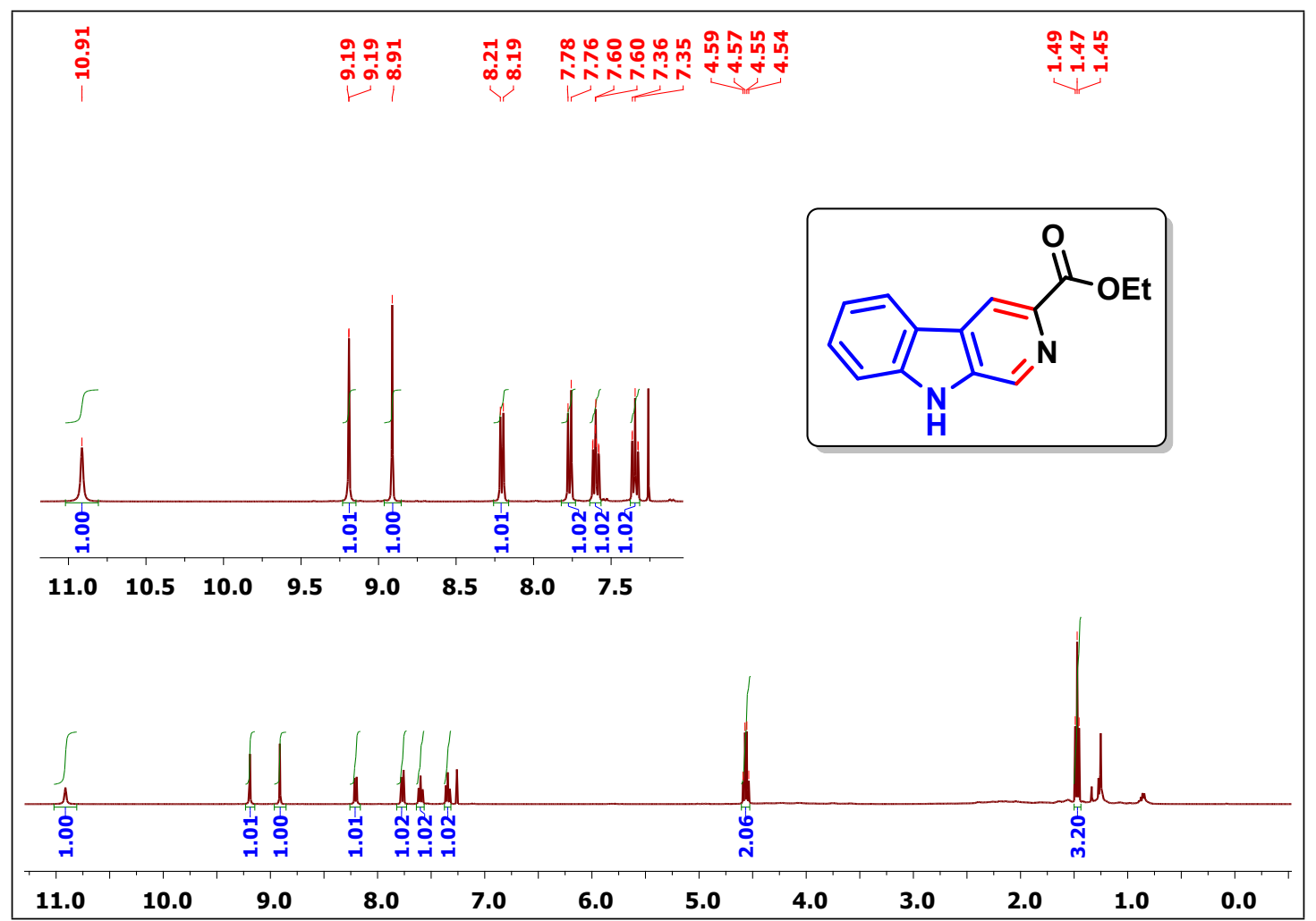

${ }^{13} \mathrm{C}$ NMR spectrum of compound 3il

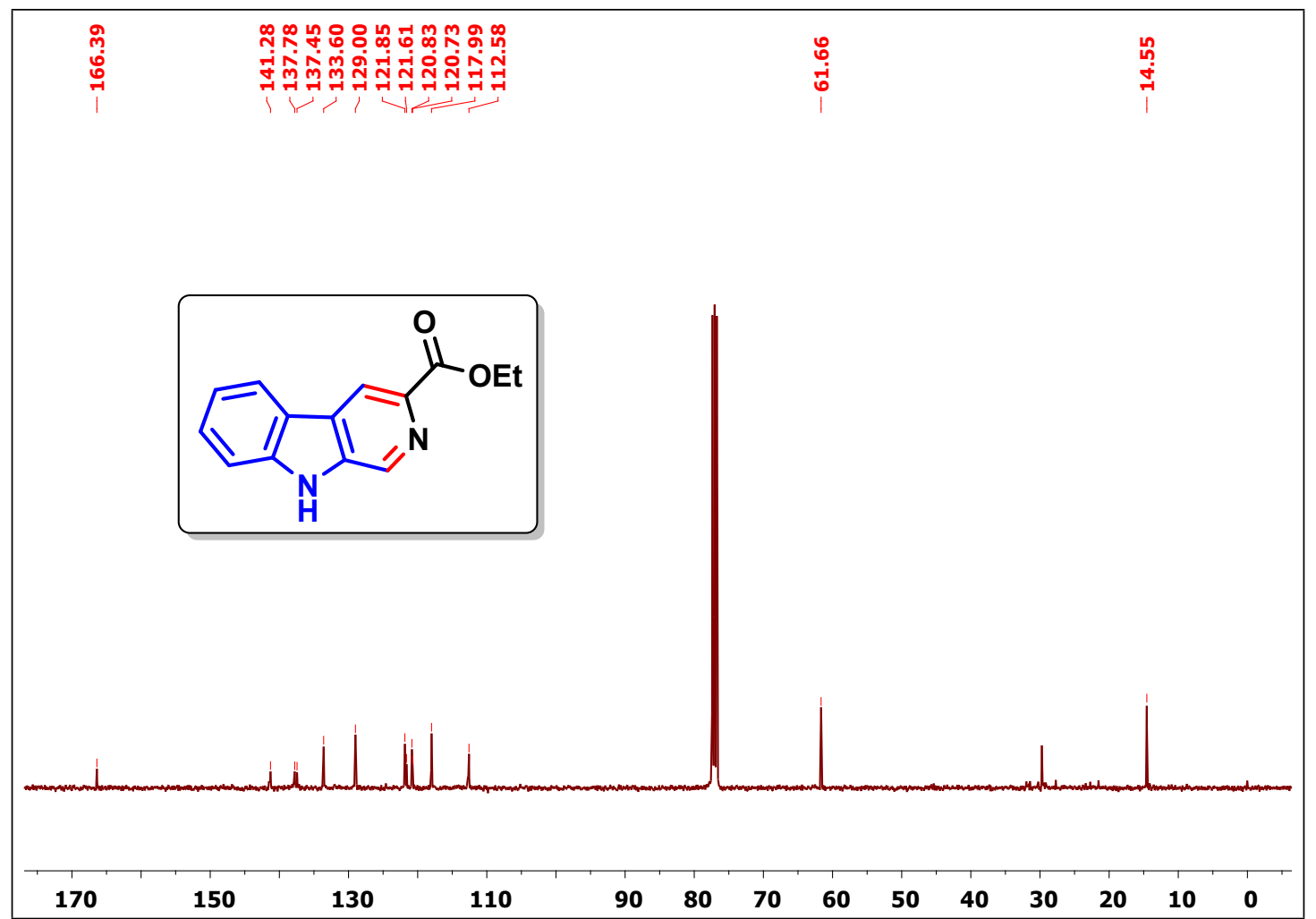


${ }^{1} \mathrm{H}$ NMR spectrum of compound $3 \mathrm{jj}$

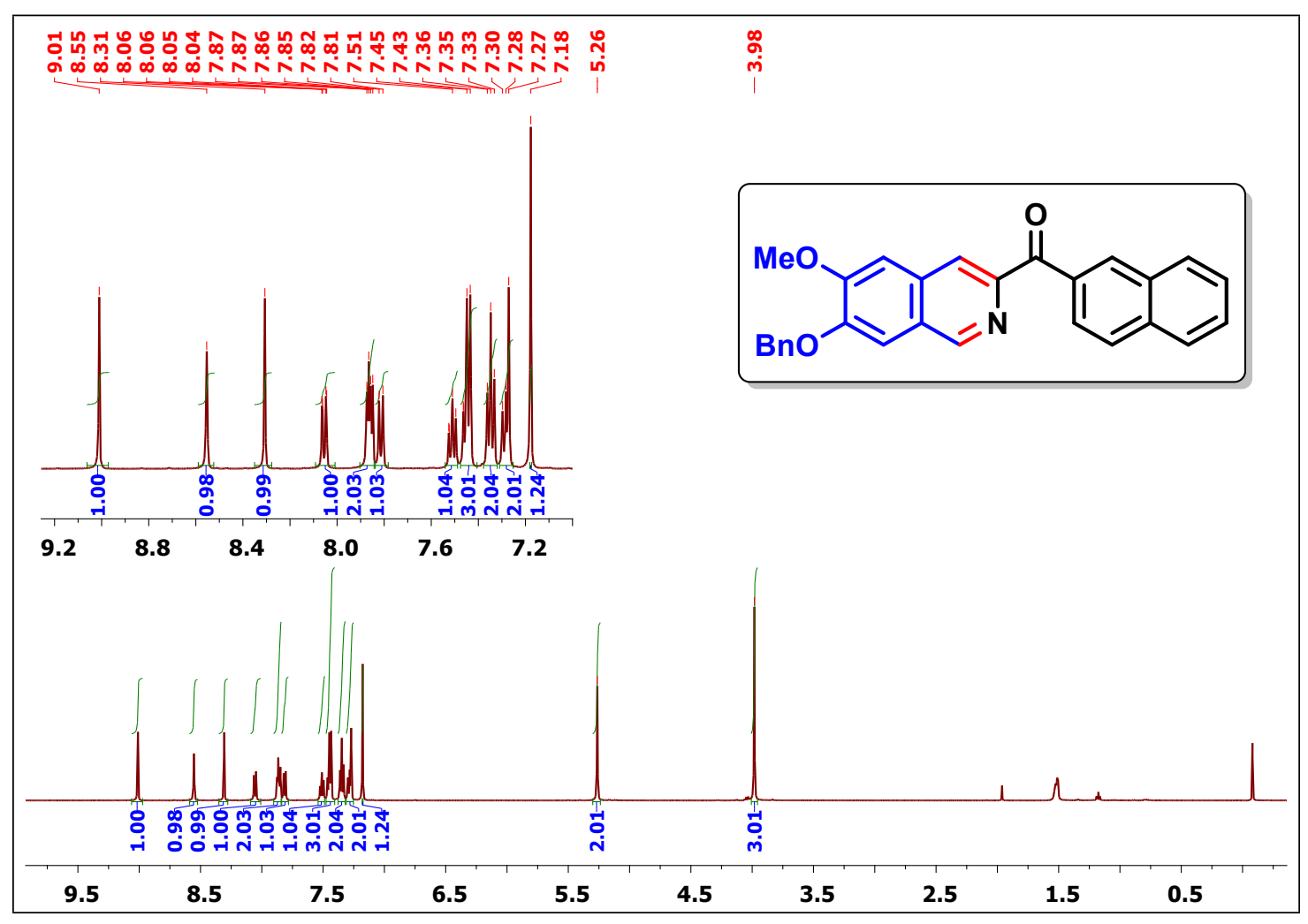

${ }^{13} \mathrm{C}$ NMR spectrum of compound $3 \mathrm{jj}$

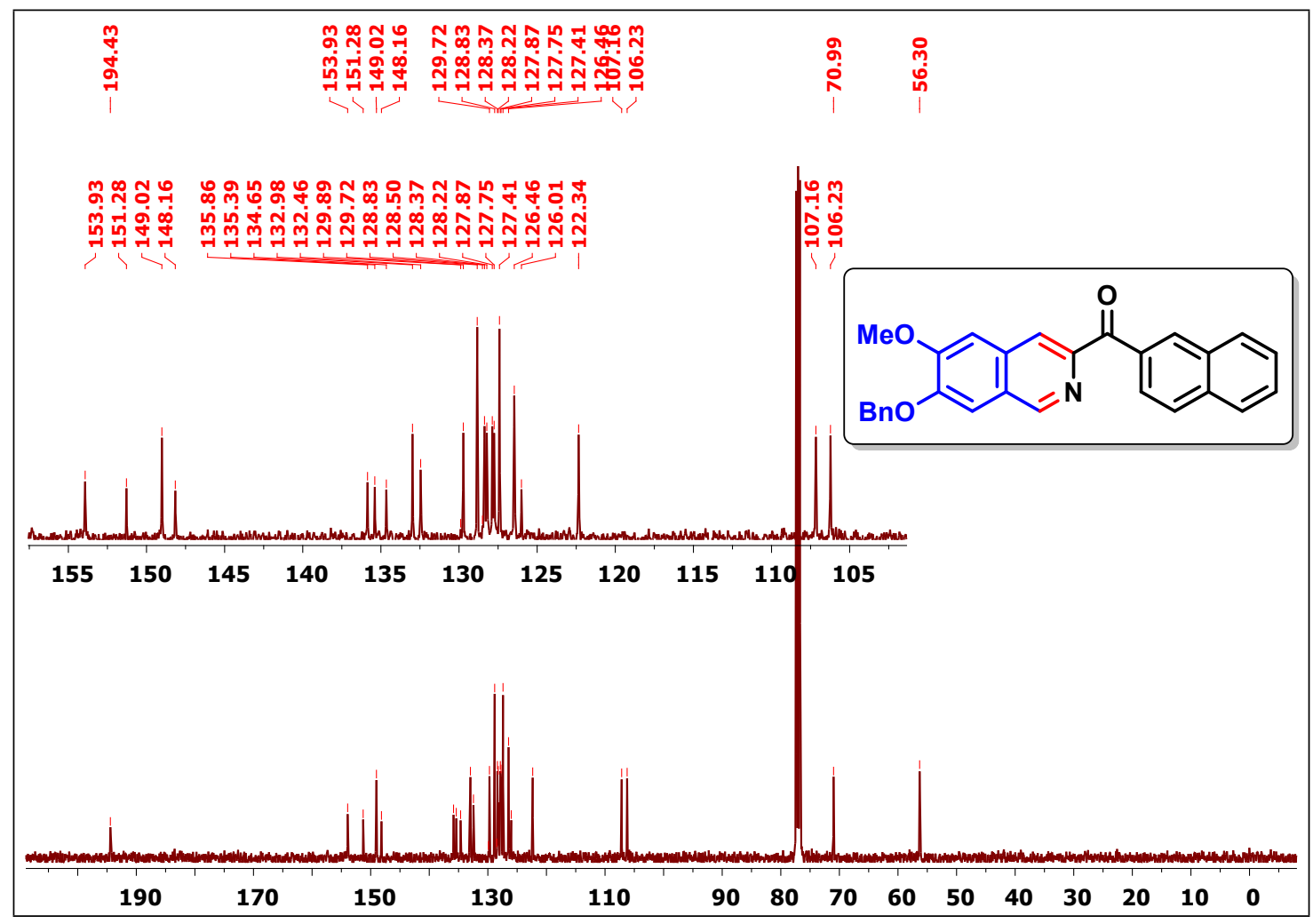


${ }^{1} \mathrm{H}$ NMR spectrum of compound $3 \mathbf{j b}$

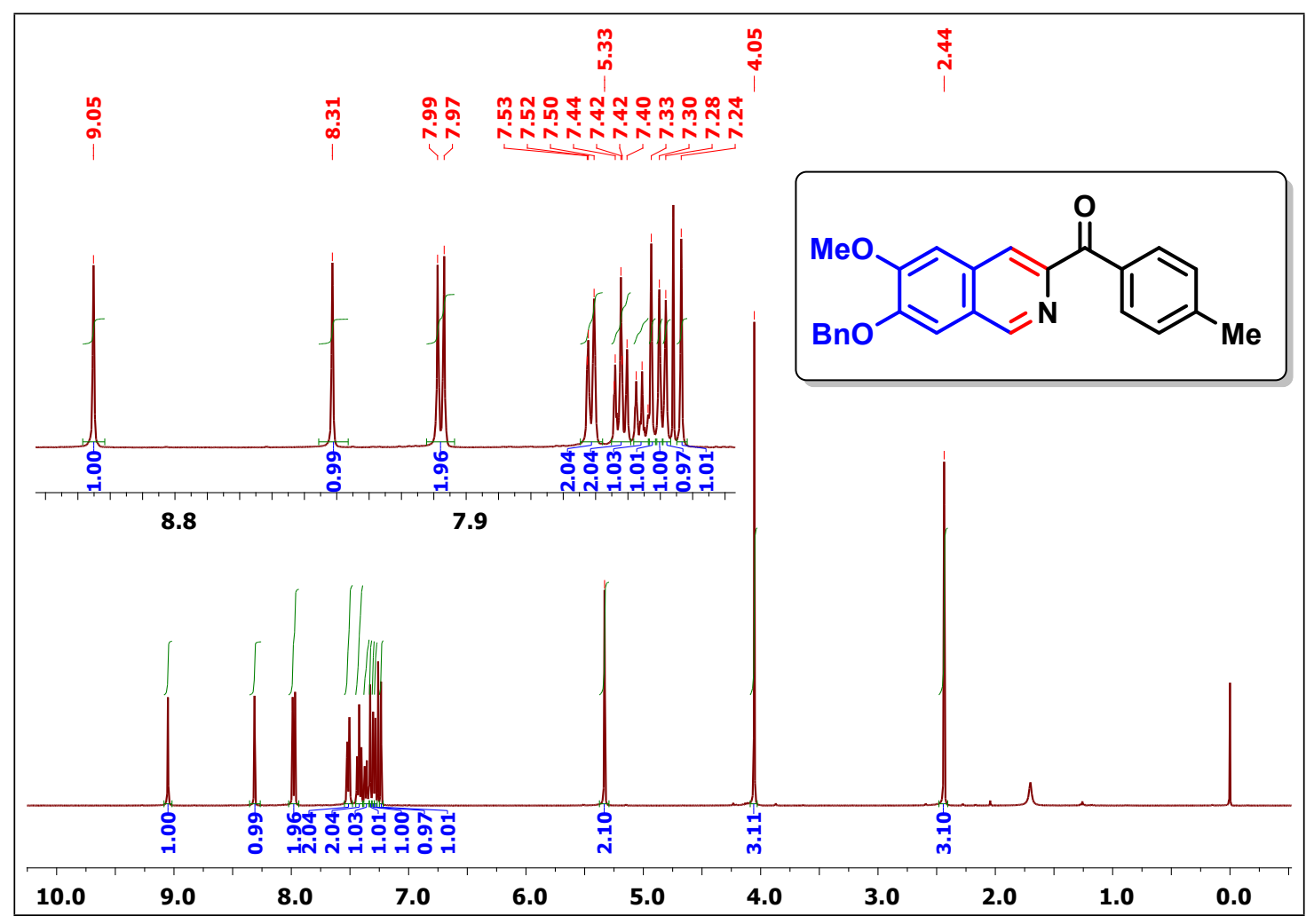

${ }^{13} \mathrm{C}$ NMR spectrum of compound $3 \mathrm{jb}$

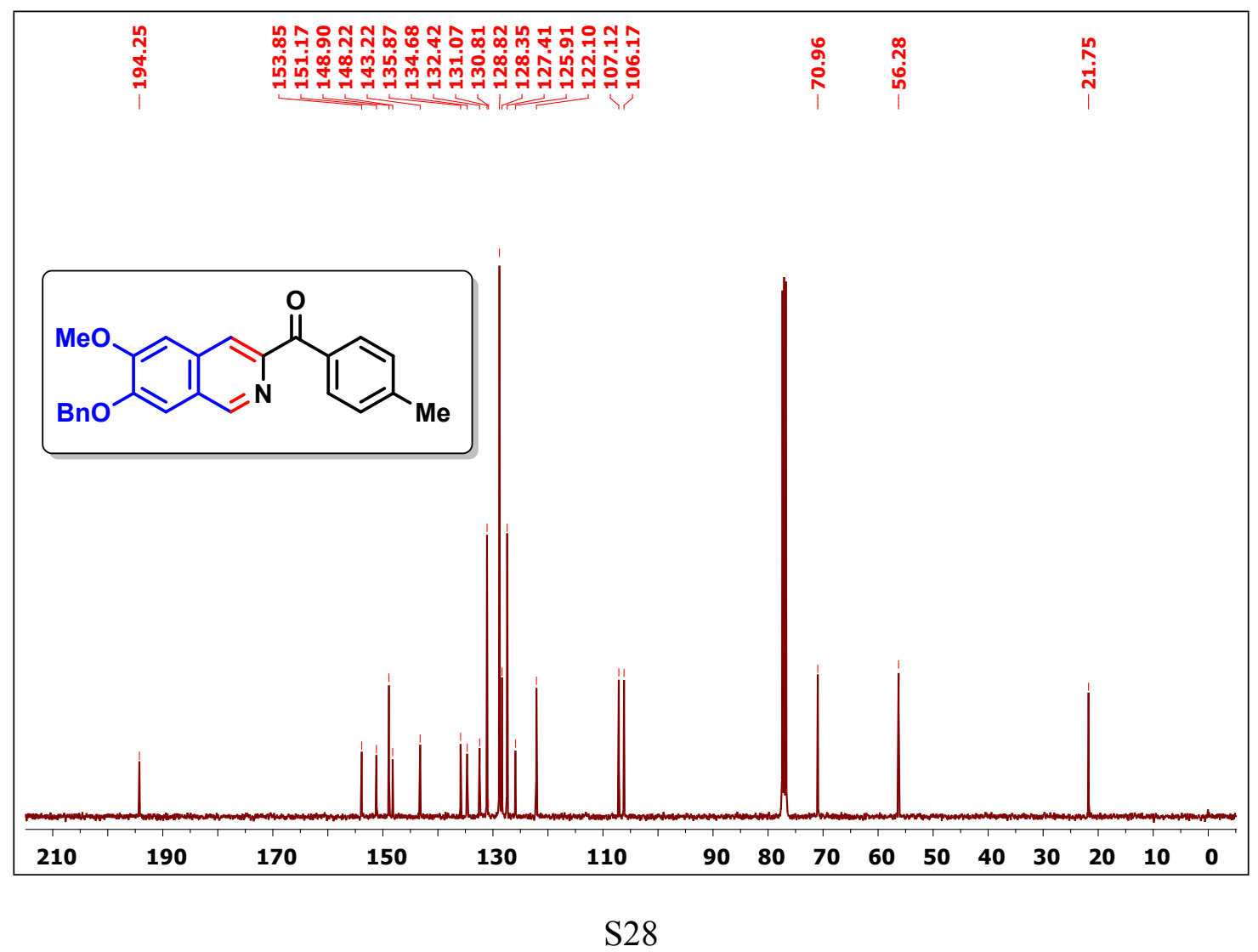


${ }^{1} \mathrm{H}$ NMR spectrum of compound $3 \mathrm{jc}$

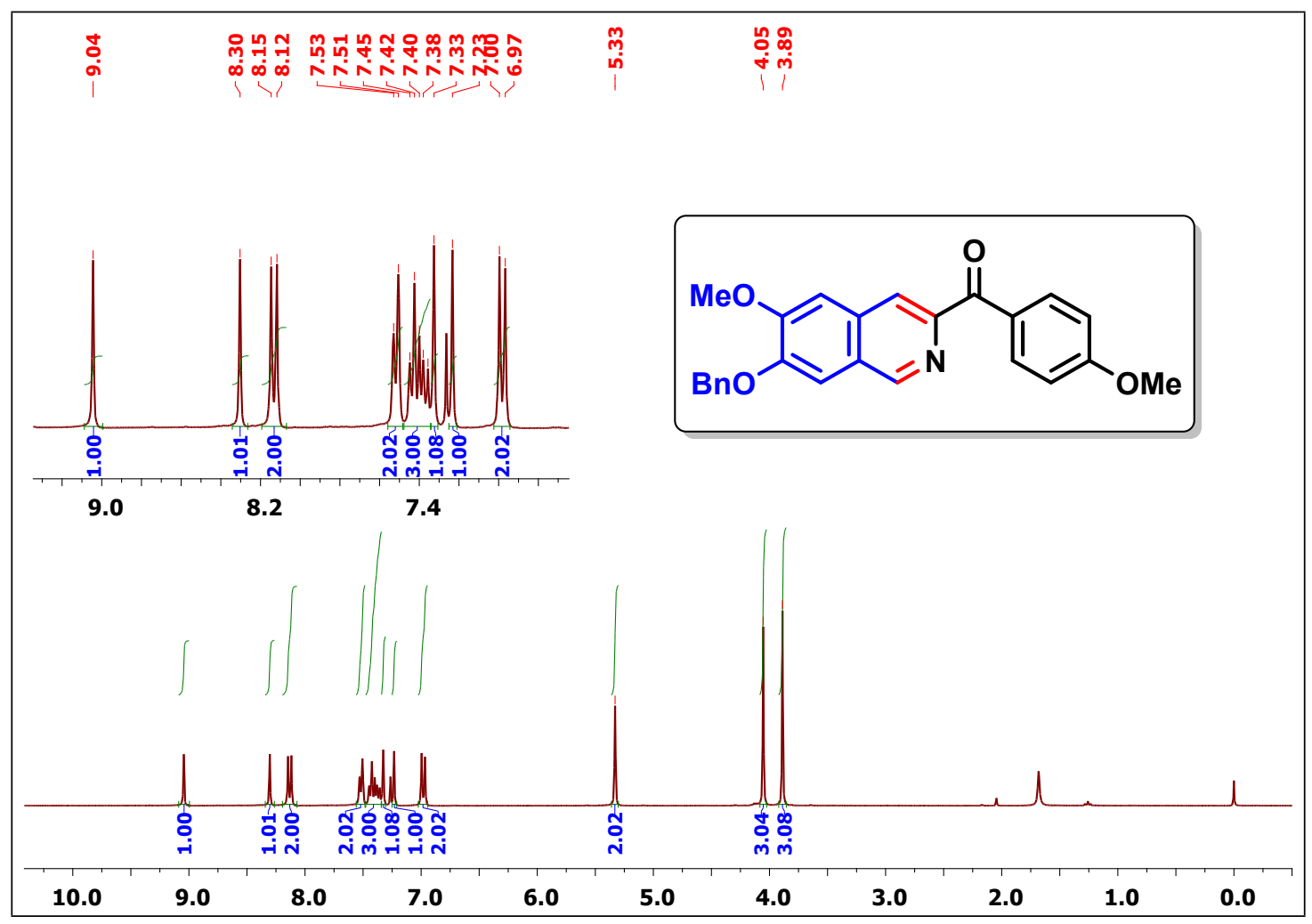

${ }^{13} \mathrm{C}$ NMR spectrum of compound $3 \mathrm{jc}$

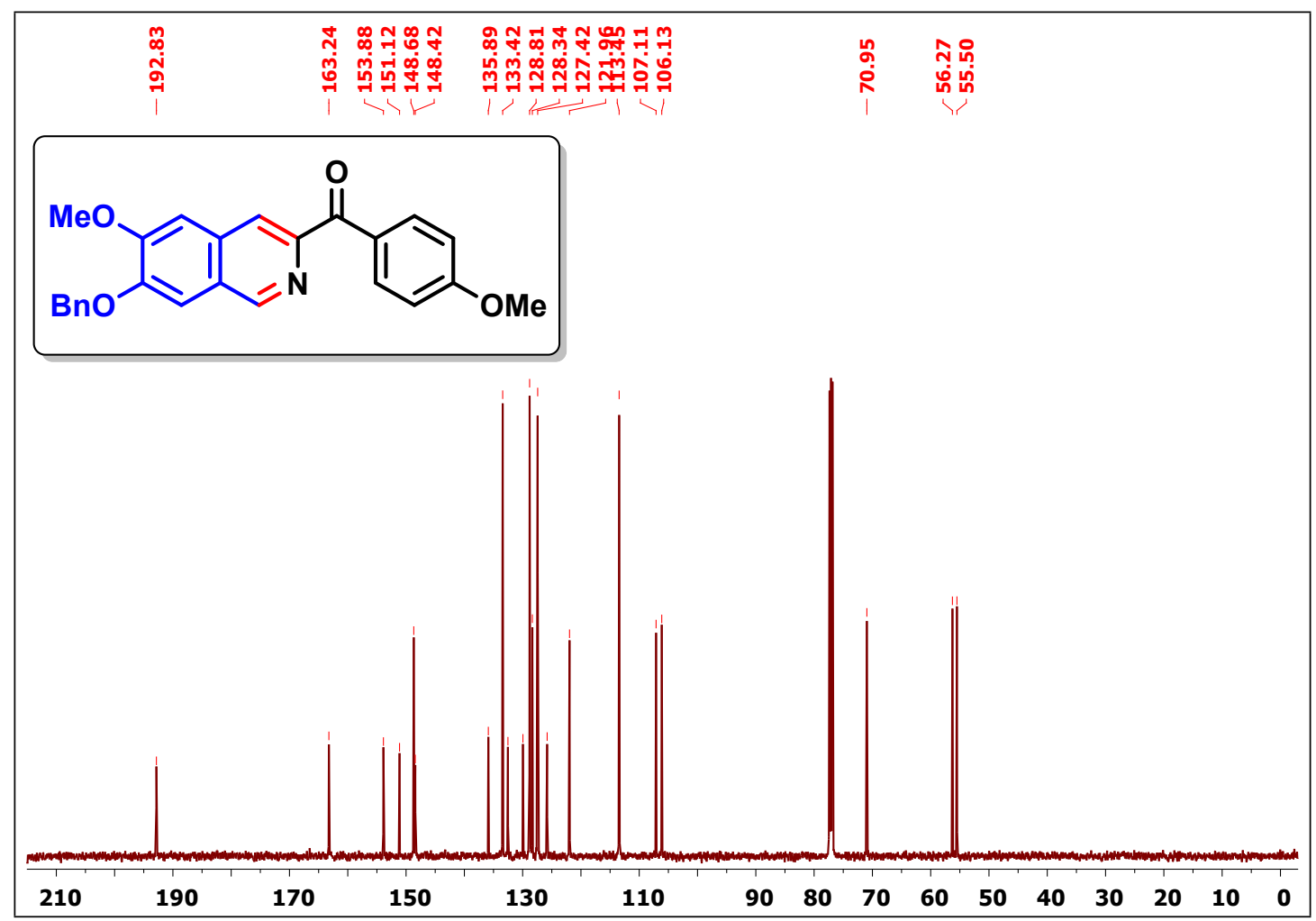




\section{${ }^{1} \mathrm{H}$ NMR spectrum of compound 3aa}

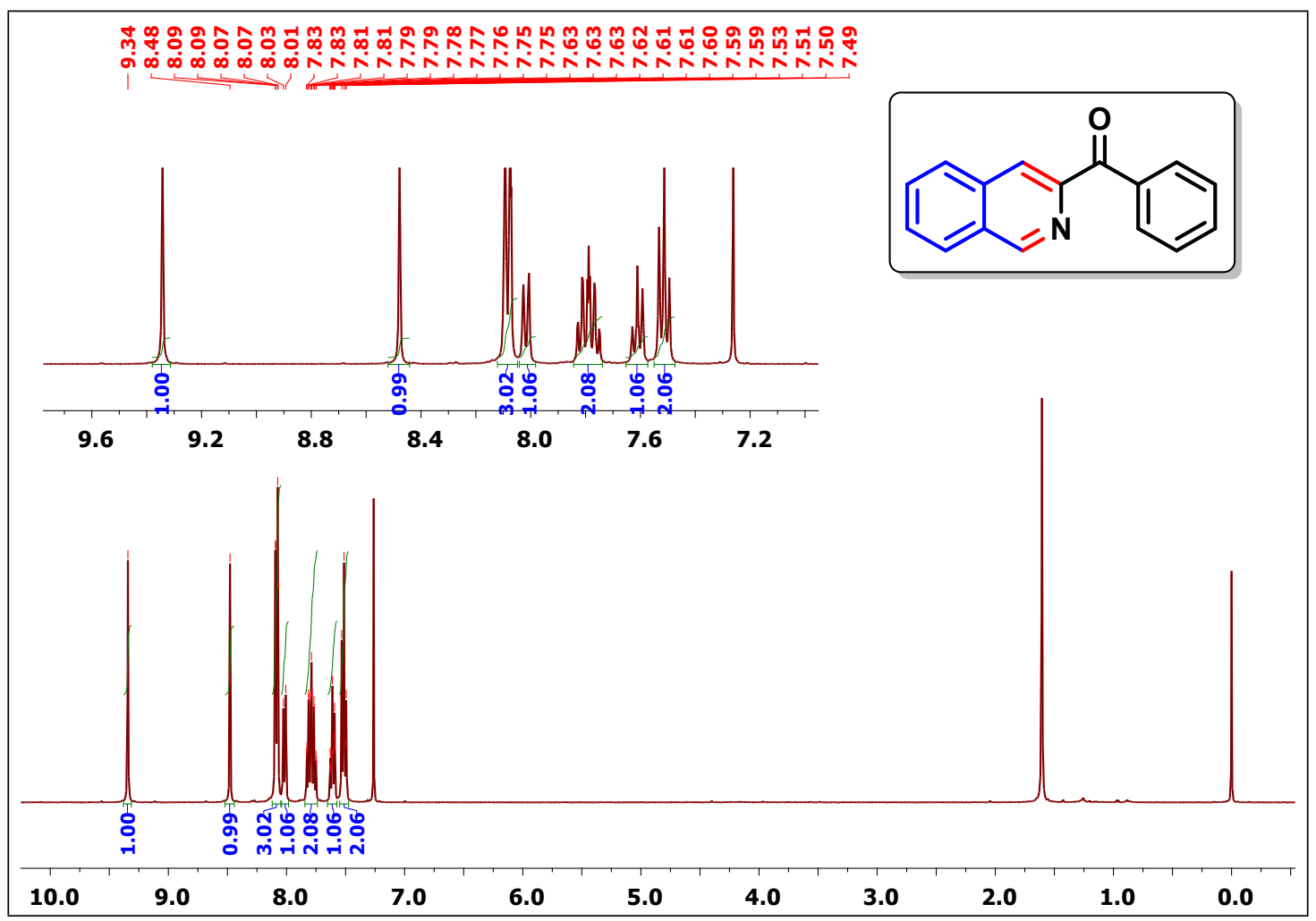

${ }^{13} \mathrm{C}$ NMR spectrum of compound 3aa

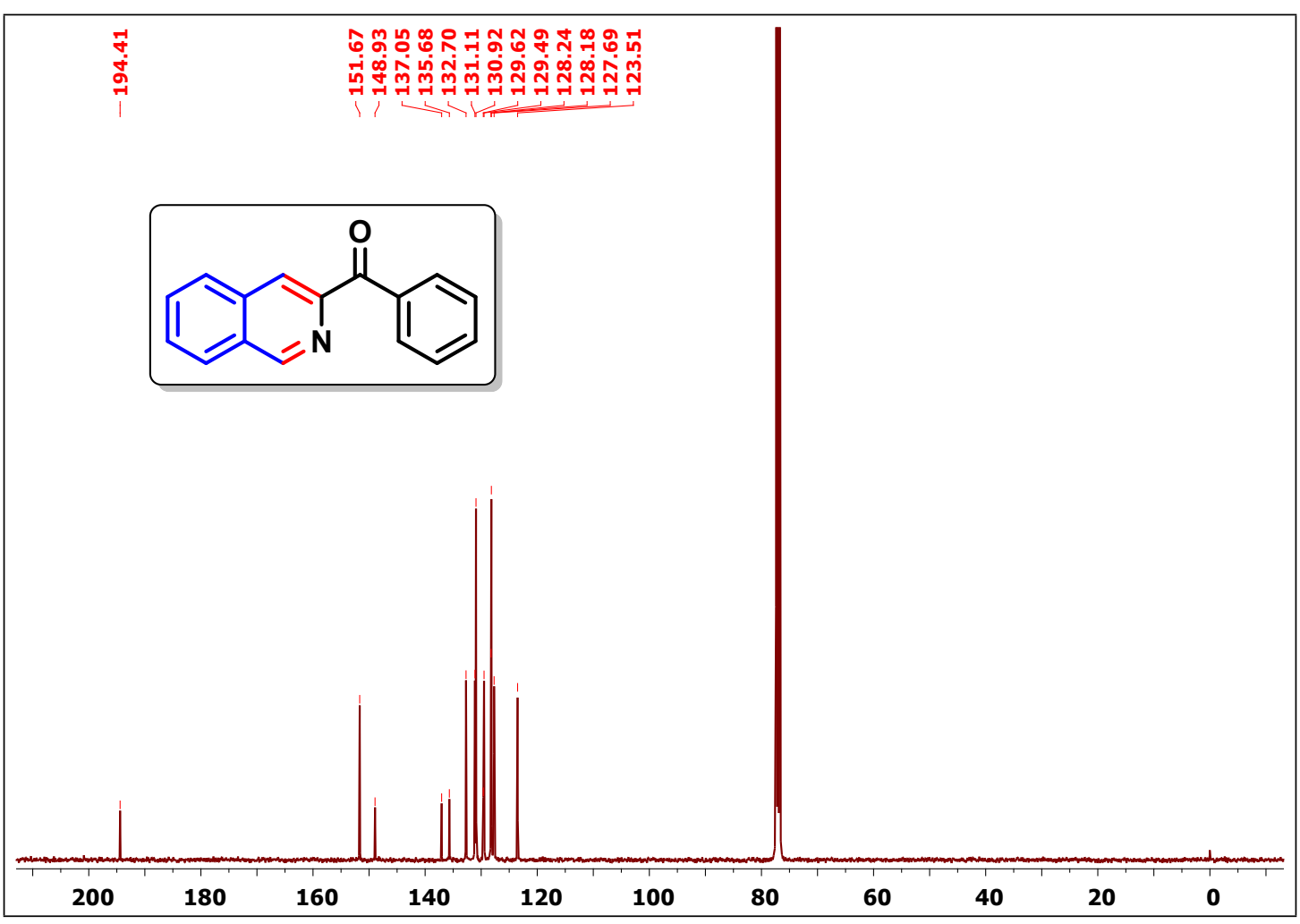




\section{${ }^{1} \mathrm{H}$ NMR spectrum of compound $3 a b$}

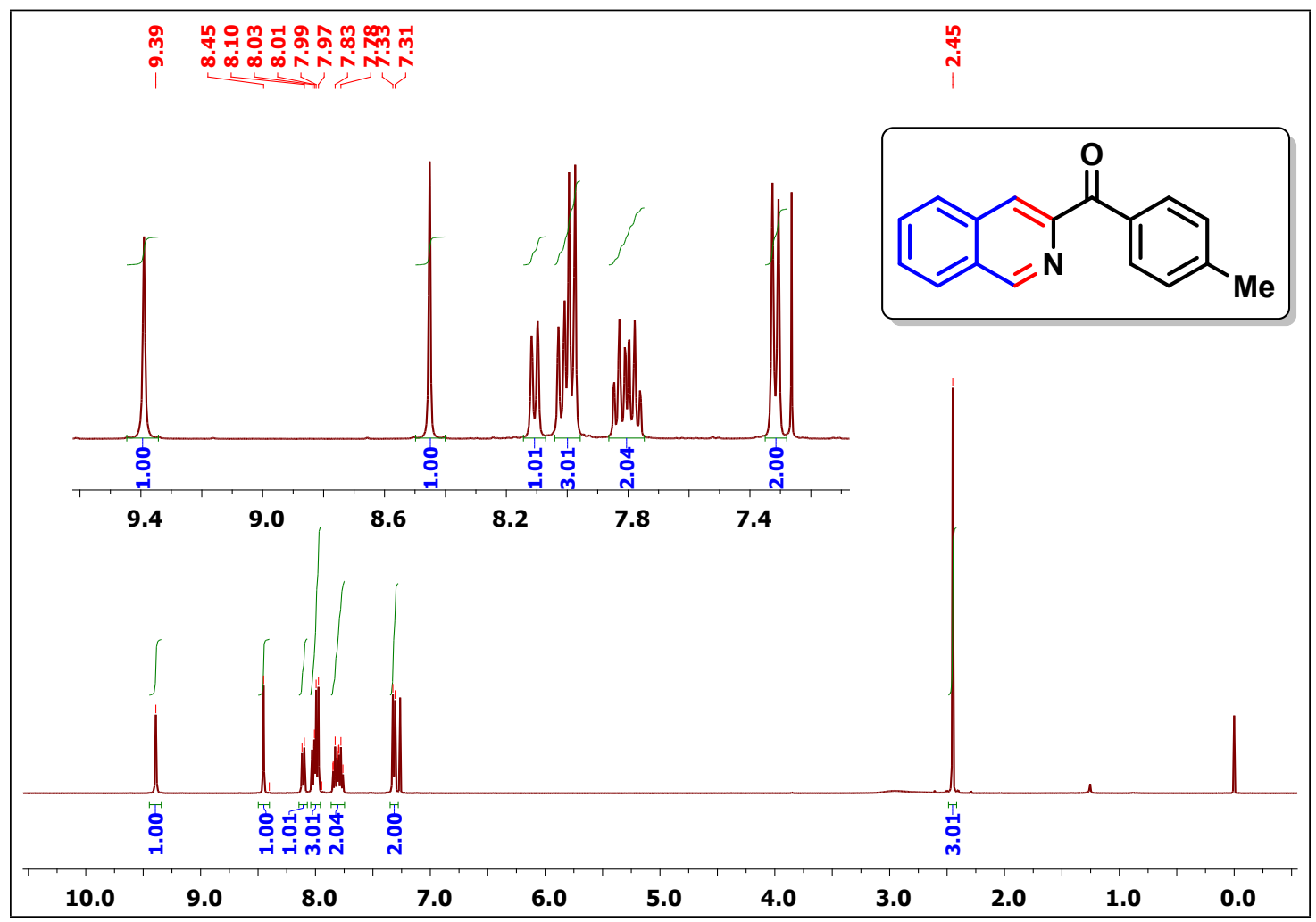

${ }^{13} \mathrm{C}$ NMR spectrum of compound $3 \mathrm{ab}$

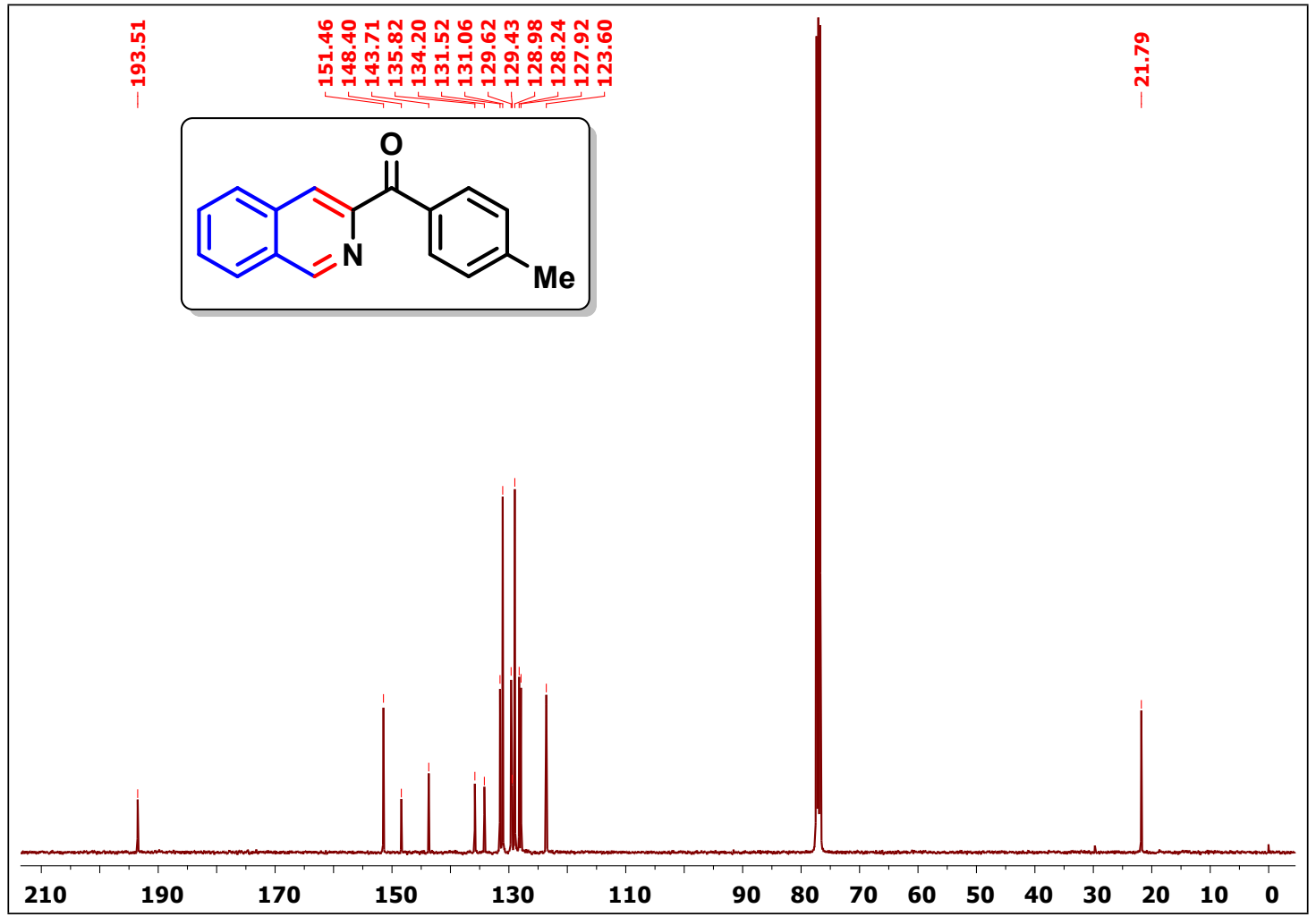




\section{${ }^{1} \mathrm{H}$ NMR spectrum of compound 3ac}

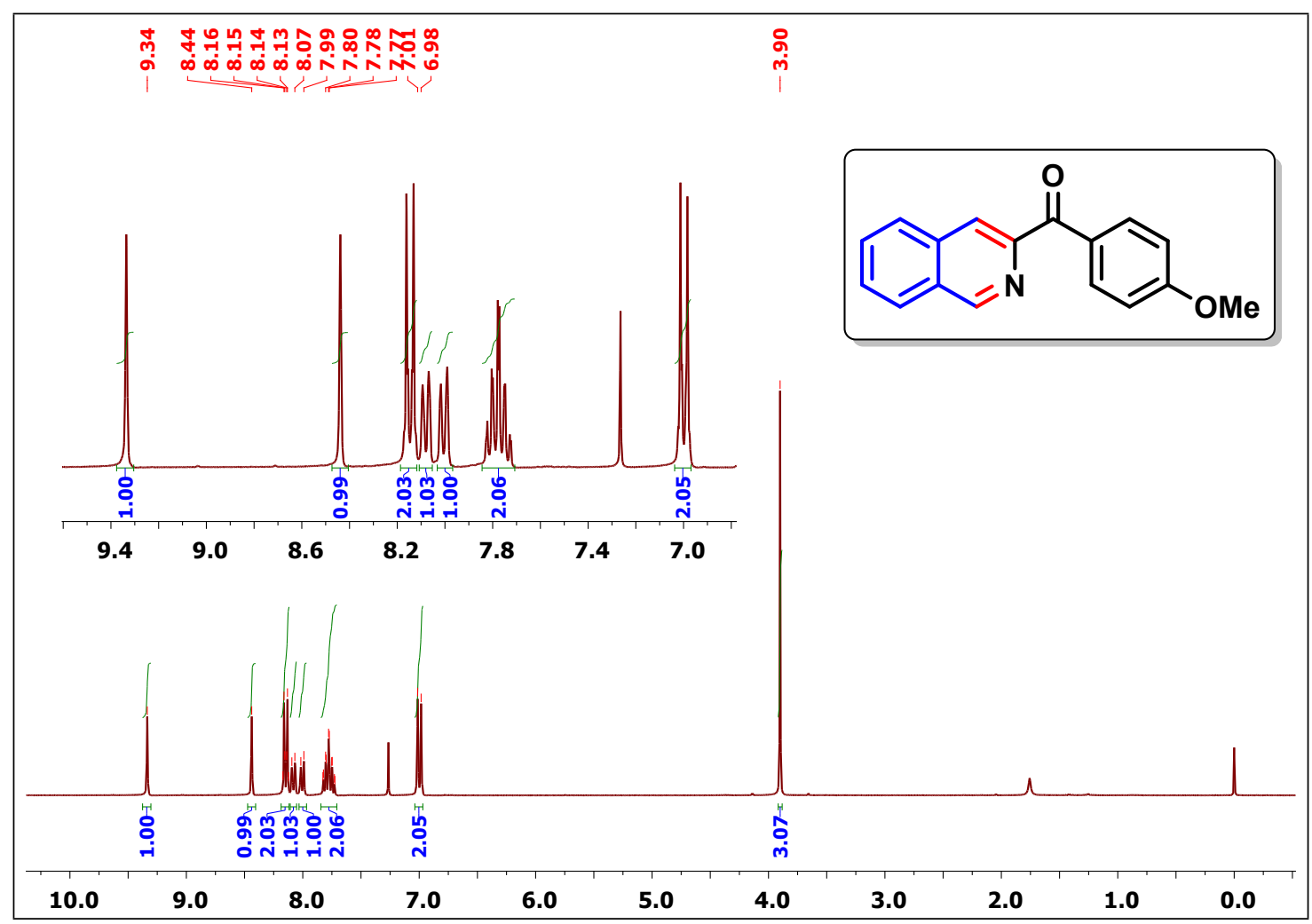

${ }^{13} \mathrm{C}$ NMR spectrum of compound 3ac

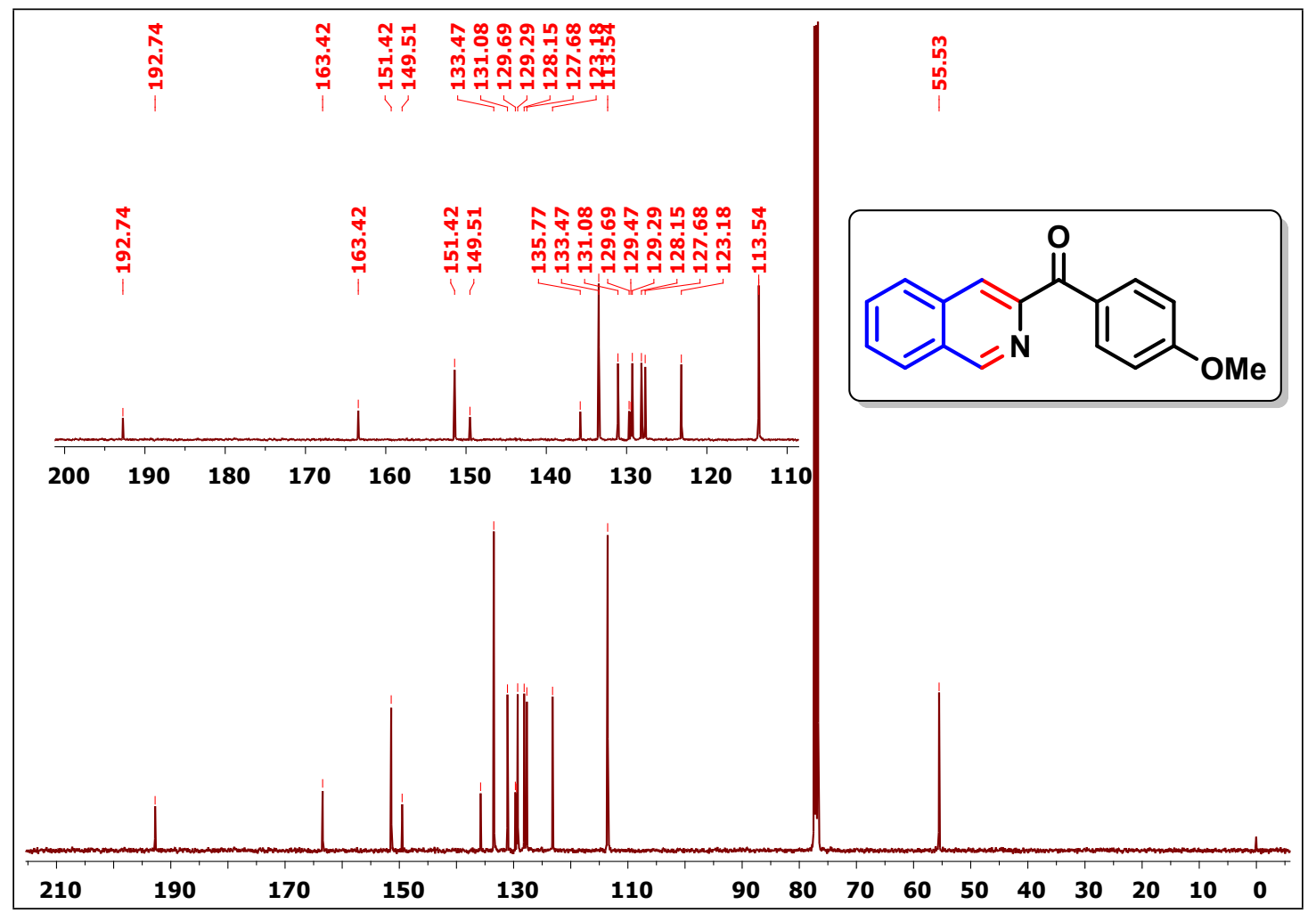




\section{${ }^{1} \mathrm{H}$ NMR spectrum of compound 3ad}

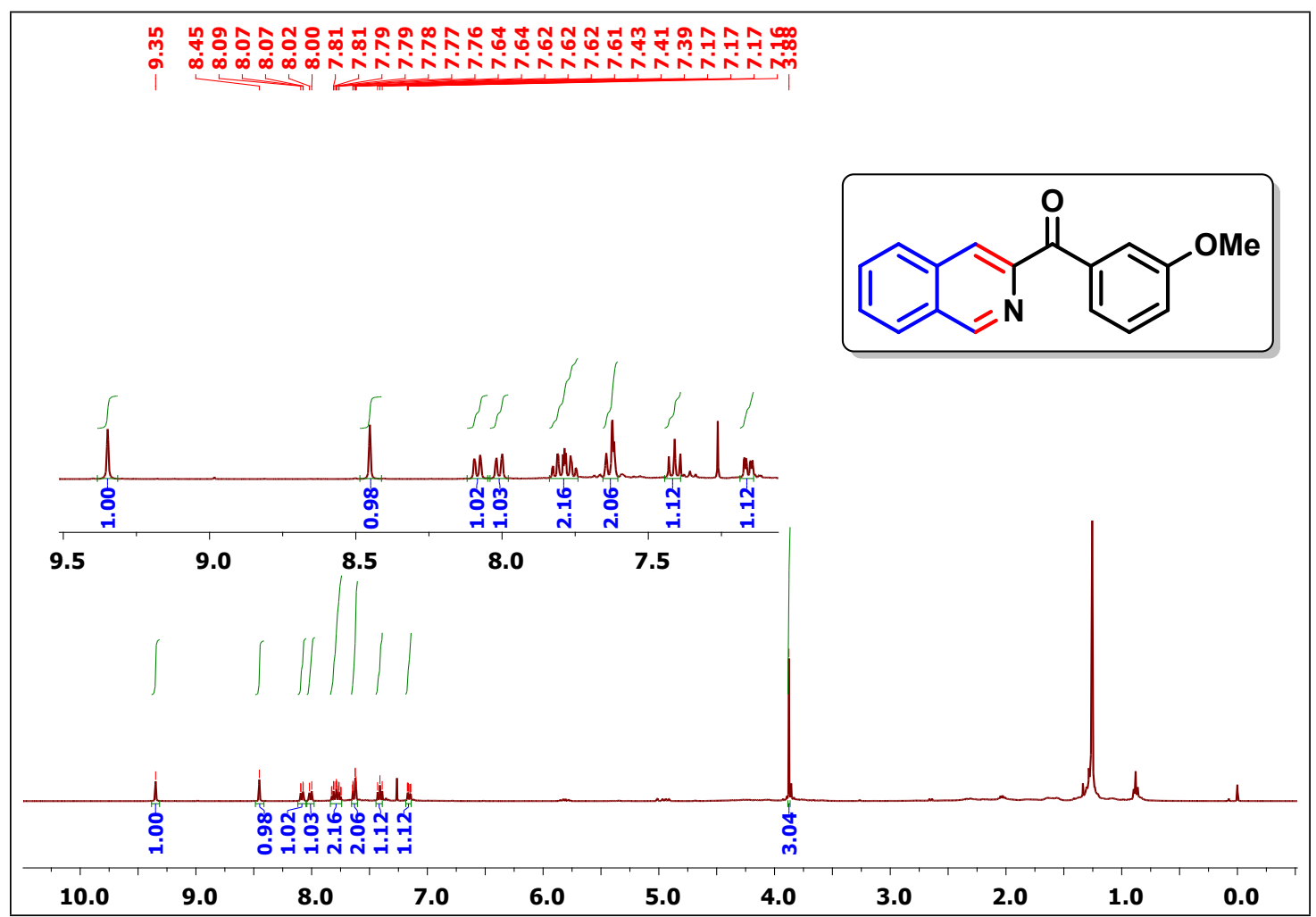

${ }^{13} \mathrm{C}$ NMR spectrum of compound 3ad

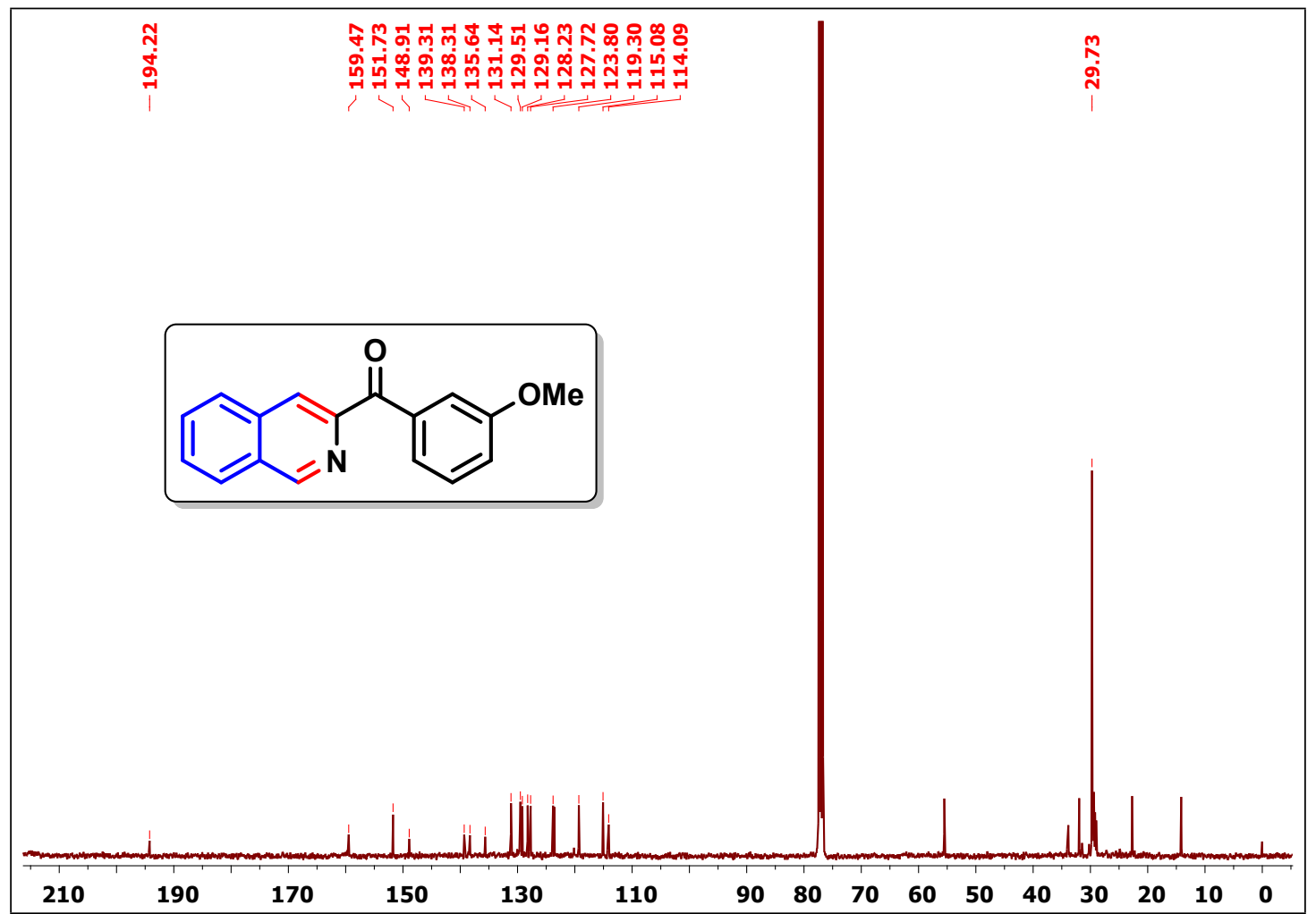




\section{${ }^{1} \mathrm{H}$ NMR spectrum of compound 3ae}

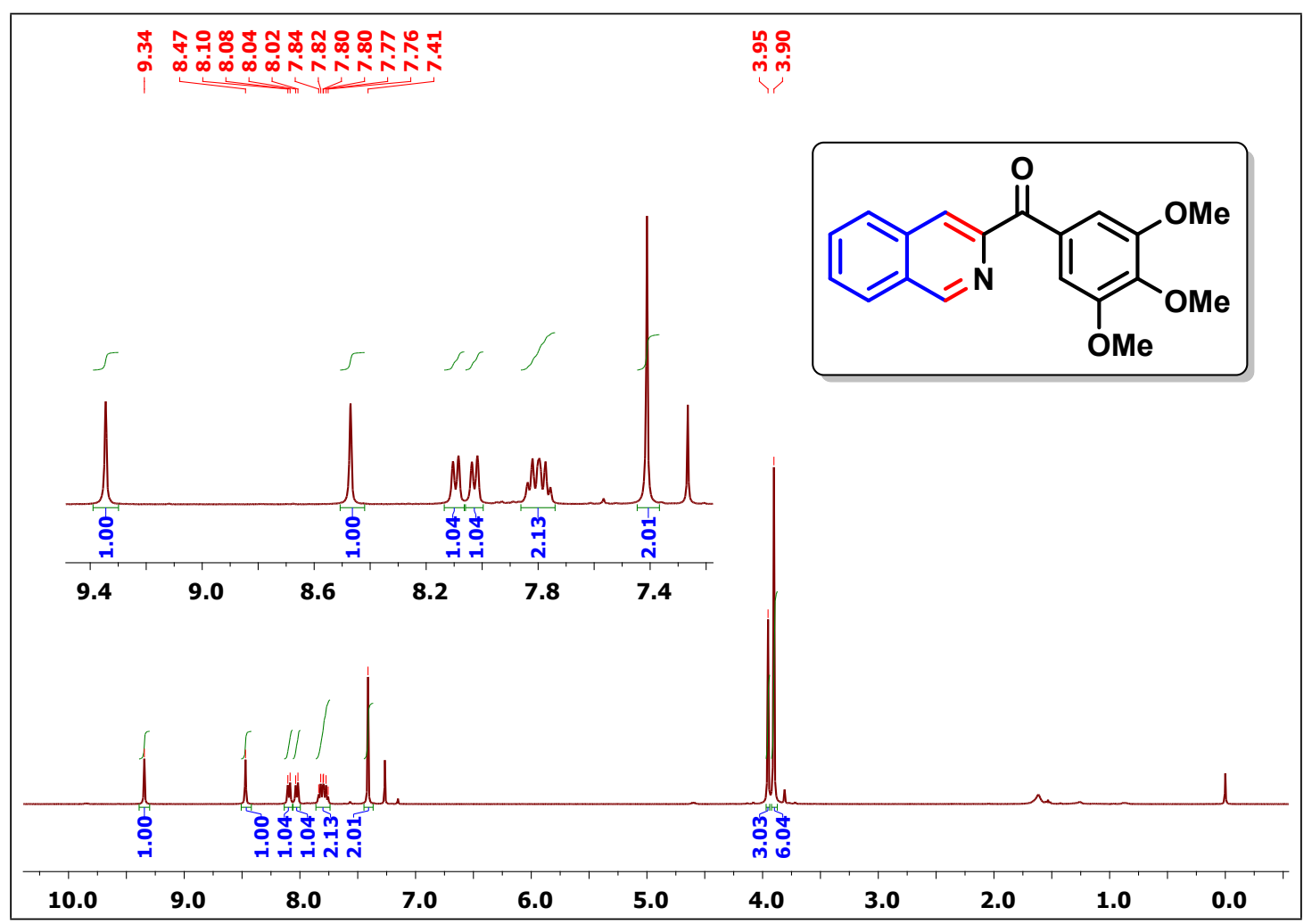

${ }^{13} \mathrm{C}$ NMR spectrum of compound 3ae

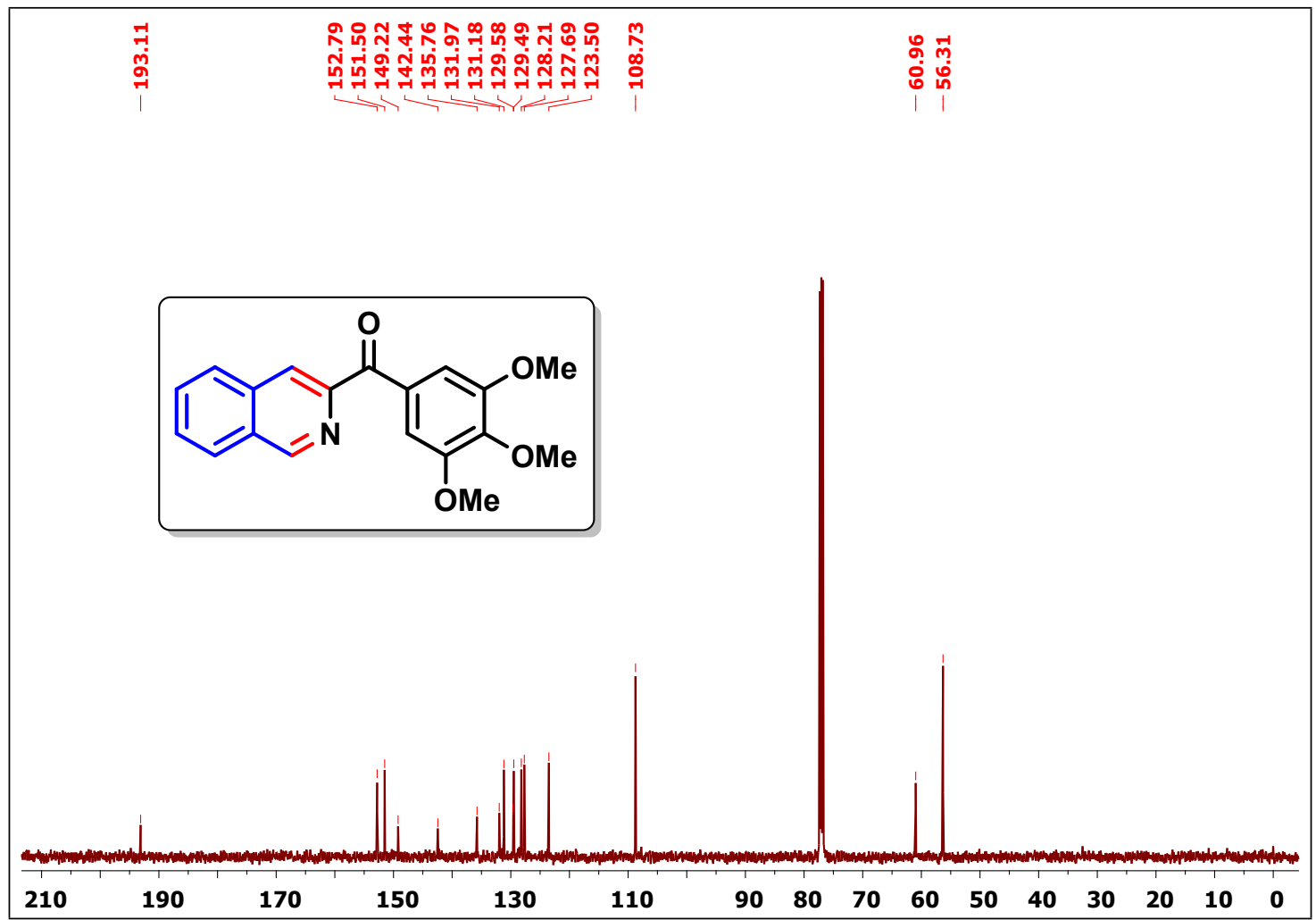


${ }^{1} \mathrm{H}$ NMR spectrum of compound 3af

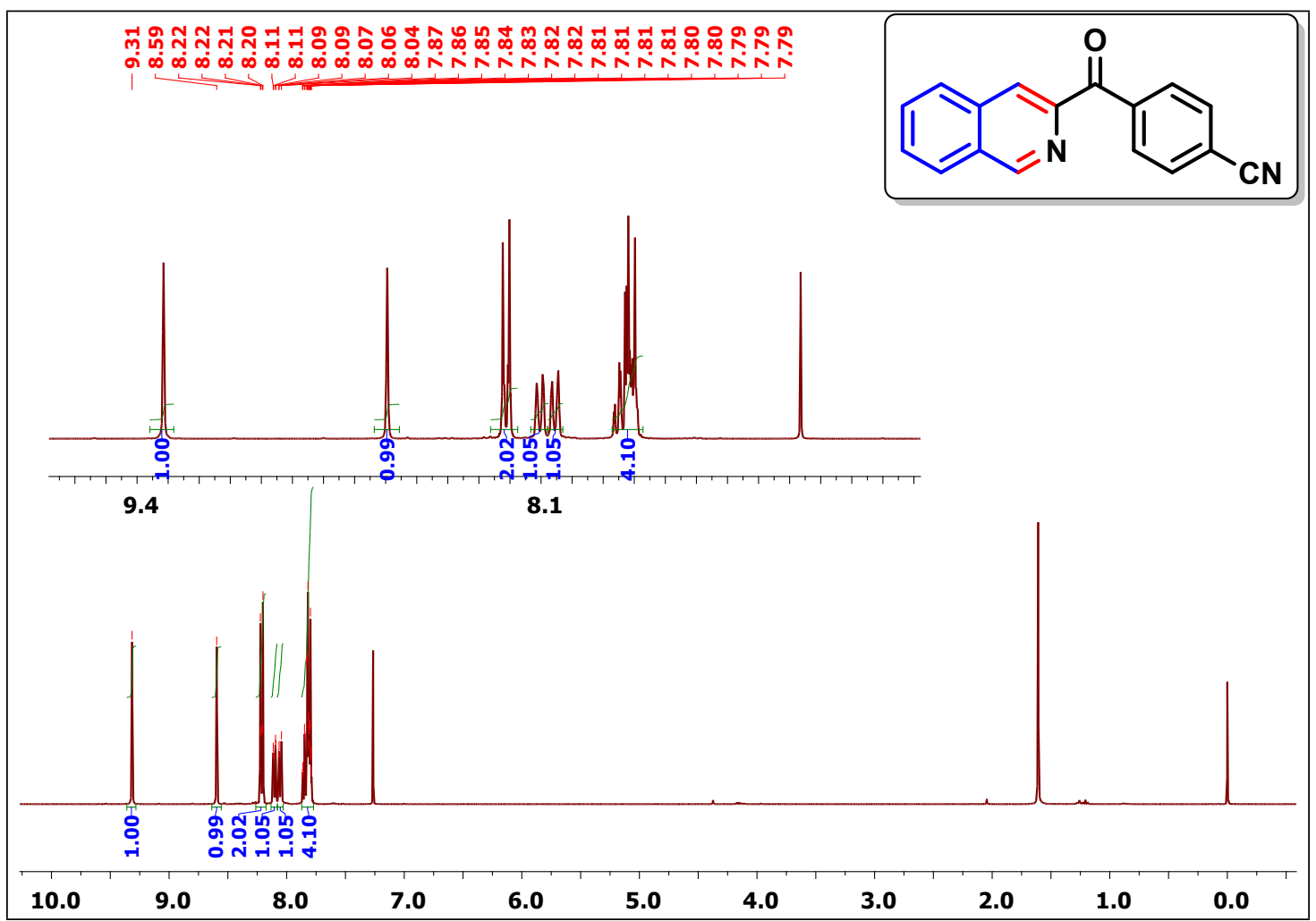

${ }^{13} \mathrm{C}$ NMR spectrum of compound 3af

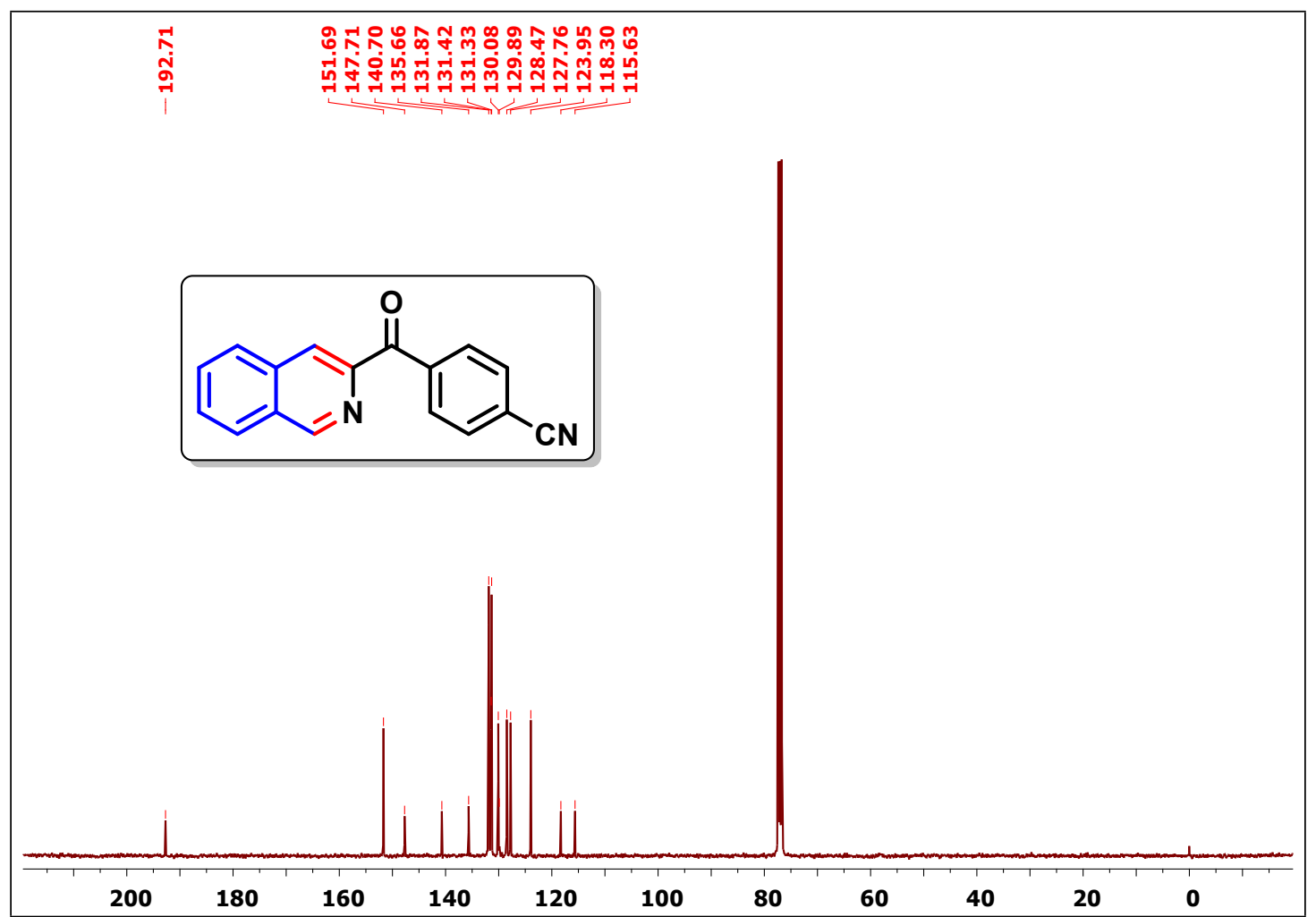


${ }^{1} \mathrm{H}$ NMR spectrum of compound 3ag

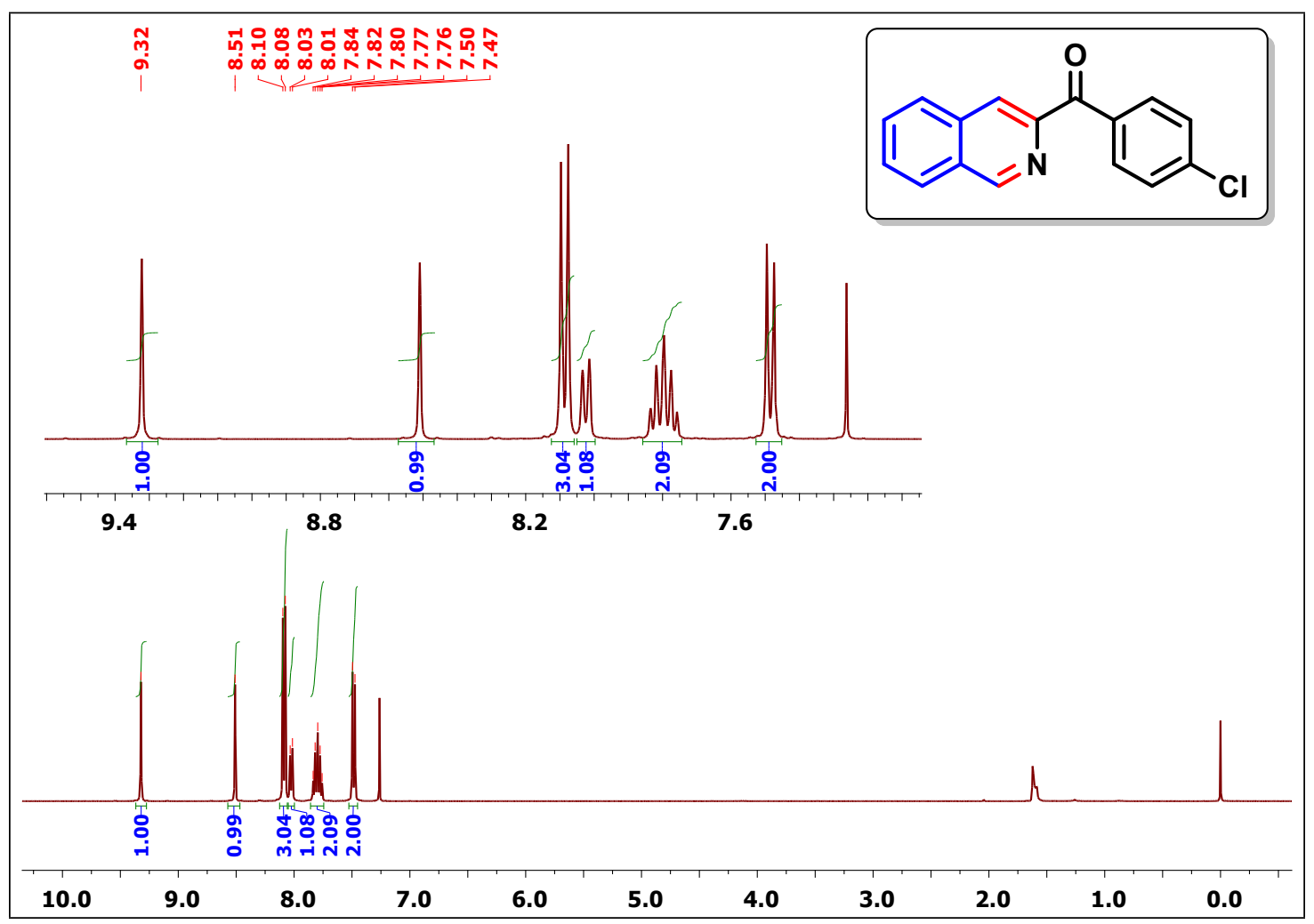

${ }^{13} \mathrm{C}$ NMR spectrum of compound $3 \mathrm{ag}$

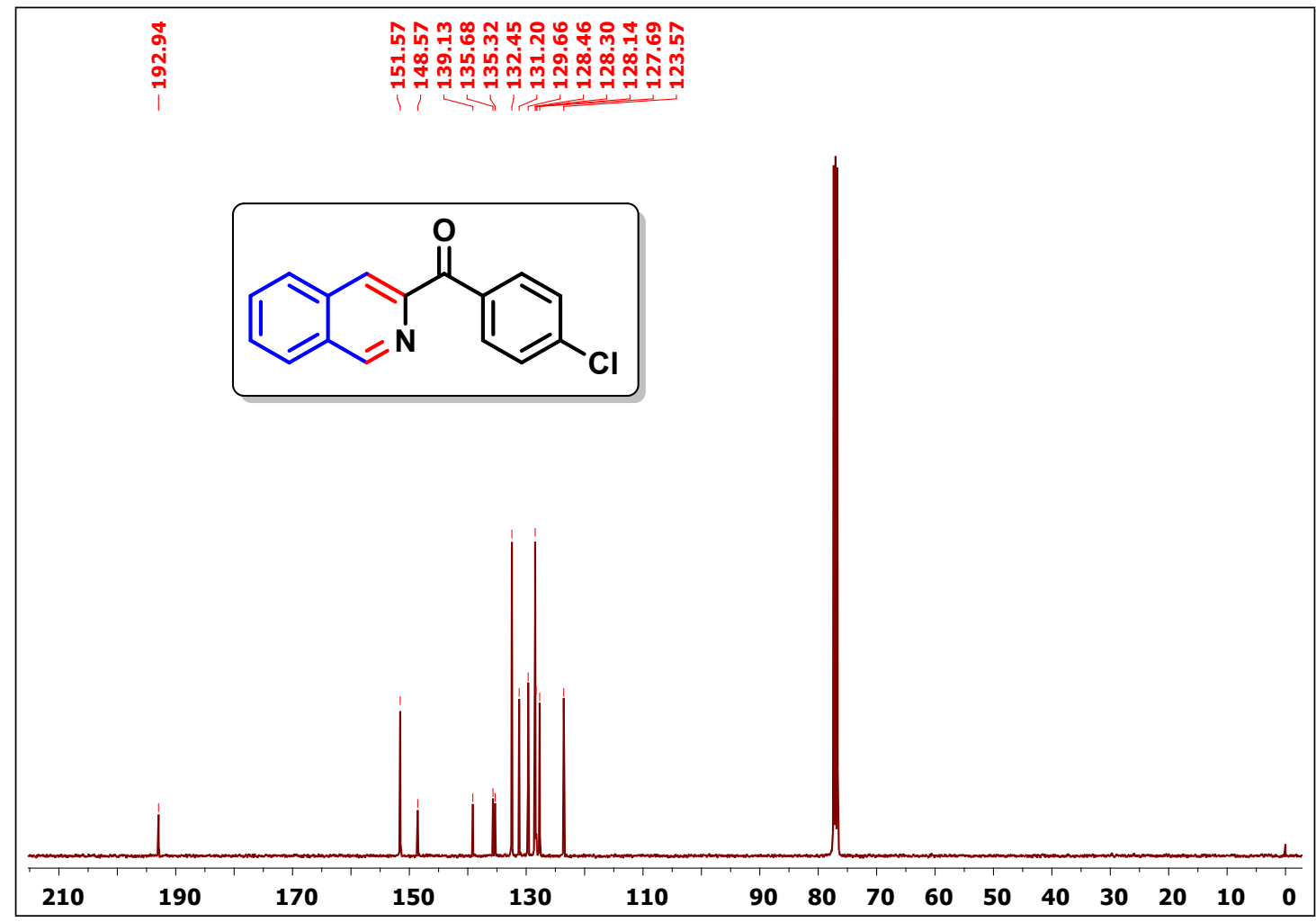




\section{${ }^{1} \mathrm{H}$ NMR spectrum of compound 3ah}

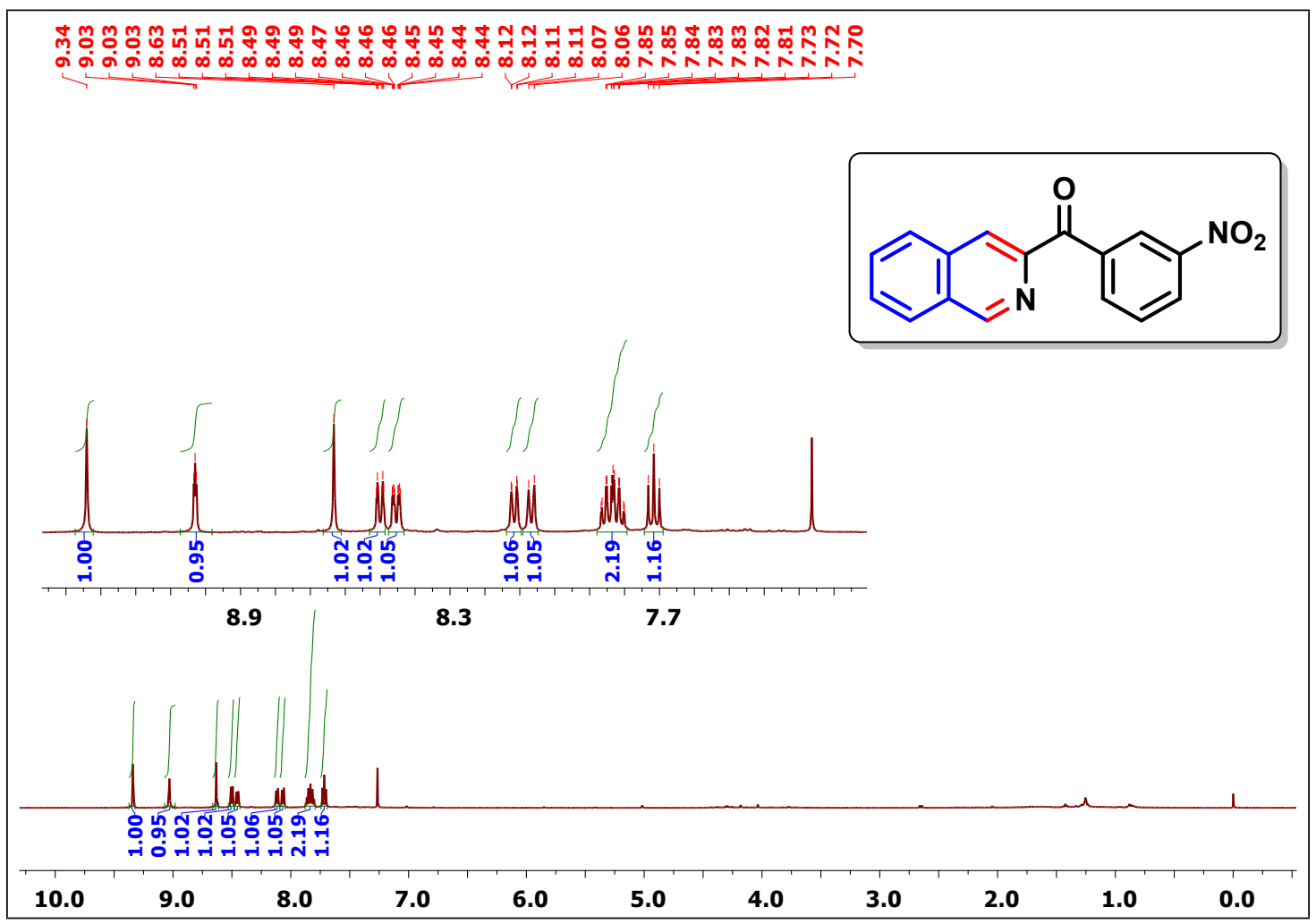

${ }^{13} \mathrm{C}$ NMR spectrum of compound 3ah

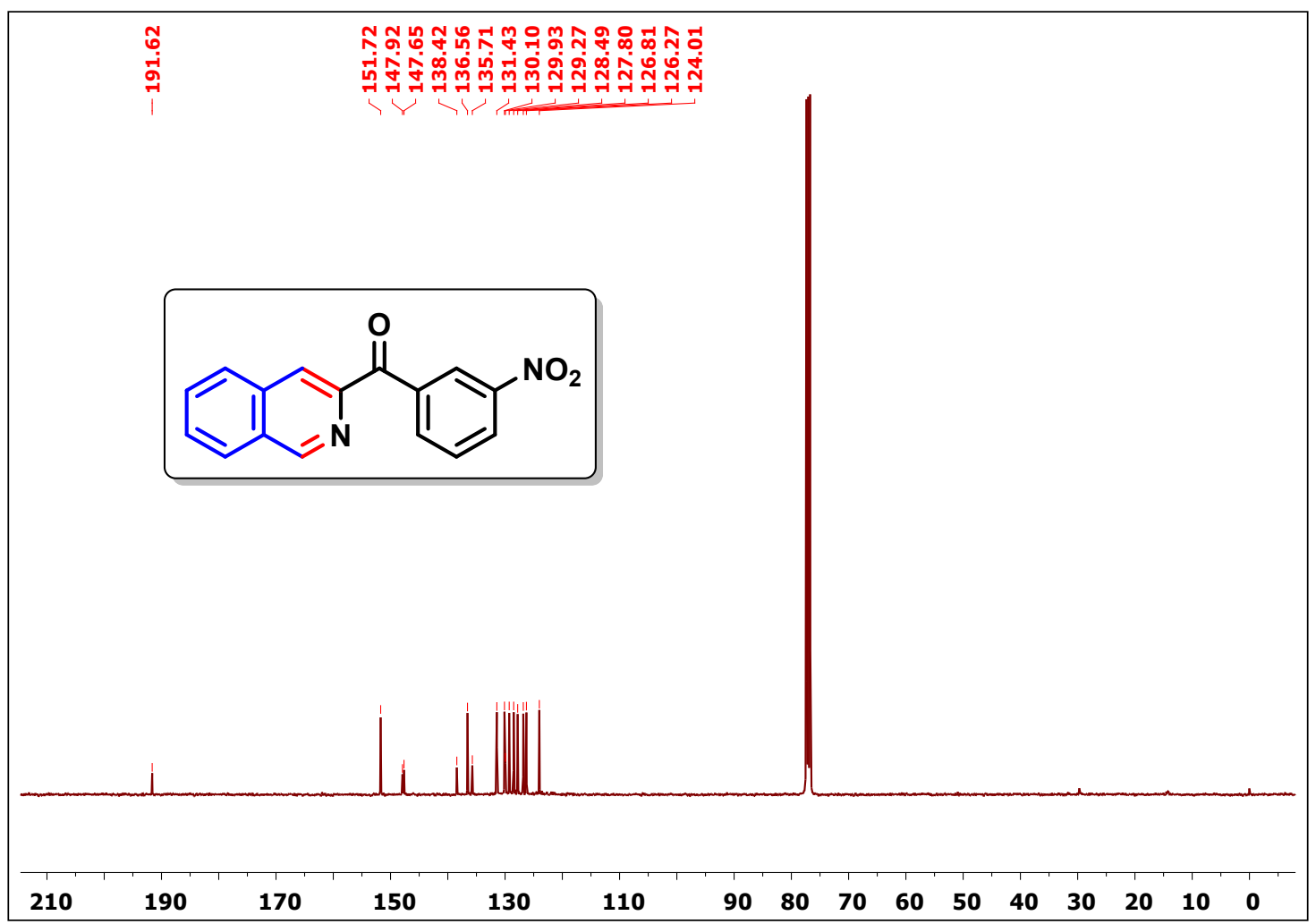




\section{${ }^{1} \mathrm{H}$ NMR spectrum of compound 3ai}

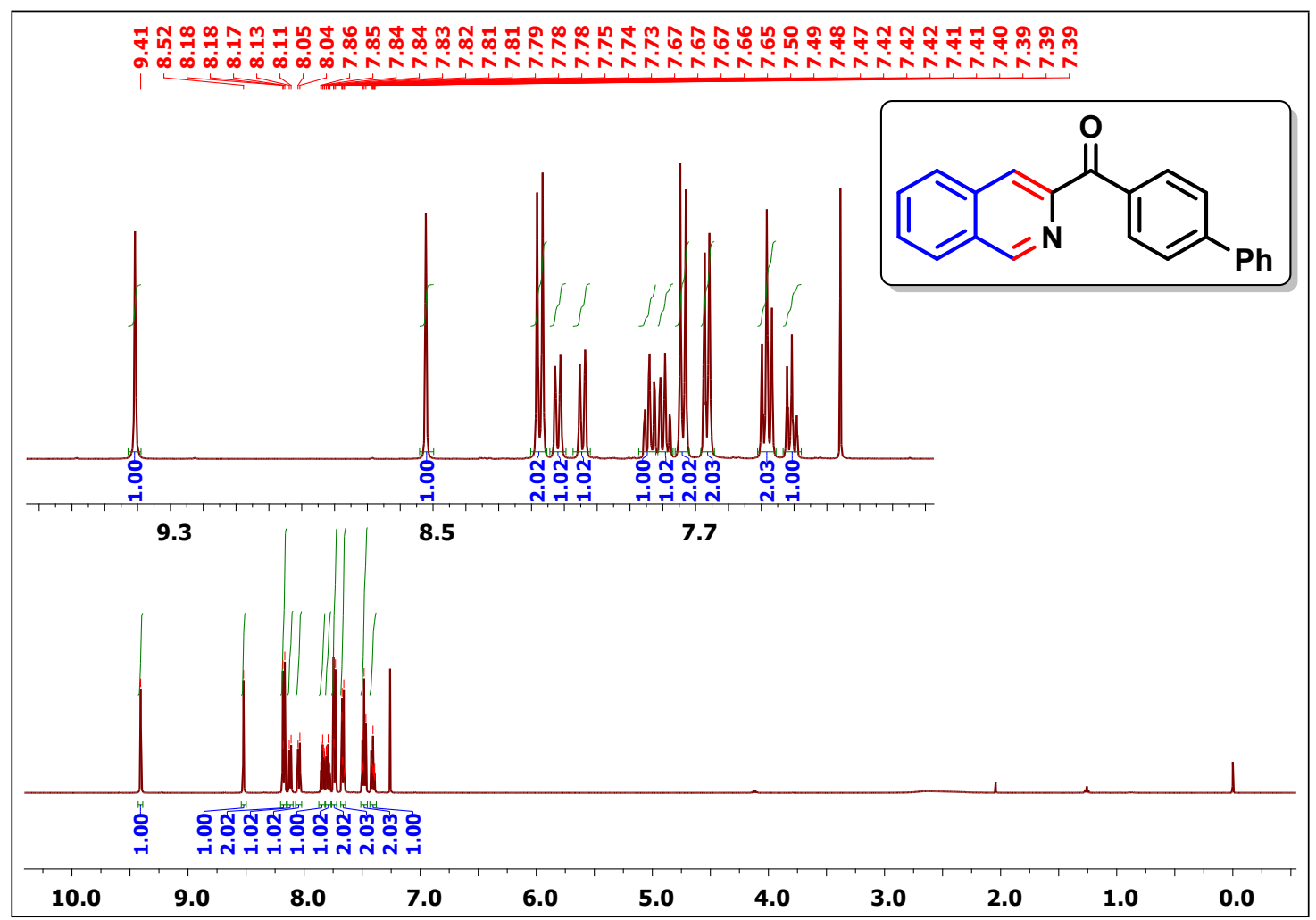

${ }^{13} \mathrm{C}$ NMR spectrum of compound 3ai

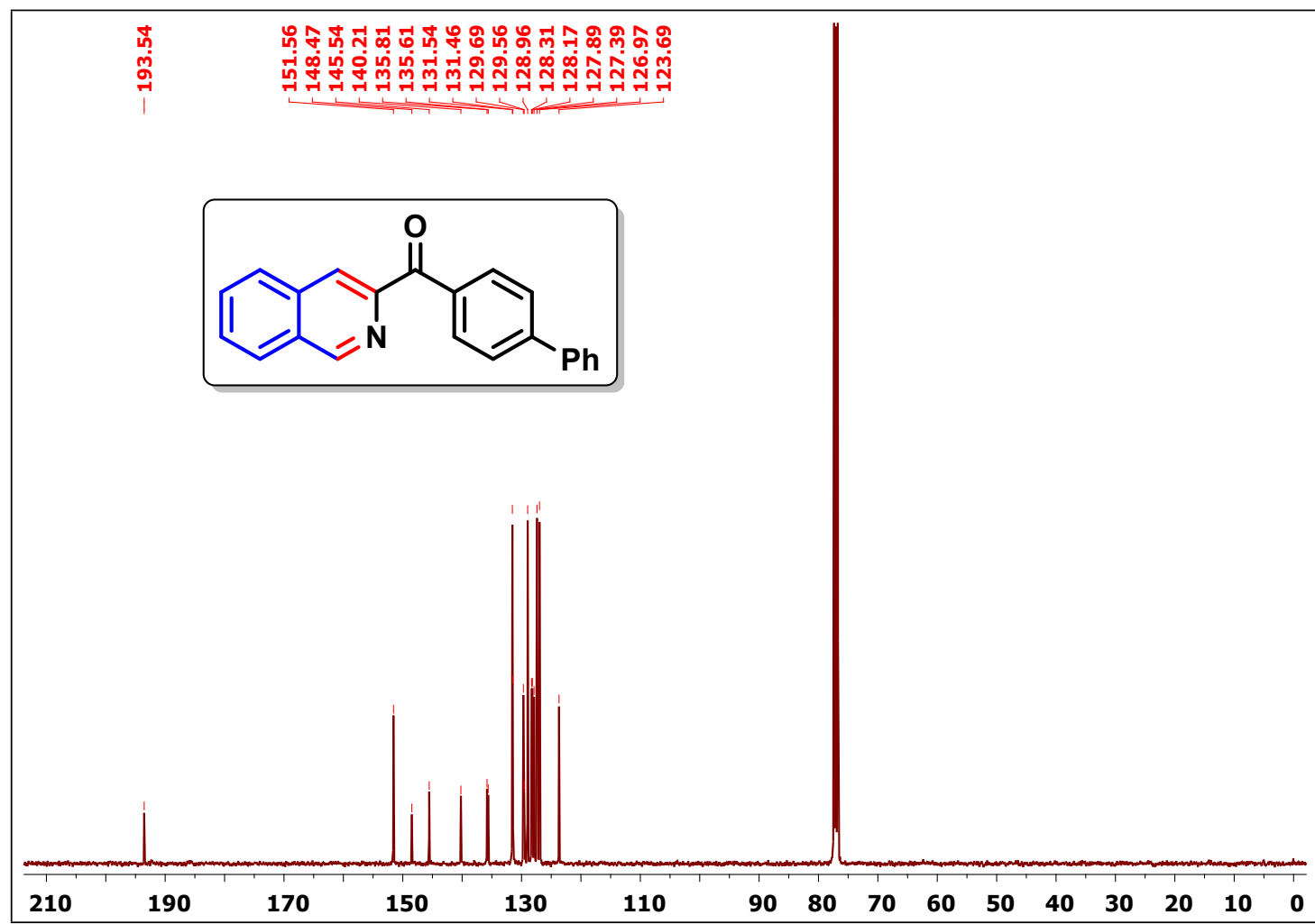


${ }^{1} \mathrm{H}$ NMR spectrum of compound 3aj

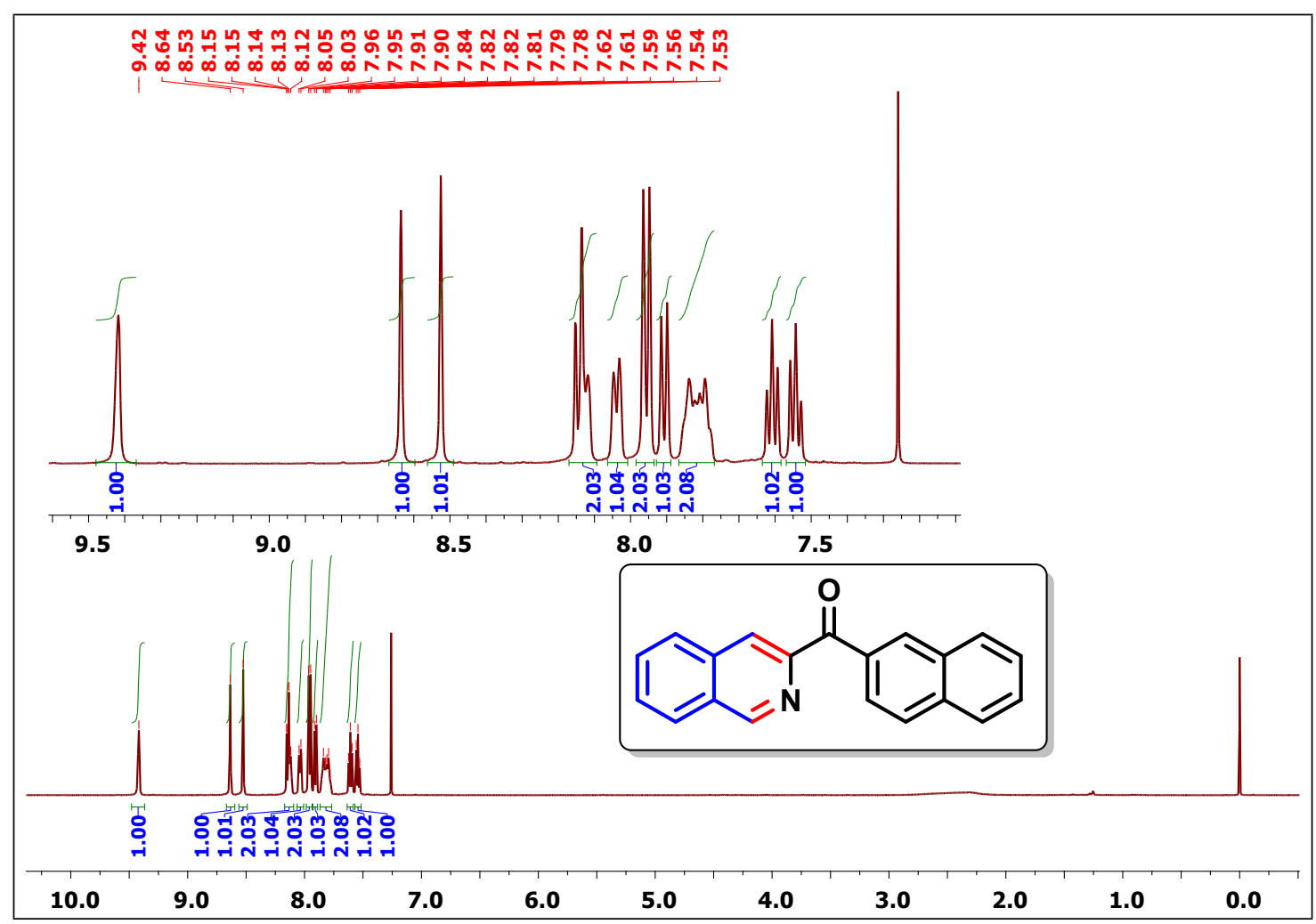

${ }^{13} \mathrm{C}$ NMR spectrum of compound $3 \mathrm{aj}$

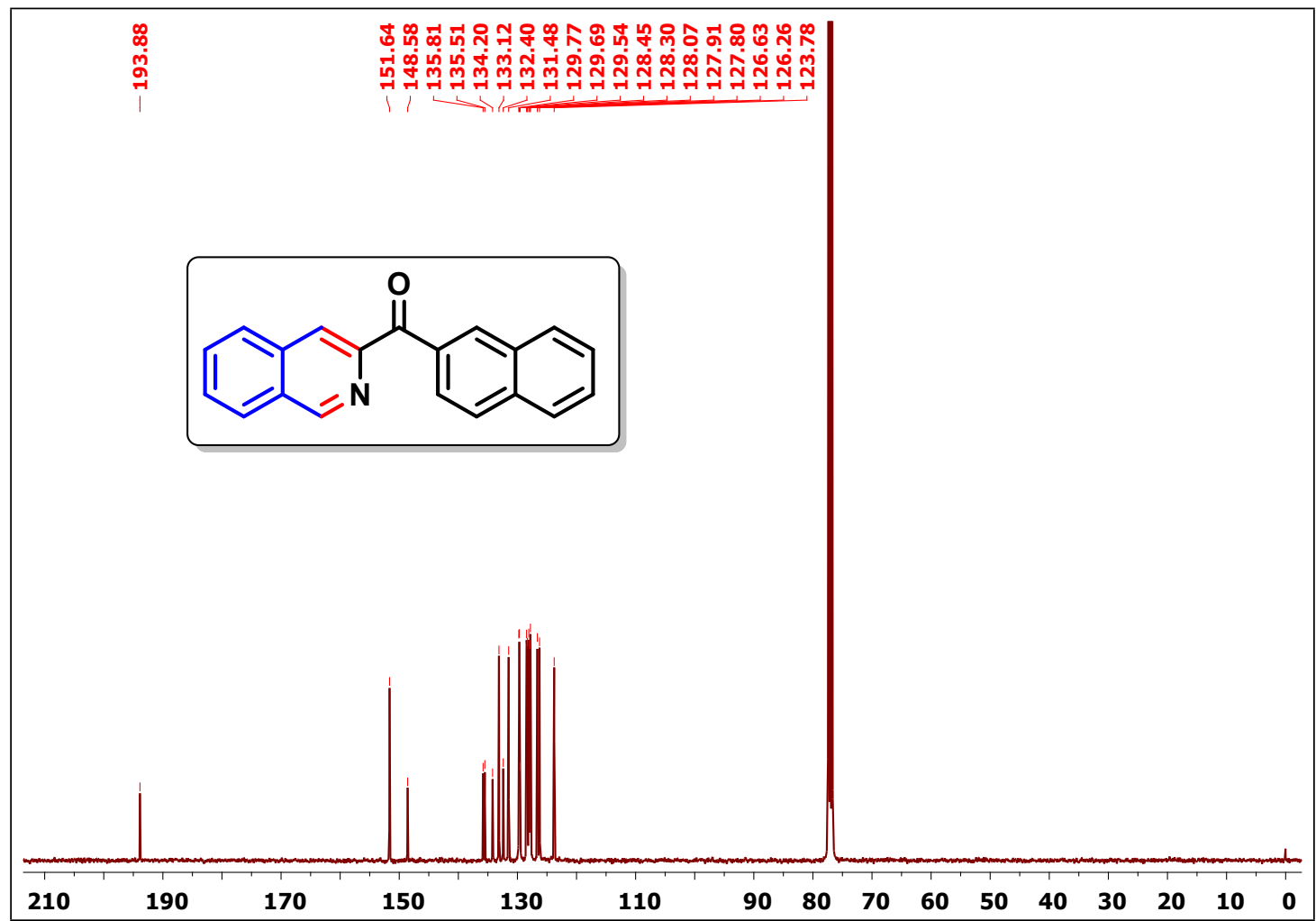




\section{${ }^{1} \mathrm{H}$ NMR spectrum of compound 3ak}

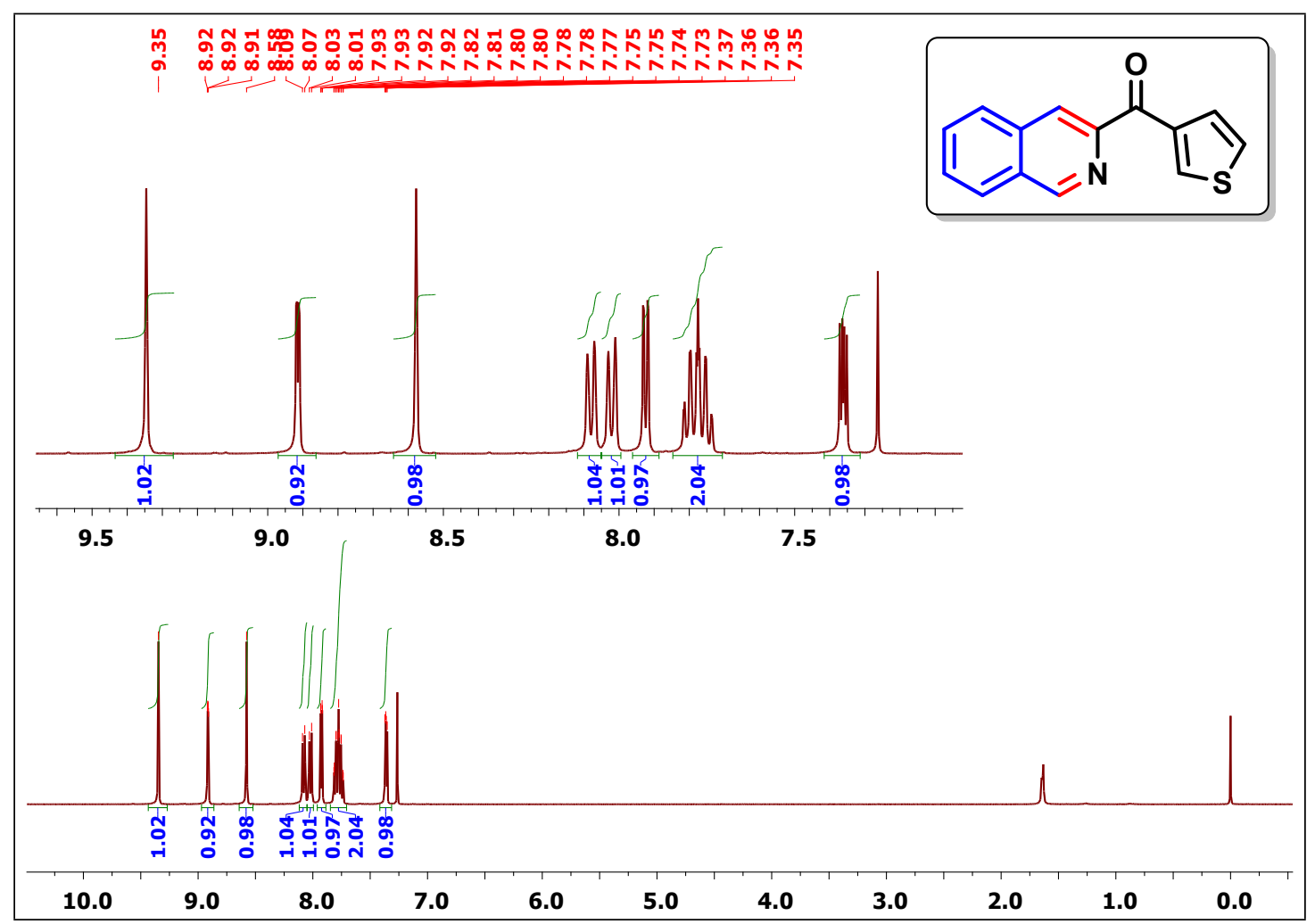

${ }^{13} \mathrm{C}$ NMR spectrum of compound 3ak

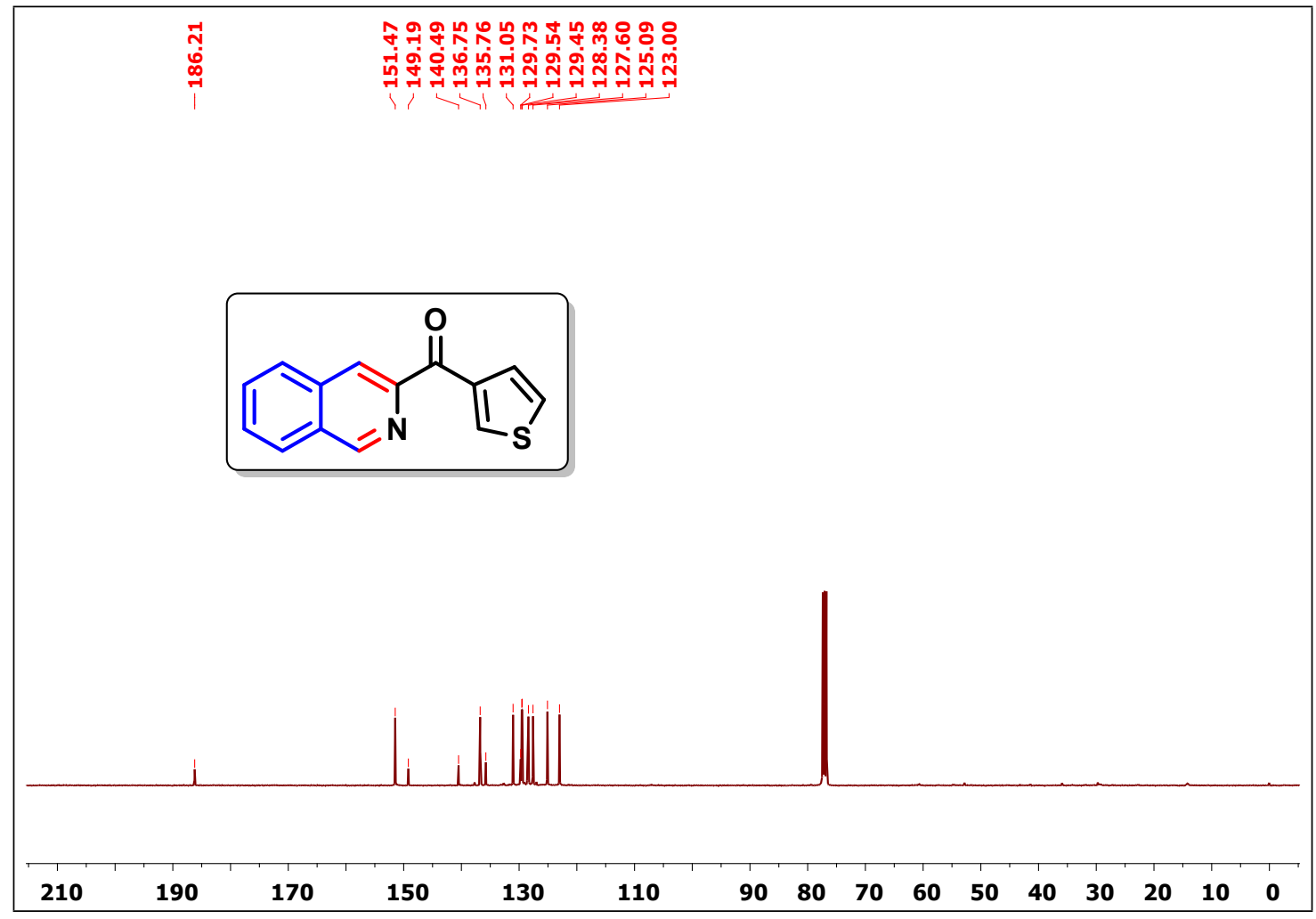


${ }^{1} \mathrm{H}$ NMR spectrum of compound $3 \mathrm{bl}$

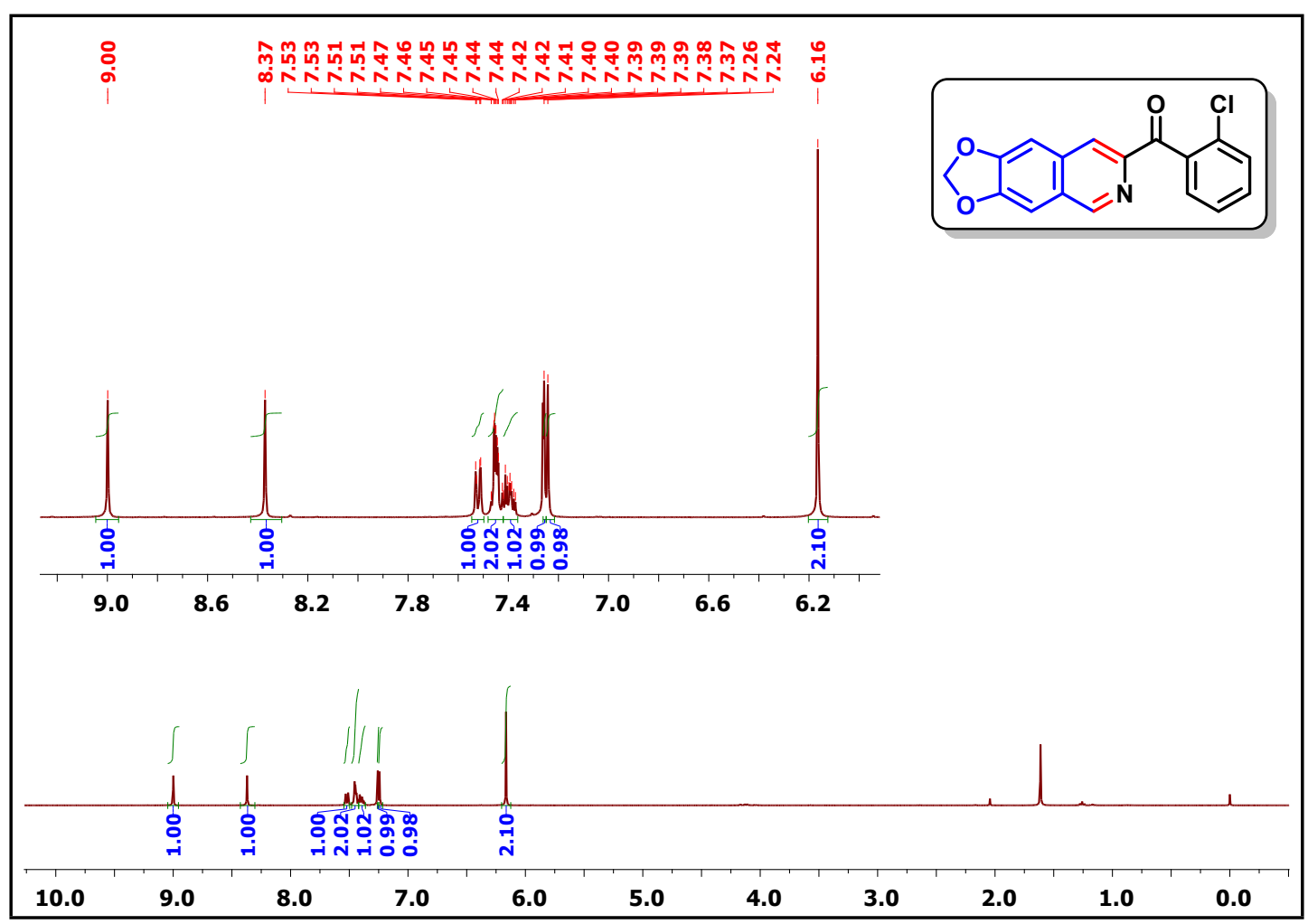

${ }^{13} \mathrm{C}$ NMR spectrum of compound $3 \mathrm{bl}$

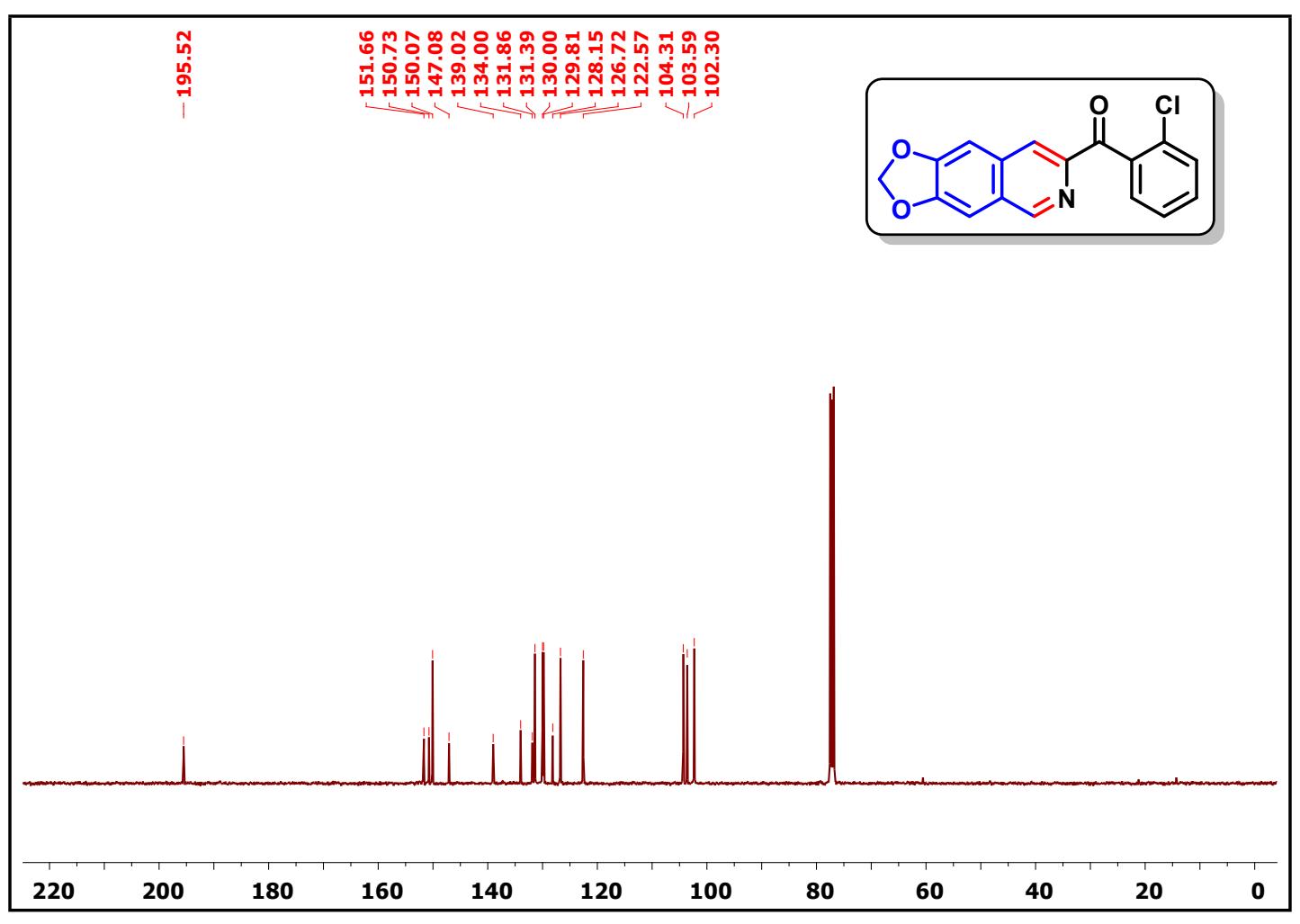




\section{${ }^{1} \mathrm{H}$ NMR spectrum of compound $3 \mathrm{bm}$}

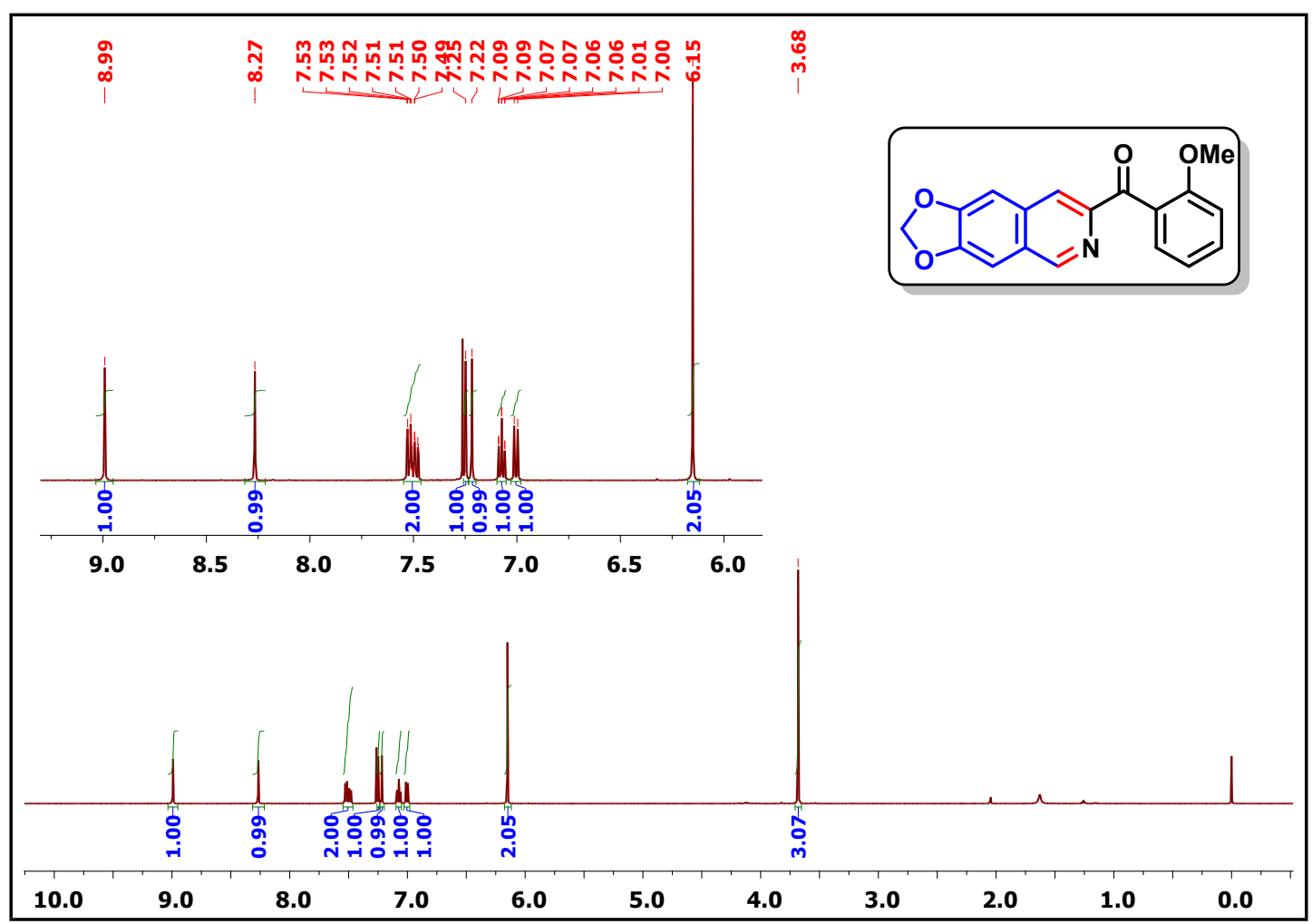

${ }^{13} \mathrm{C}$ NMR spectrum of compound $3 \mathrm{bm}$

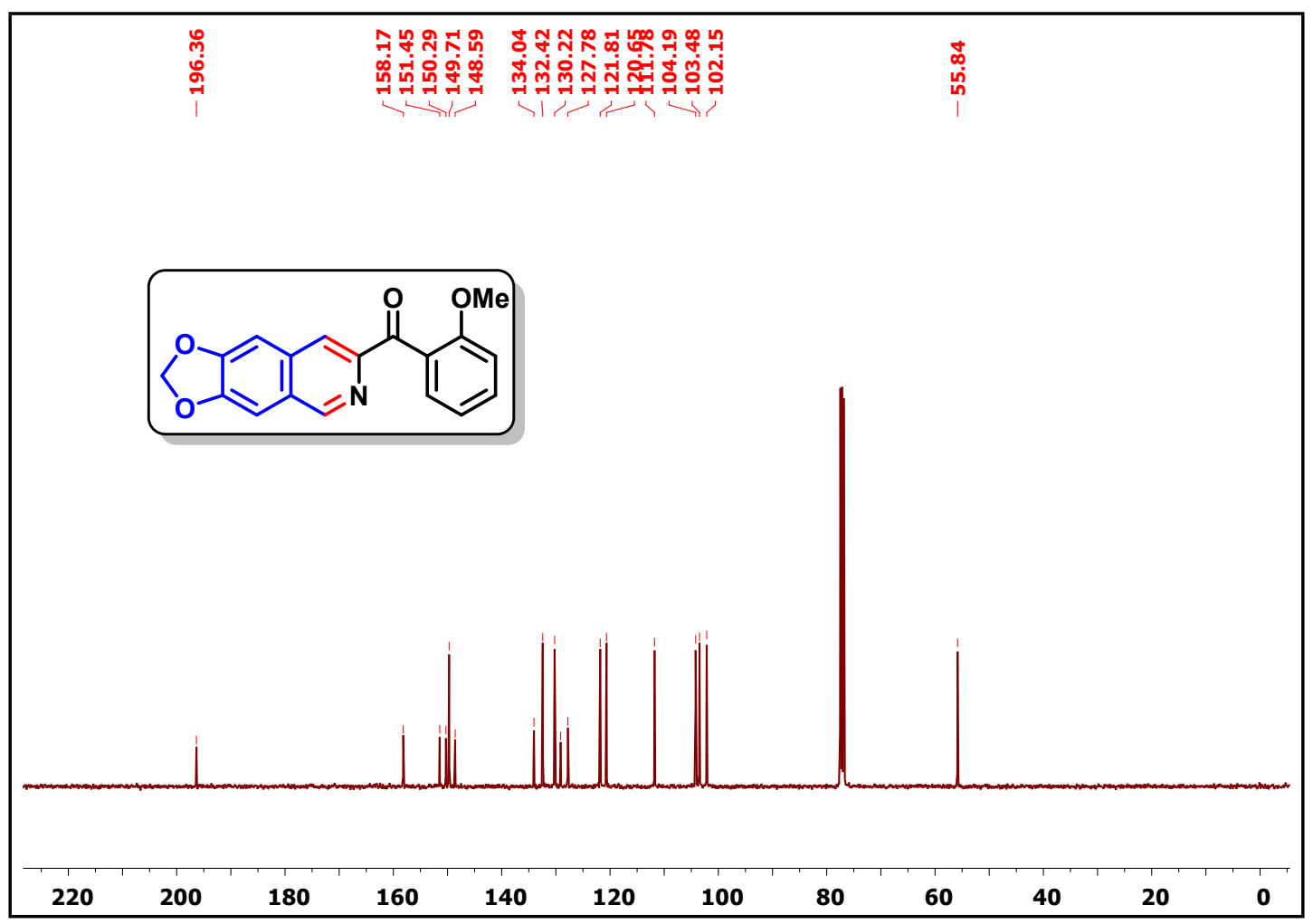




\section{${ }^{1} \mathrm{H}$ NMR spectrum of compound 4}

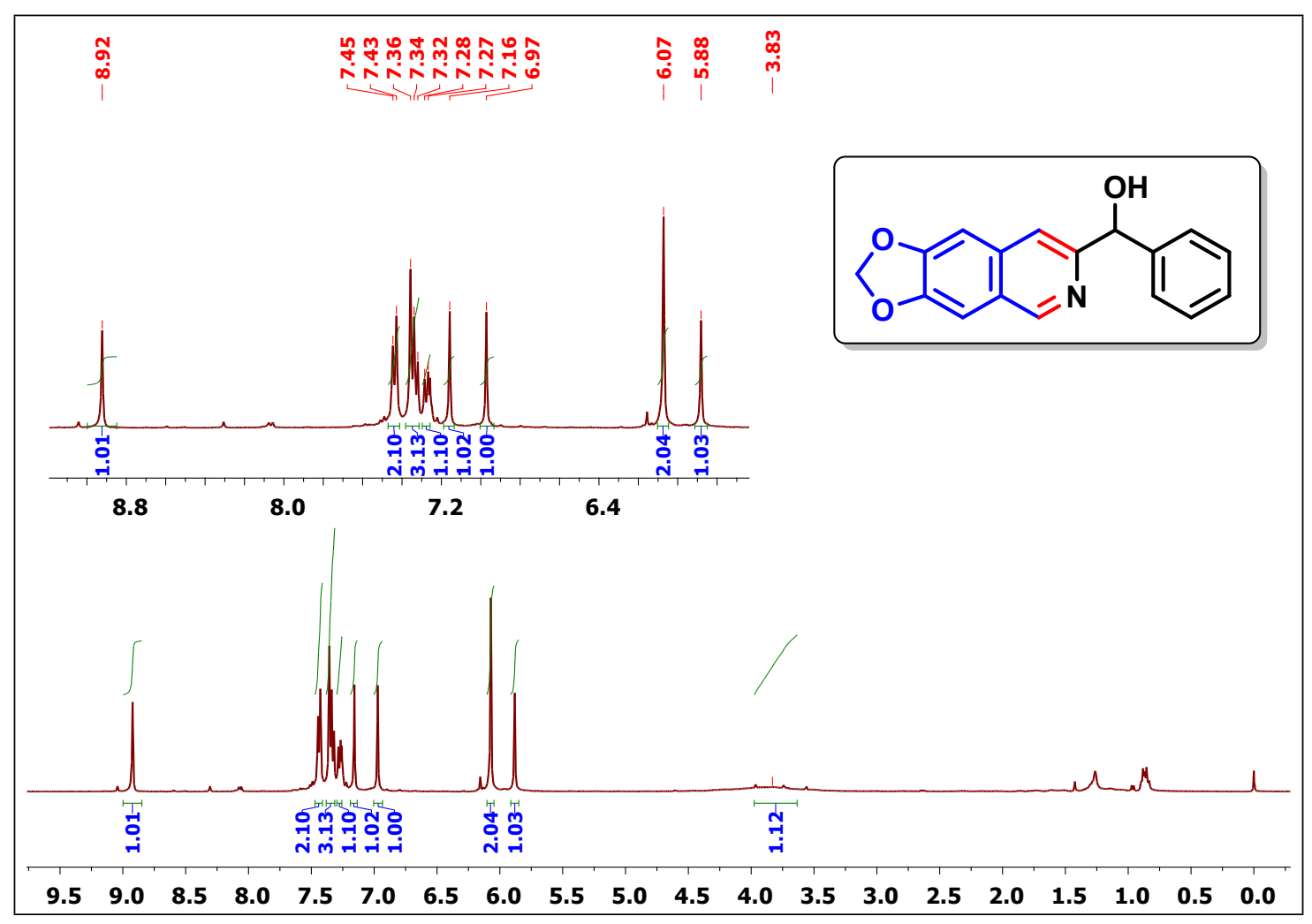

${ }^{13} \mathrm{C}$ NMR spectrum of compound 4

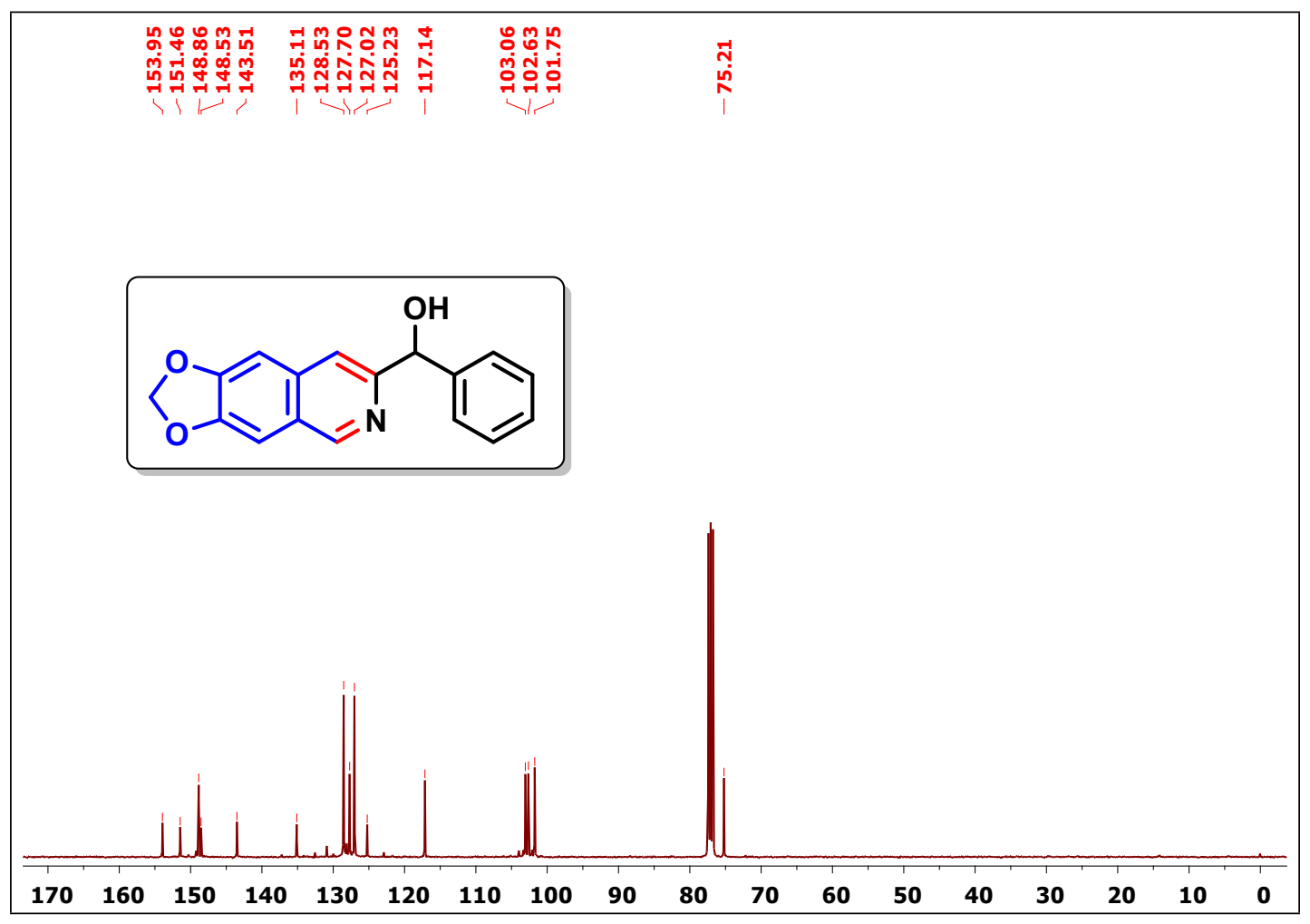




\section{${ }^{1} \mathrm{H}$ NMR spectrum of compound 5}

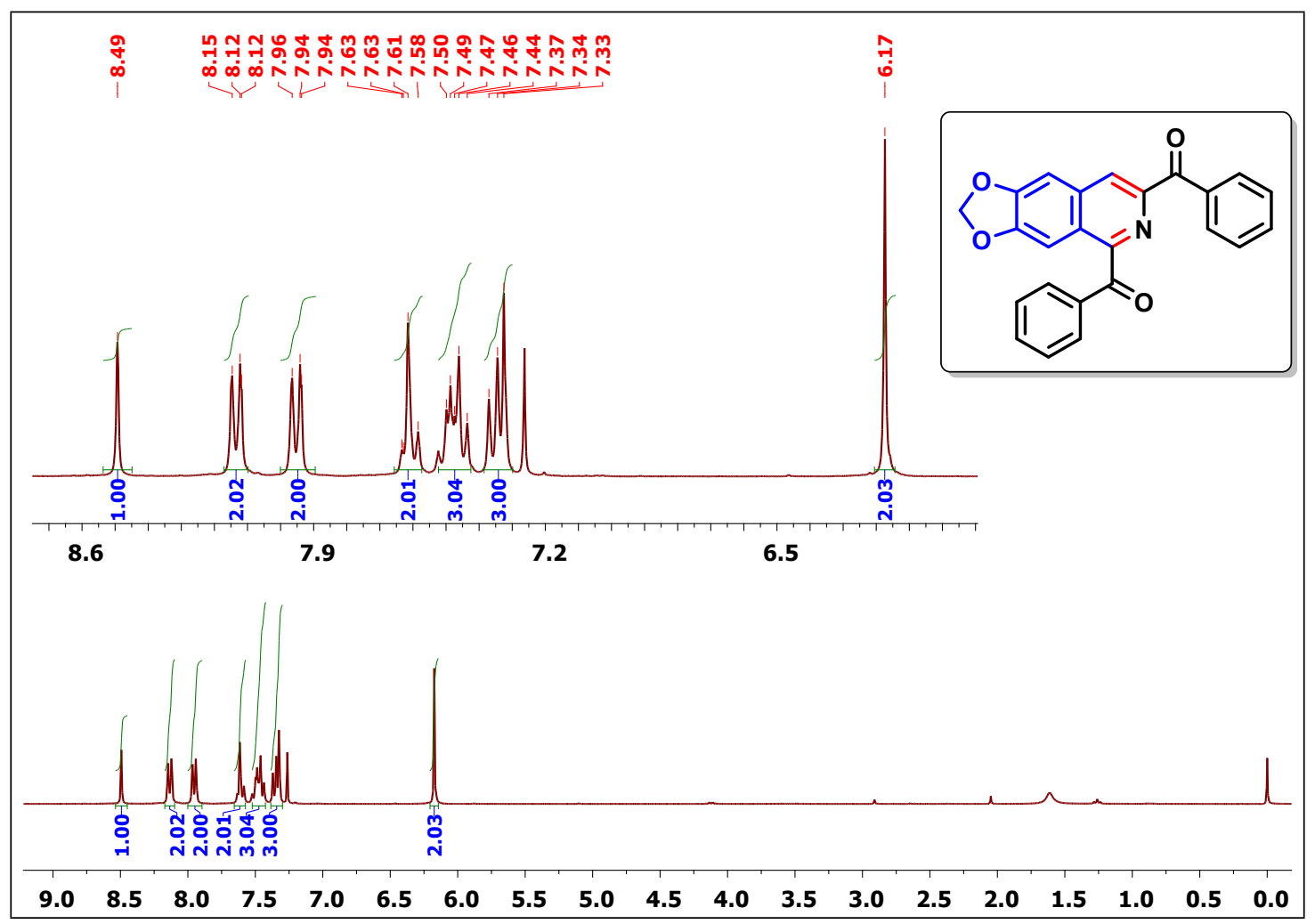

${ }^{13} \mathrm{C}$ NMR spectrum of compound 5

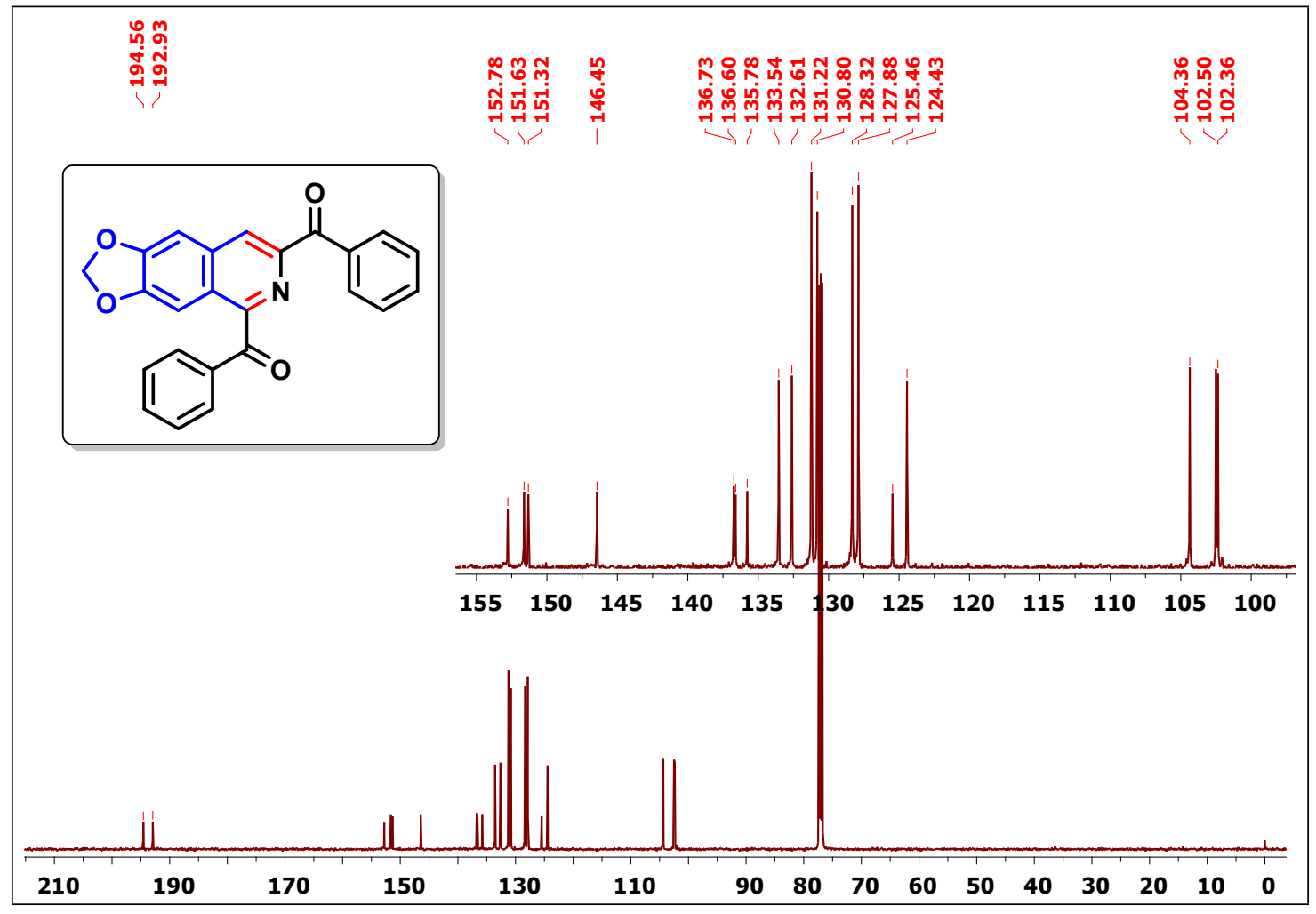




\section{${ }^{1} \mathrm{H}$ NMR spectrum of compound 6}

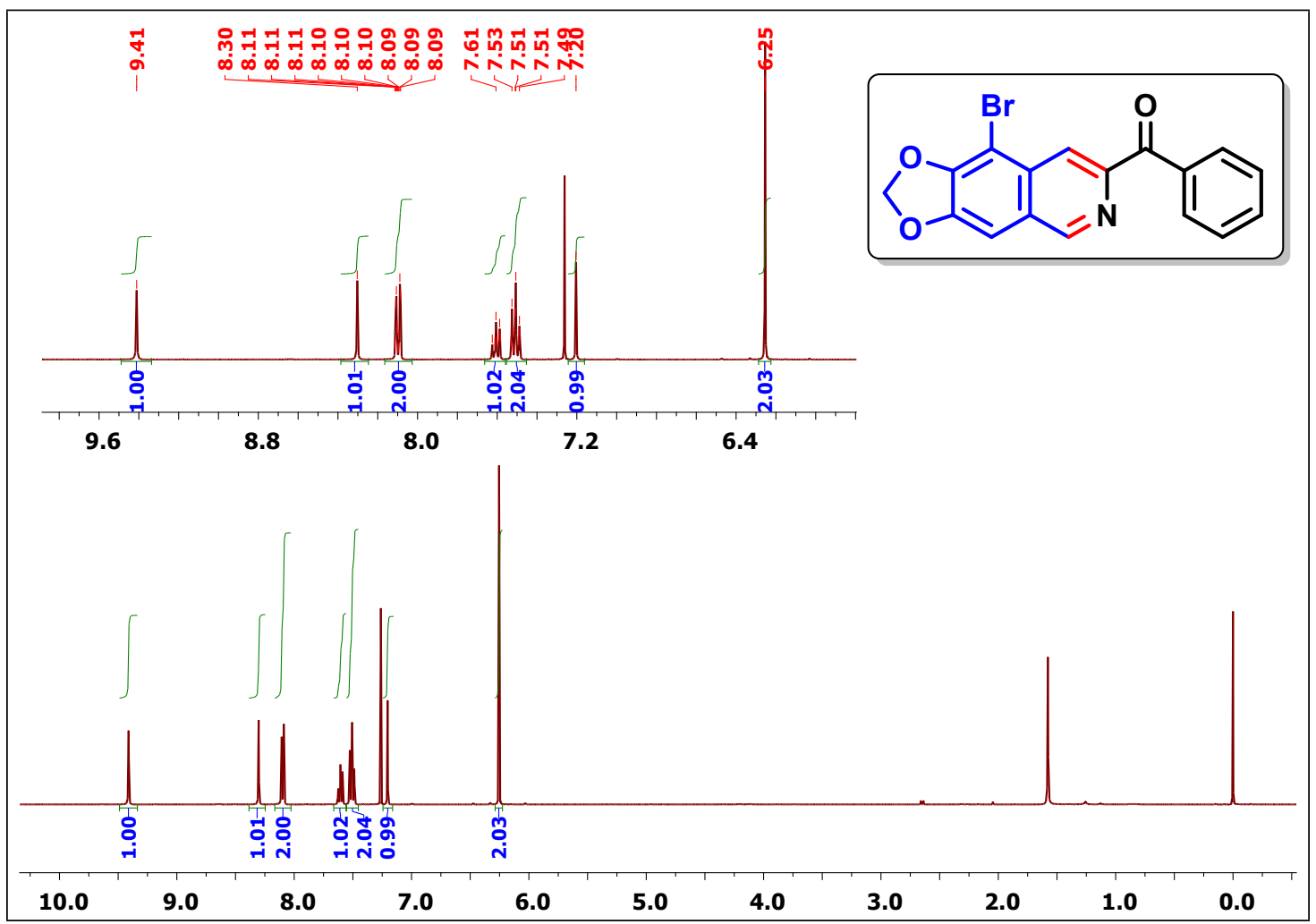

${ }^{13} \mathrm{C}$ NMR spectrum of compound 6

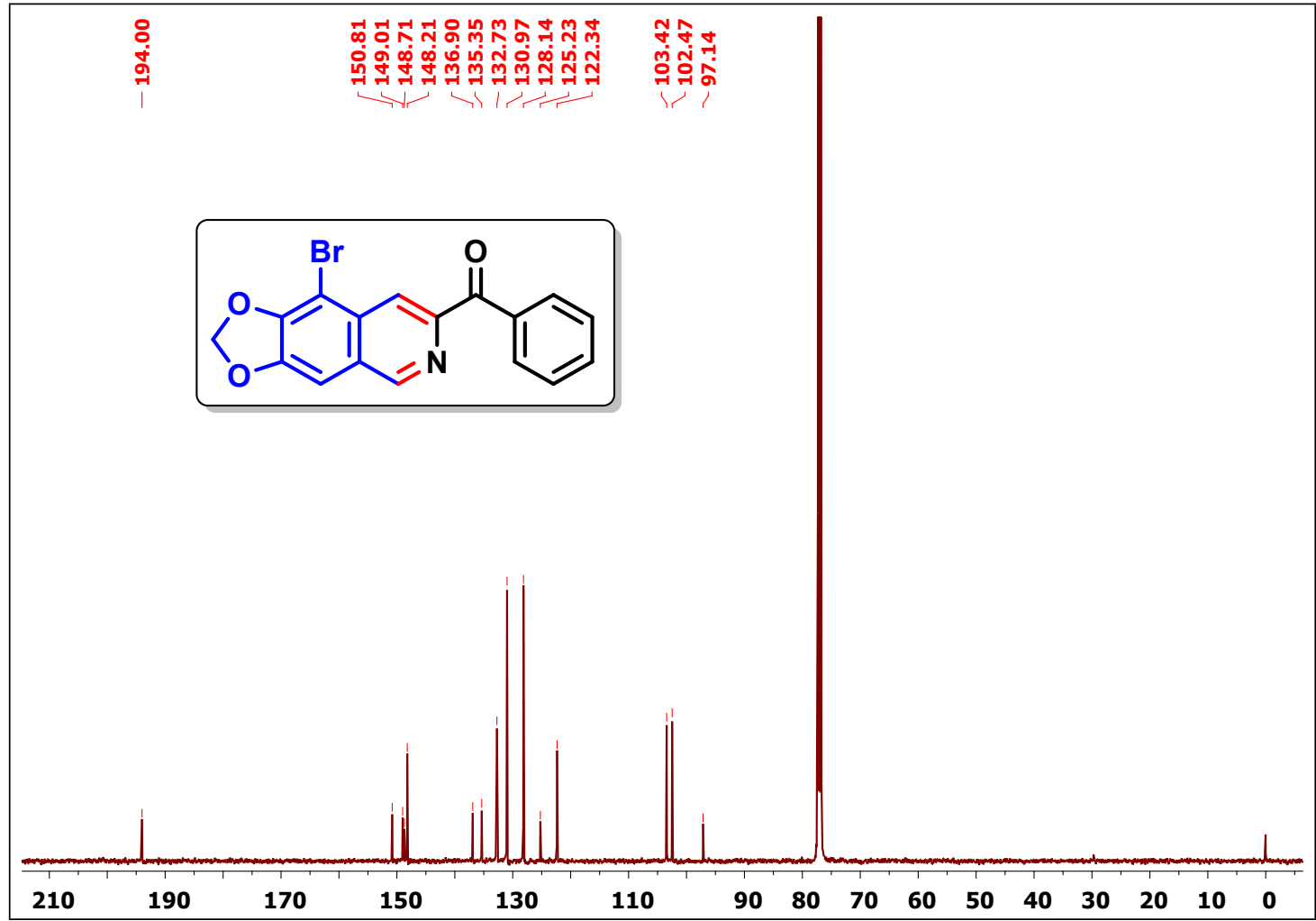




\section{${ }^{1} \mathrm{H}$ NMR spectrum of compound 7}

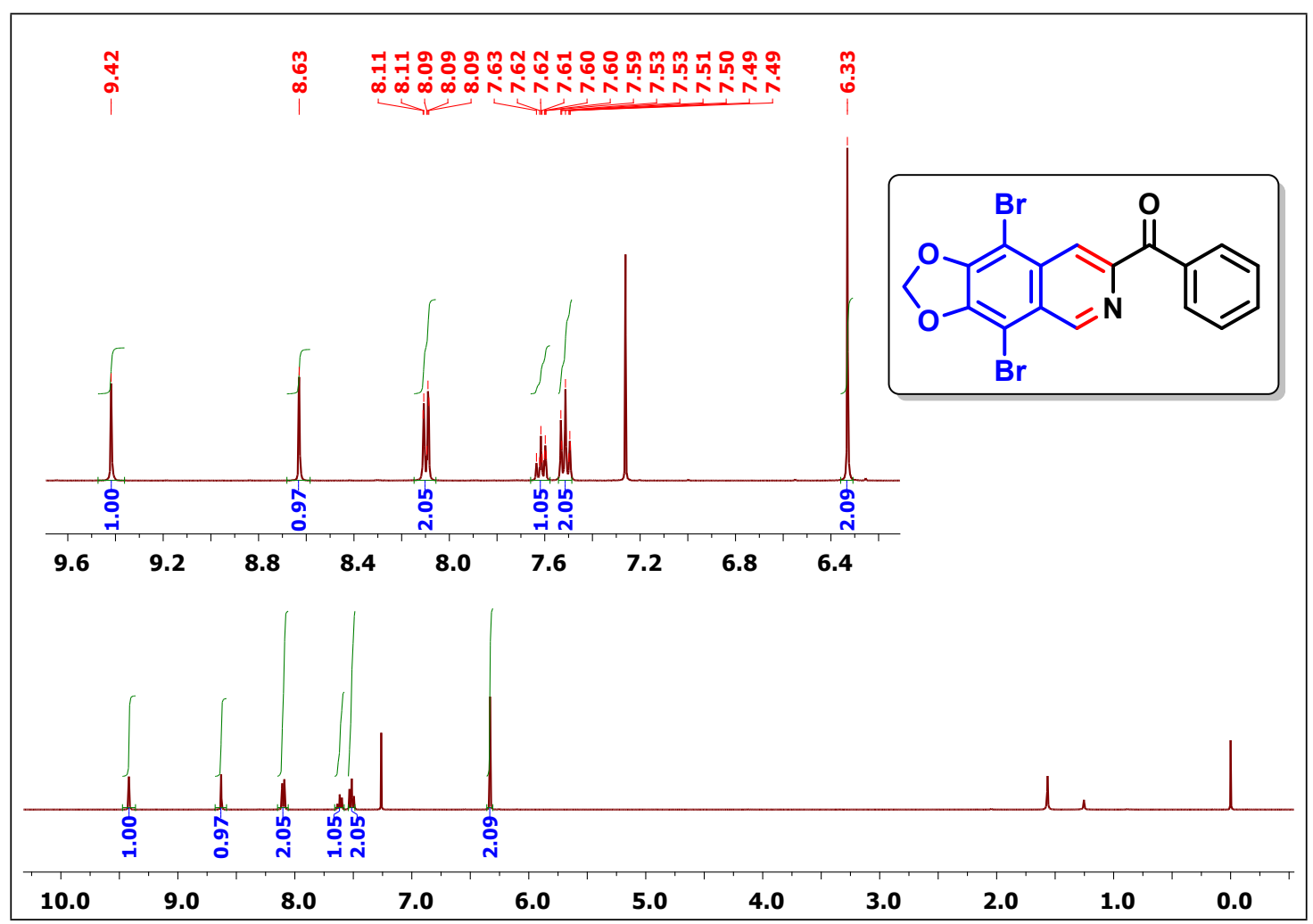

${ }^{13} \mathrm{C}$ NMR spectrum of compound 7

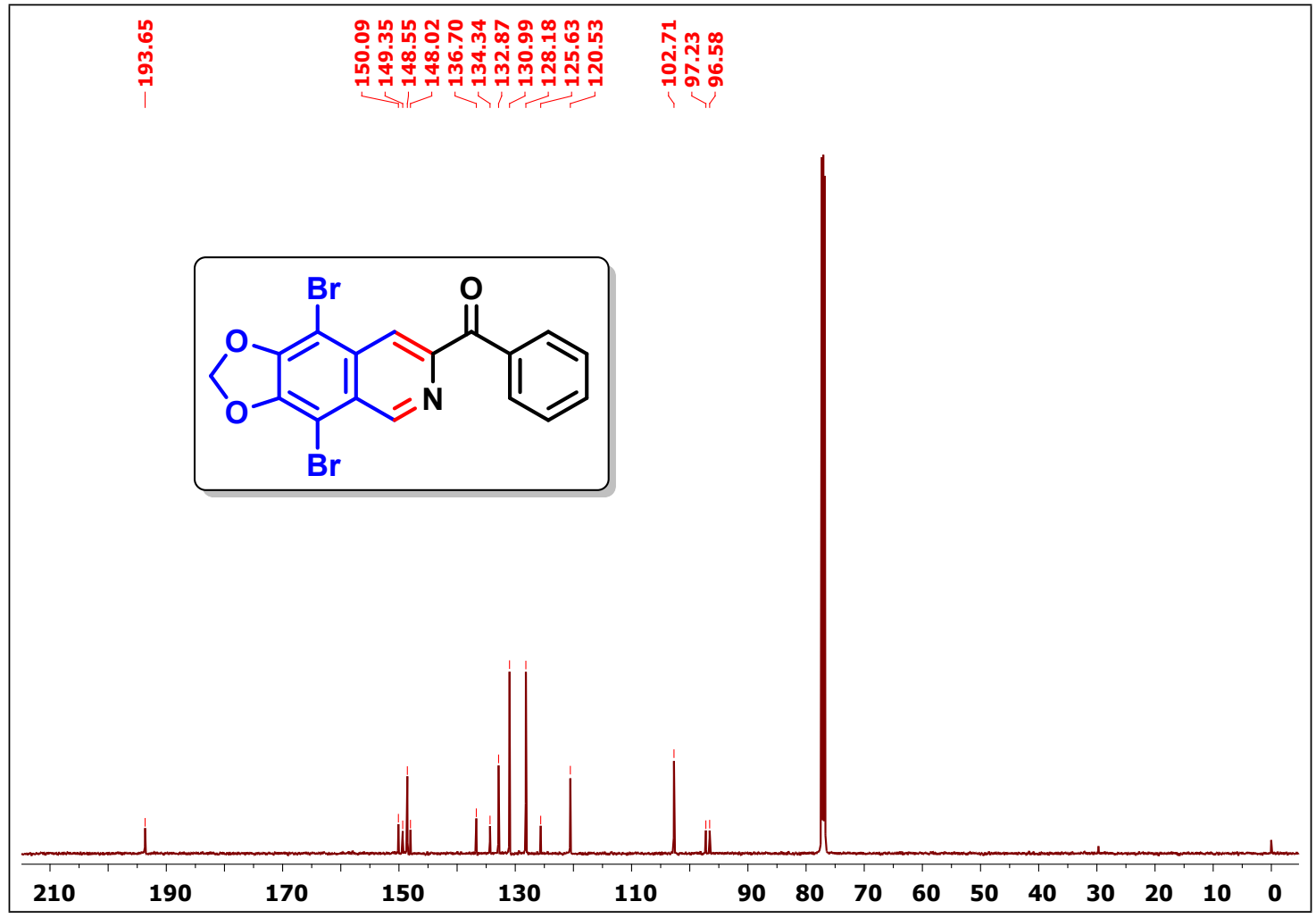




\section{${ }^{1} \mathrm{H}$ NMR spectrum of compound 8}

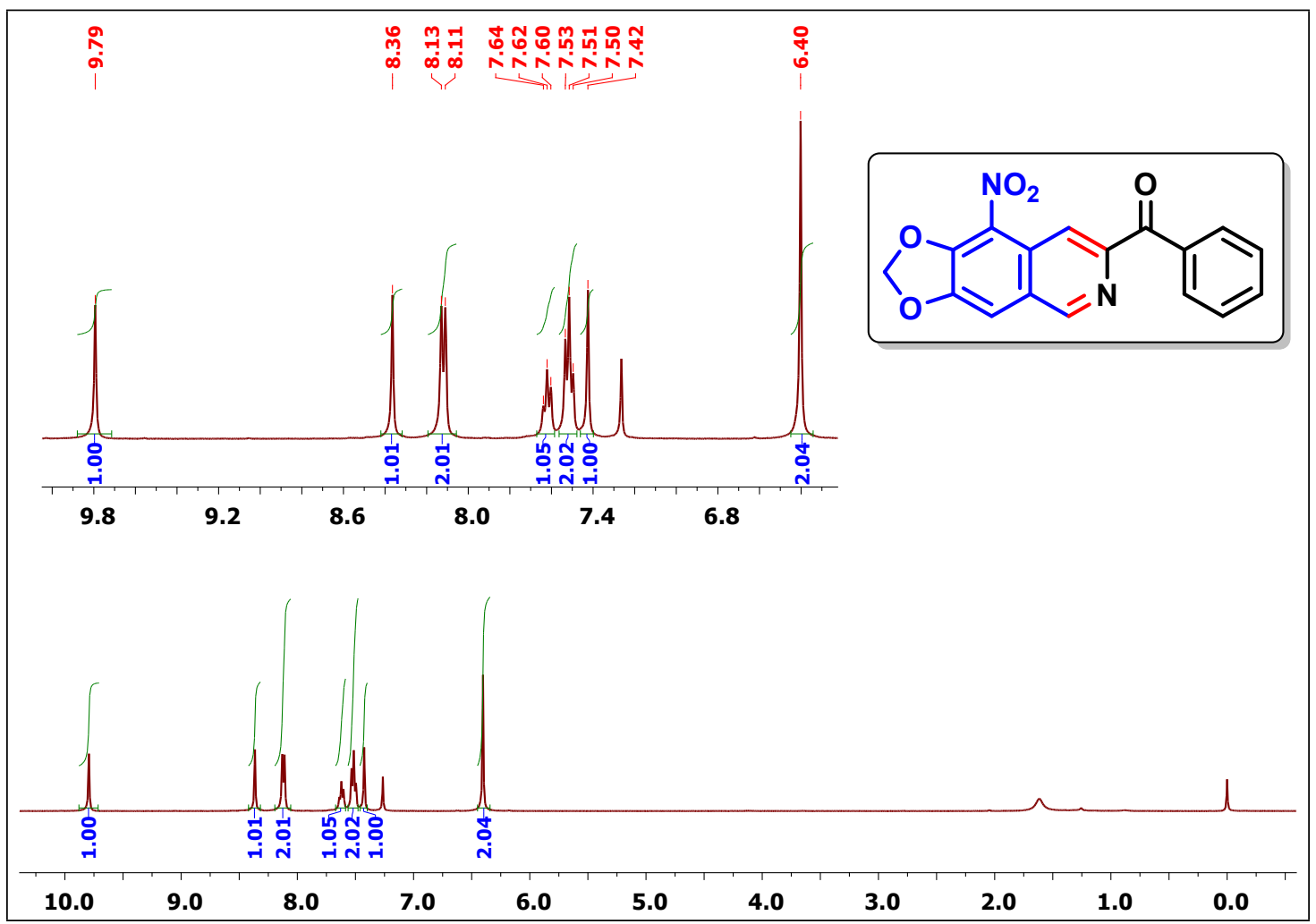

${ }^{13} \mathrm{C}$ NMR spectrum of compound 8

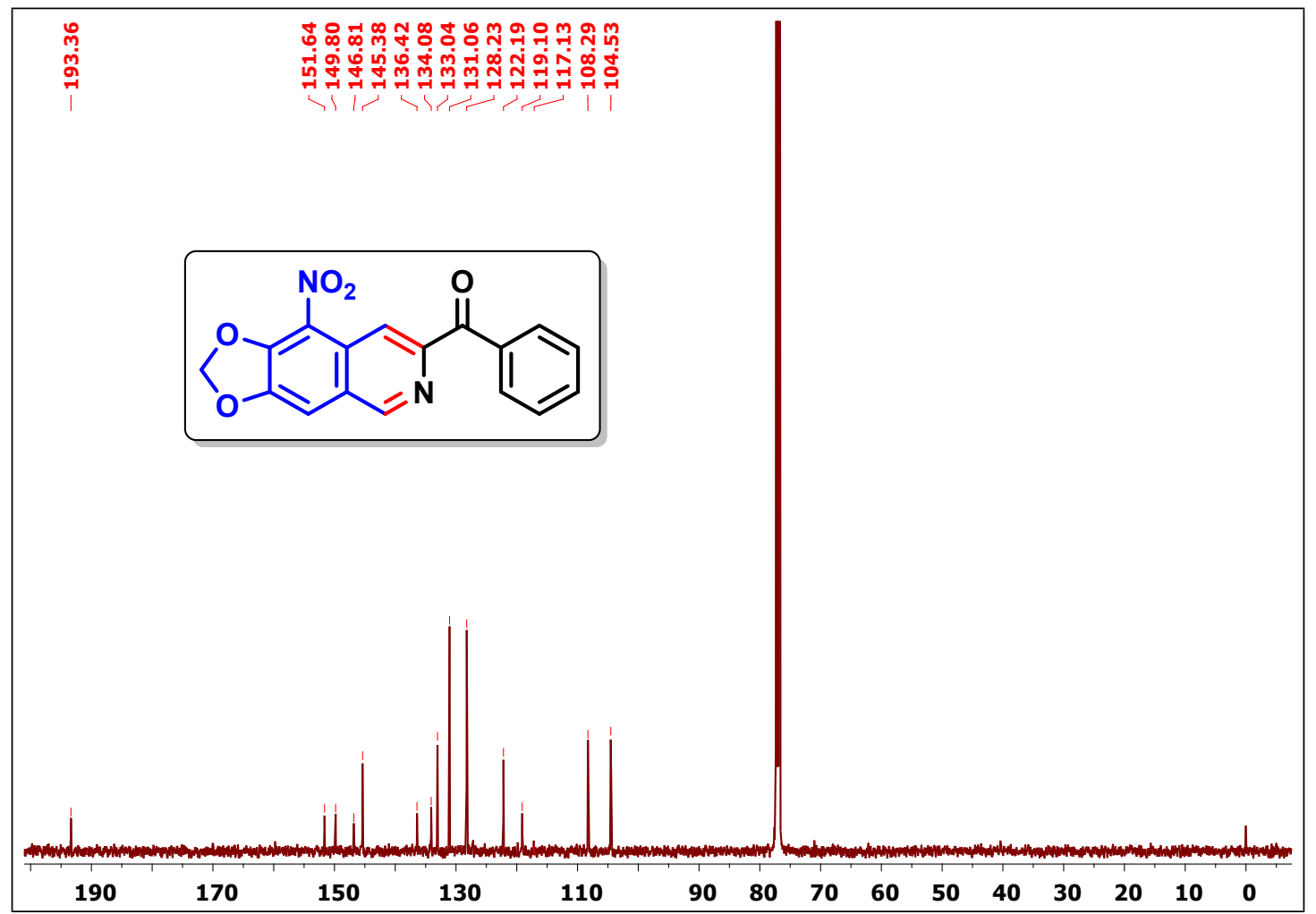




\section{${ }^{1} \mathrm{H}$ NMR spectrum of compound 9}

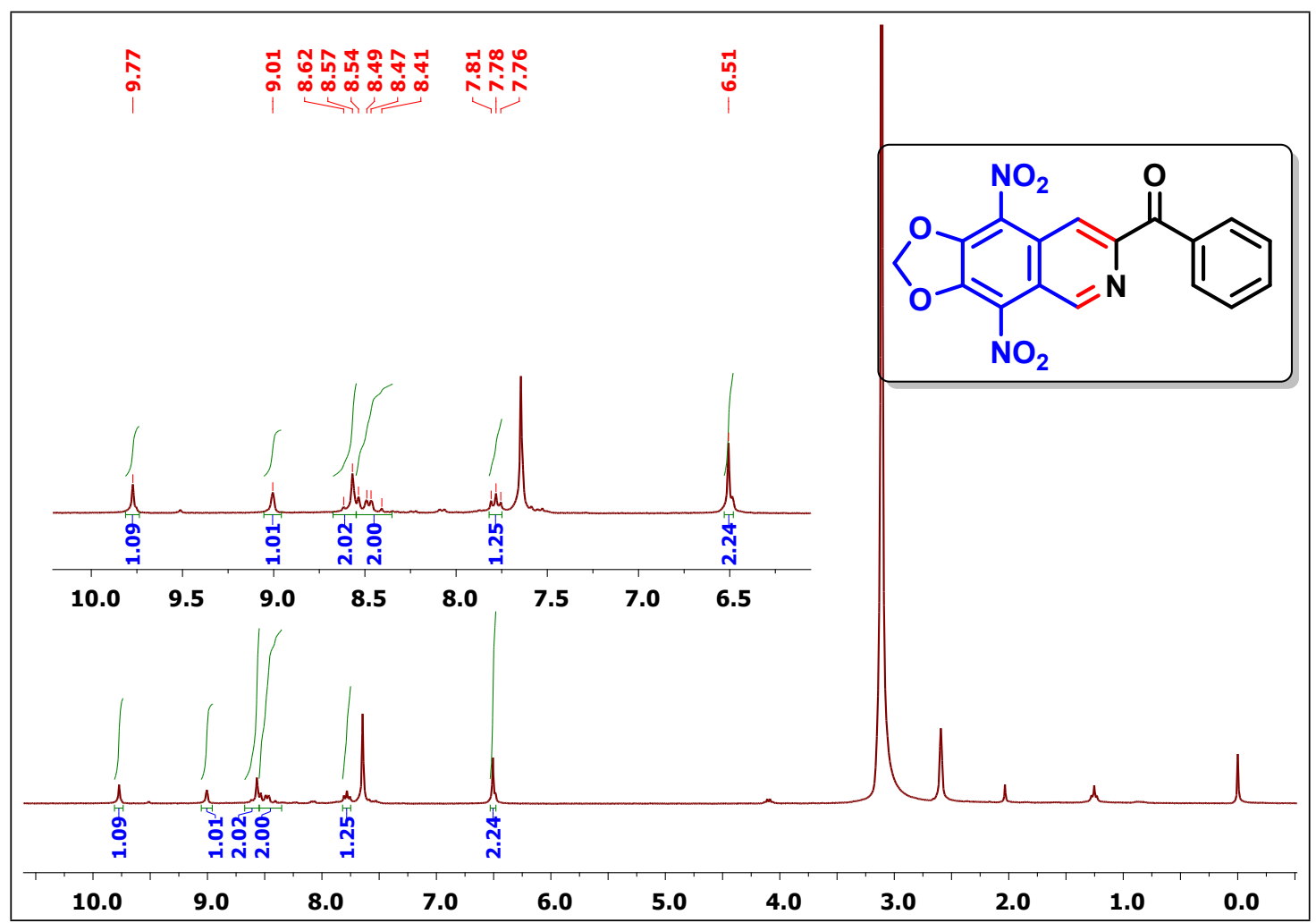

${ }^{13} \mathrm{C}$ NMR spectrum of compound 9

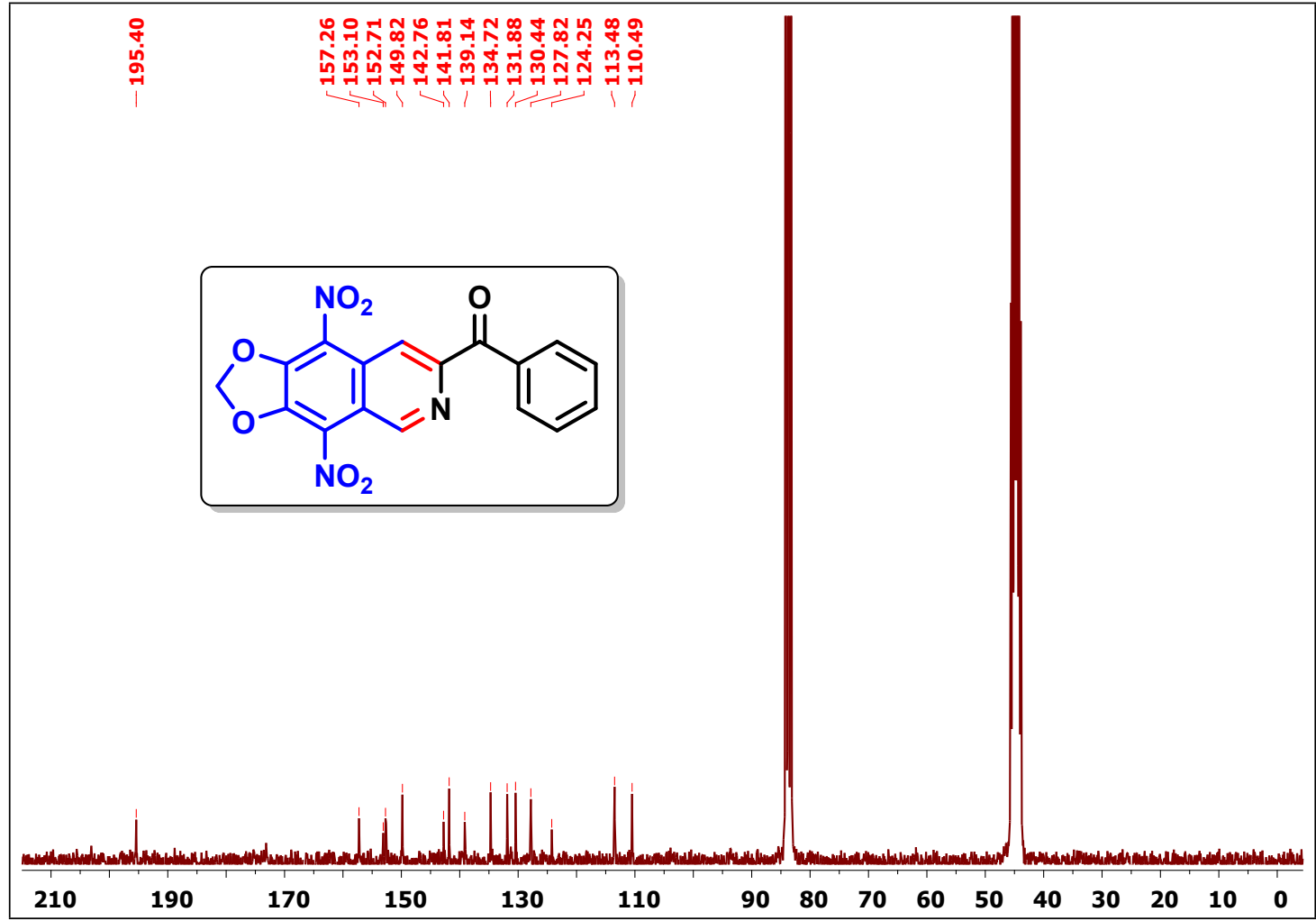




\section{${ }^{1} \mathrm{H}$ NMR spectrum of compound 3aa'}

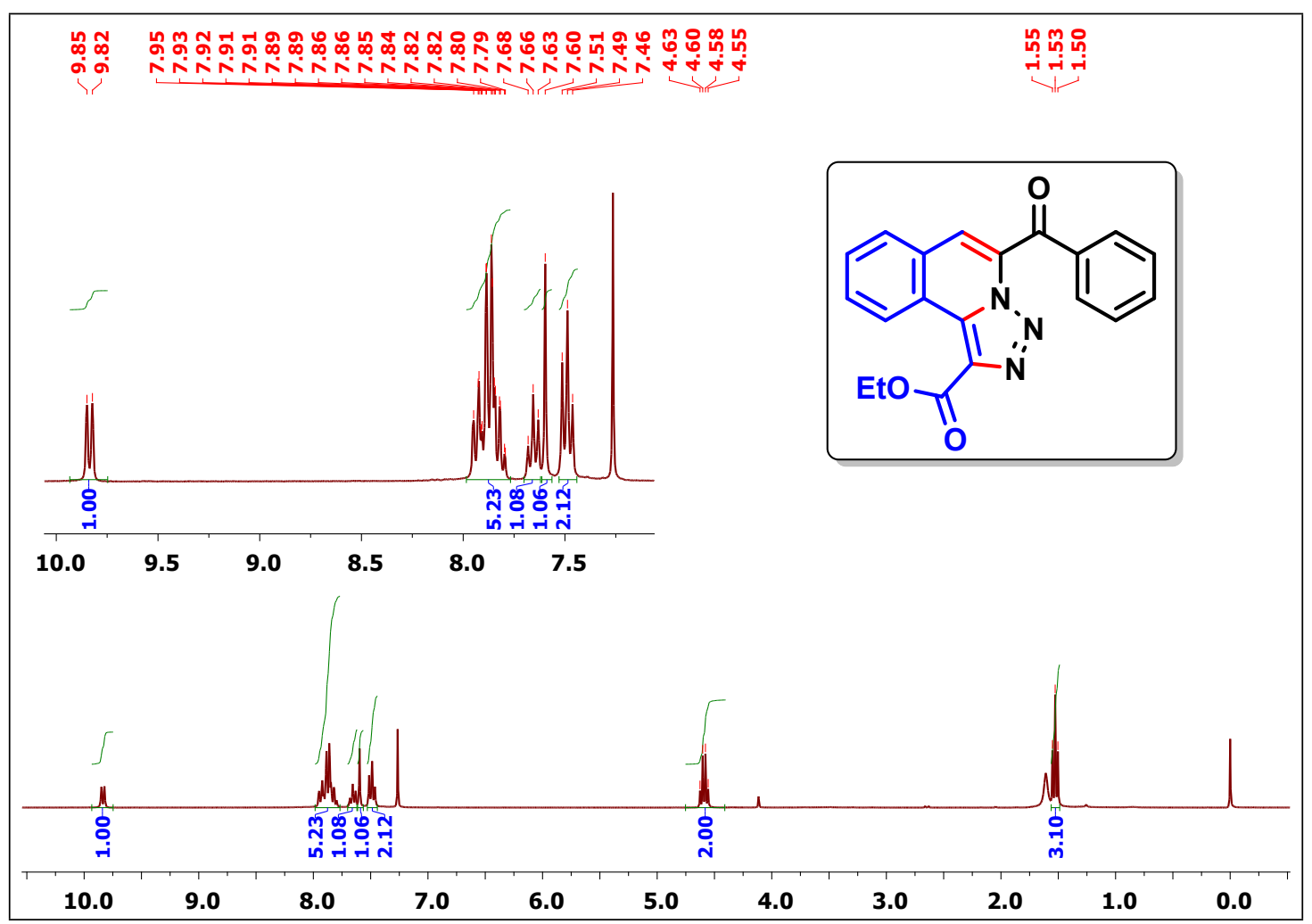

\section{${ }^{13} \mathrm{C}$ NMR spectrum of compound 3aa'}

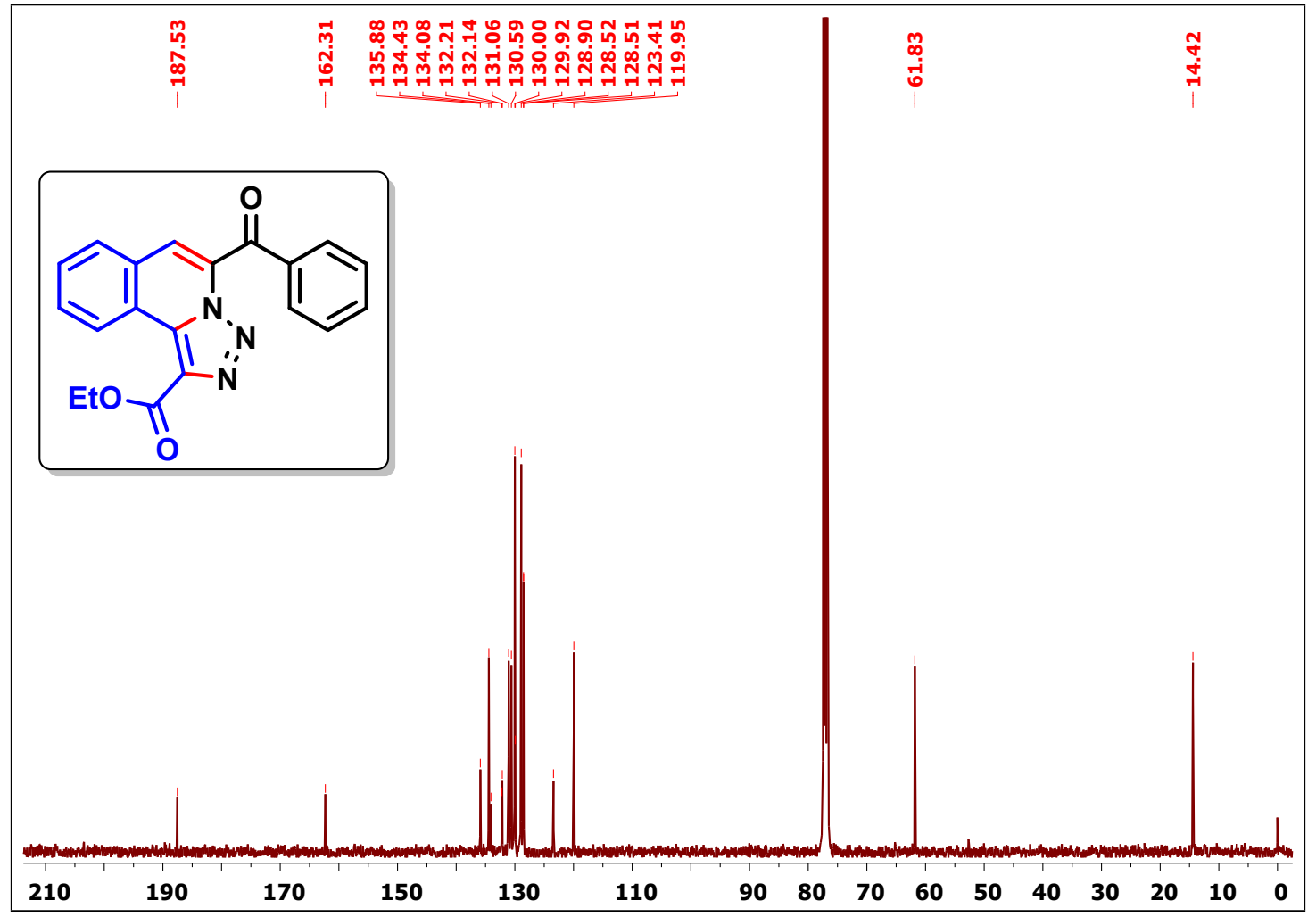

